\title{
لفائف الباتا المزينة بالتصاوير في غرب البنغال \\ "في ضوء لفافة محفوظة بالمتحف البريطاني ترجع إلى القرن باهـ/N ام"
}

\section{Pata Scrolls Decorated with Miniatures in West Bengal}

"In light of scroll painting in The British Museum dated12th/18th century."

$$
\text { مدرس - كلية الآداب- جابر محمد جامعة عين شمس }
$$

\section{Nawal Gaber Mohammed}

Lecturer-Faculty of arts Ain Shams University

nawal.gaber@yahoo.com

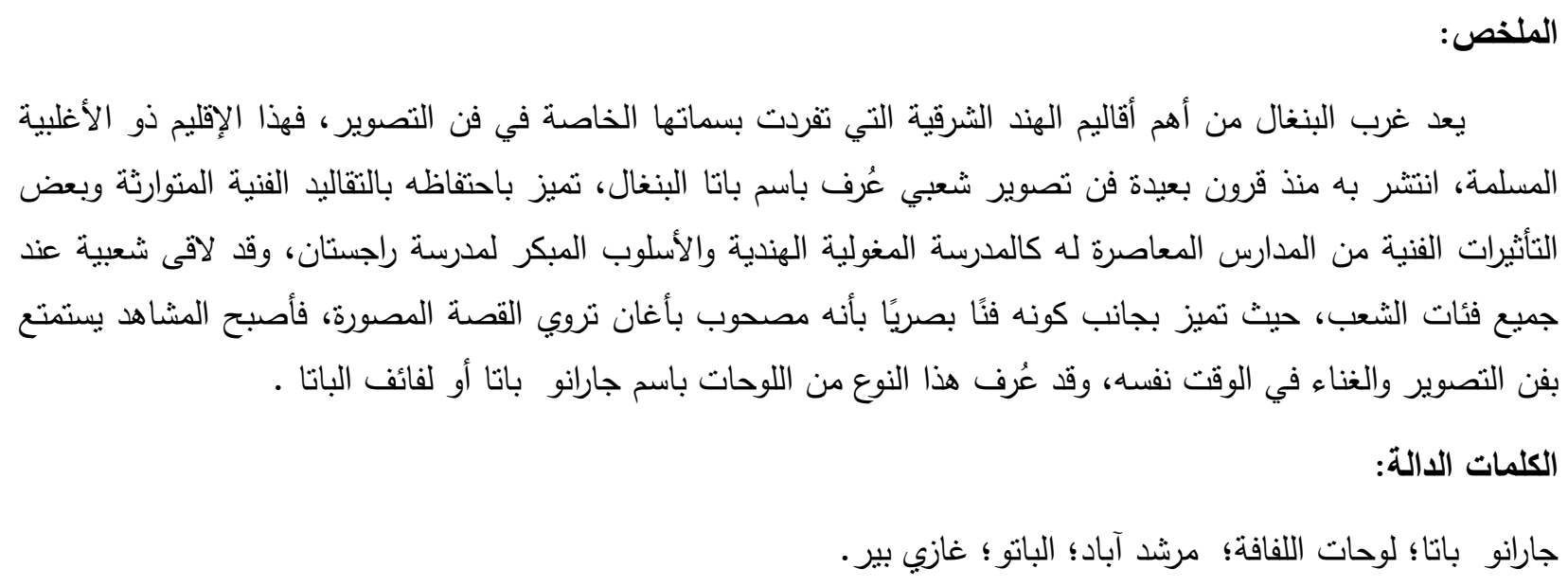

\section{Abstract:}

West Bengal is one of the most Important Provinces of East India, with its own Special features in Indian Painting, and This region with a Muslim majority, There are distinct types of folk paintings in eastern India, Pata is a product of a traditional society, rooted in village based culture. It has been characterized by the retaining of inherited artistic traditions and some artistic influences from schools Contemporary to as the Indian Mongol School and the early style of Rajasthan School, and it has been popular with all segments of the people, It was distinguished by being a visual art as accompanied by songs that tell the storyboard, and know of Jarano pata or Scroll painting.

\section{Keywords:}

Jarano pata, scroll painting, Murshidabad, Patu, Ghazi Pir. 
كان لإتساع رقعة الأراضي الهندية سبياً في تعدد مدارس التصوير تحت رعاية حكام الهند من المسلمين، فقد ازدهر فن التصوير وتطور برعاية الأباطرة المغول وحكام الممالك الإسلامية الأخرى في الهند مثل مدارس التصوير بهضبة الدكن، سواء كان ذلك في المراكز الفنية للبلاط الحاكم، مثل: دلهي، وأجرا، وبيجابور، أو غيرها من مدارس التصوير الفرعية في الأقاليم التابعة لحكم الدولة المغولية، ومنها مدرسة التصوير بغرب البنغال' التي ازدهر بها خلال القرن (اهـ/1 ام مدرسة فنية تعد فرعًا منطورًا من مدرسة التصوير المغولية الهندية، نشأت وتطورت في مدينة مرشد آبادَّتحت رعاية نواب البنغال، وتحمل السمات الفنية للمدرسة المغولية، وجدير بالذكر أن منطقة البنغال كان لها تاريخ فني تمتذ جذوره إلى عهد حكم أسرة

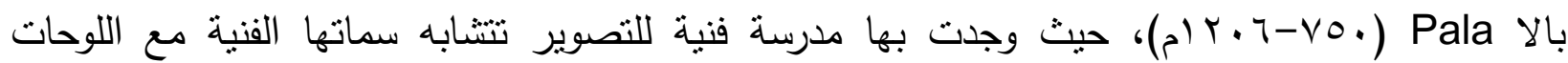
الجدارية بكهوف اجانتا، وترجع إلى هذه المدرسة مجموعة من المخطوطات التي توضح التعاليم البوذية ــ. وبعد الفتح الإسلامي للبنغال في فترة حكم سلاطين البنغال وجدت مدرسة تصوير تتبع السمات الفنية الفارسية في مدينة جور العاصمة ؛، ومن الملاحظ أنه على الرغم من وقوع البنغال تحت حكم المغول في عهد جلال الدين أكبر منذ عام 10 • اهـ/OV ام فإنه لم يرد ذكر لتأثز مدرسة تصوير البنغال بالسمات الفنية للتصوير المغولي إلا في القرن ا اهـ/N ام مع حكم نواب البنغال، فأصبحت البنغال الغربية - وخاصة مدينة مرشد آباد - بها نوعان من فن التصوير؛ الأول: فن تصوير بلاط نواب البنغال المعروف بفرع المدرسة المغولية بمدينة مرشد آباد، وكان يصور أحداث البلاط الحاكم والاحتفالات والمهرجات بالأسلوب المغولي الهندي وأسلوب مدرسة الثركة بعد ذلك، وتميز بالبراعة الفنية في التفاصيل الدقيقة واستخدام درجات الألوان المتتوعة بالإضافة إلى استخدام القواعد الفنية والتقنيات الحديثة المعاصرة وبالطبع تركز هذا في

' تقع البنغال في الجهة الثمالية الثرقية من شبه القارة الهندية، قائمة على رأس خليج البنغال، وقد ظلت حدودها السياسية منذ الفتح الإسلامي حتى الغزو المغولي متغيرة وغير مستقرة وخاصة الغربية والثمالية والثرقية منها بسبب قيام بعض من فن سلاطين البنغال بتوسيع رقعة دولتهم، وكان اسم البنغال يشير عند بداية الفتح الإسلامي إلى منطقة دلتا الجانج. عبد الحليم، الإنهاء وفاء، الأوضاع الاقتصادية والاجتماعية للبنغال منذ الفتح الإسلامي حتى الغزو الدغولي، القاهرة: مكتبة الثقافة الدينية،

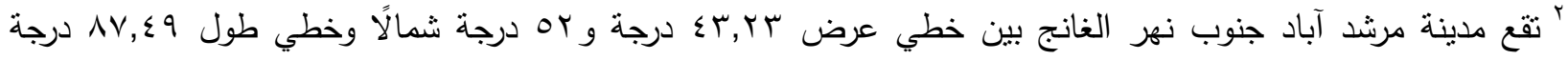

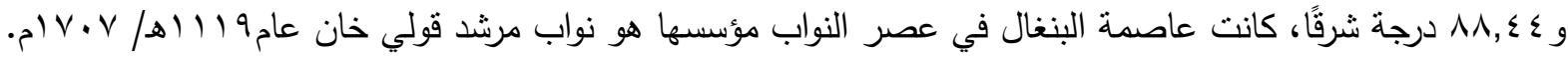
MITRA ,A.: District handbooks Murshidabad ,Calcutta: Sree Saraswaty press,1953, II.

${ }^{3}$ Dasgupta,G.," Buddhism During the Pala Period", PhD of Philosophy, Department of Fine Arts, Calcutta University,1976,114-116.

" من المخطوطات التي ترجع إلى فترة حكم سلاطين البنغال مخطوط اسكندر نامة بتكليف من سلطان البنغال نصرت

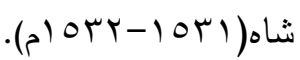
BRITSCHGI , J. \& GUY, J., Wonder of the Age : Master Painters of India, 1100-1900 „New York: Metropolitan Museum of Art, 2011, 204. 
المدن الرئيسة ومراكز الحكم؛ النوع الثاني: التصوير الثتبي البنغالي، وتركز هذا في القرى ذات الأغلبية

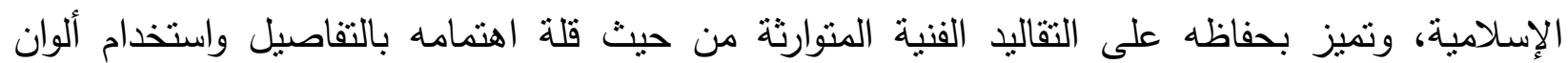

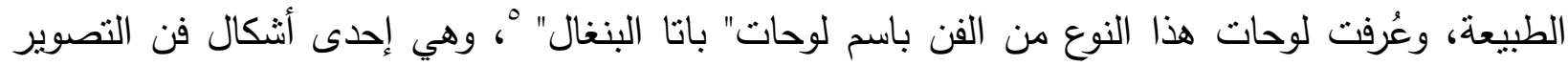

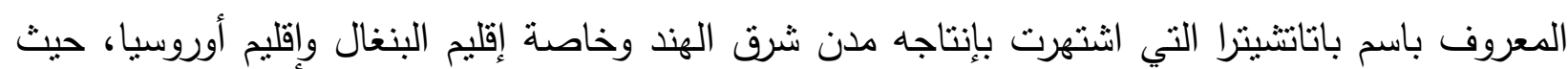

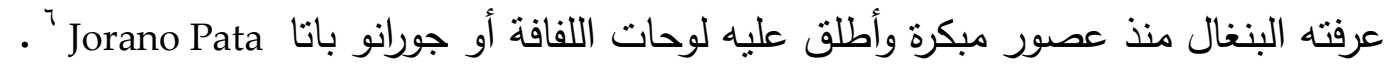
وقد انتشر هذا النوع من فن التصوير في كثير من قرى البنغال الغربية ذات الأغلبية المسلمة، وقاموا

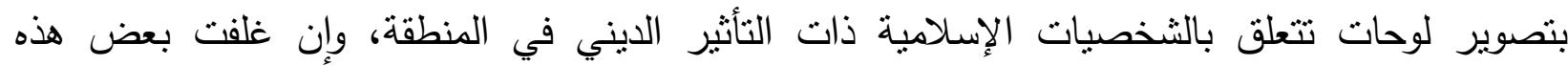

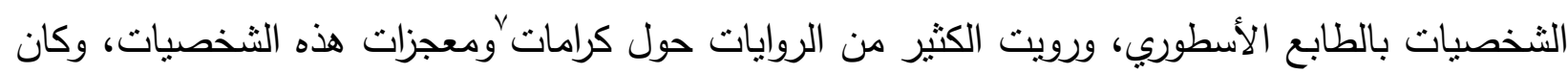

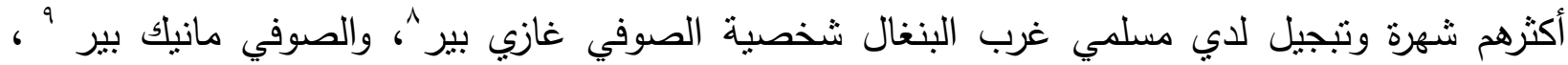

• أحد أنواع الفنون الني اشتهرت بولايات شرق الهند وخاصة ولاية البنغال وساحل ولاية أورويسا عرف باسم باتاتثتيرا Patachitra

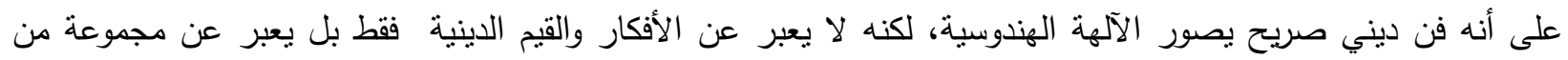

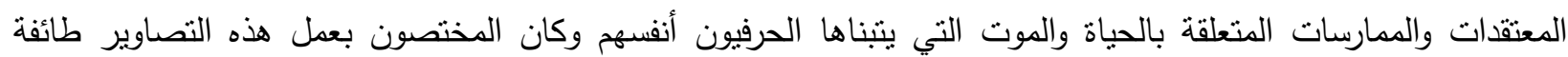

تيشتراكارا Chitrakara كوظيفة طبقية.

TRIPTHY, M., «Folk art at the Crossroads of Tradition and Modernity: A Study of Patta Painting in Orissa», Journal of the Anthropological Society of Oxford29, №. 3, 1998, 197.

${ }^{6}$ SOUMIK, N. M., Bengal Pata Chitra: Painting, Narrating and Siging with Twists and Turns ,New Delhi, Satrangi Bengal Patachitra, Ojas Art,2018, 14.

"يقد بمصطلح كرامات عند الصوفية هو ظهور أمر خارق للعادة، على يد ولي لله تعالى، عبد ظاهر الصلاح، ملتزم

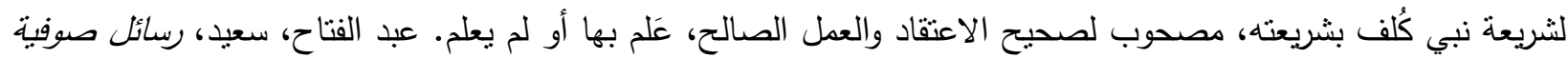

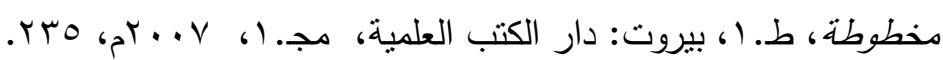

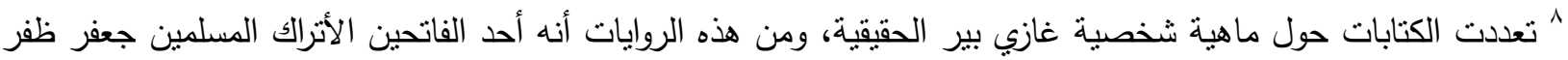

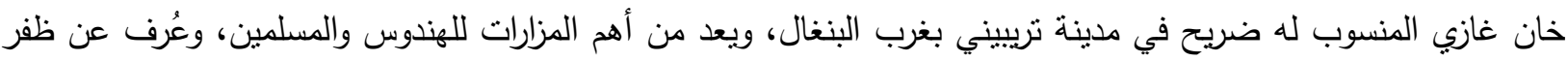

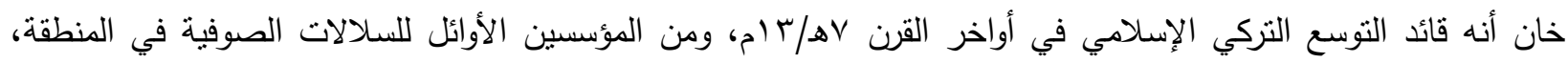
ونتيجة لطبيعة شخصية ظفر خان القائد والمحارب من جهة والصوفي من جهة أخرى، فقد عدَّه بعضهم الثخصية الأسطورية في القصص الثعبي البنغالي "غازي بير"، وهناك من قال: إنه ظفر خان غازي أحد قادة جيش السلطان فيروز شاه، وأنه مؤسس أقدم نظام صوفي في المنطقة، ويعتقد الكثيرون أن له دوراً كبيراً في اعتناق البنغاليين للدين الإسلامي، وهناك الكئ الكثير من الروايات عن مآثره البطولية من نرويضه للنمور والتماسيح ومعاركه مع العفاريت وغيرها من المحن والمعجزات التي توصف في الأدب الشعبي البنغالي خلال العصور الوسطى. وأكثر الروايات تداولًا في القصص الثعبي البنغالي عن شخصية غازي بير أن "جاجي Gaji كما بطلق عليه في منطقة البنغال ابن إسكندر شاه حاكم مملكة فيرات Vairat والملكة أجوبا Ajupa وكان له أخ بالتبني يدعى كالو قسوة والدهم قرر غازي وكالو ترك العائلة والتتازل عن المملكة وسافرا بعيدًا وخلال رحلاتهما المتعددة استقرا في غابات السونداربانس بالبنغال بصفتهما صوفيين أو فقراء Sundarbans قاما بترويض التماسيح والنمور وهزم الملك الهندوسي تركي

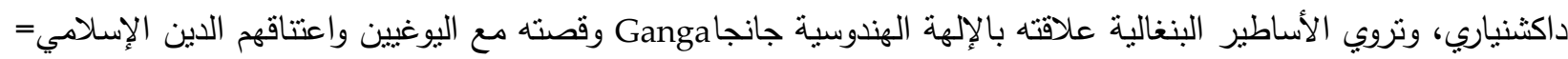


ويقال: إن لهذه الثخصيات دورًا في نشر الدين الإسلامي في قرى البنغال '، وبجانب هذه اللوحات وجدت

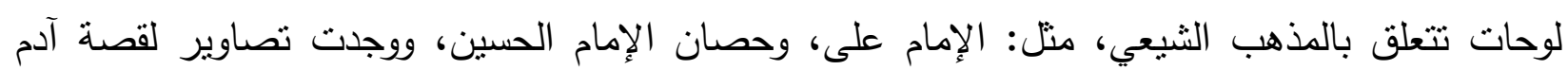

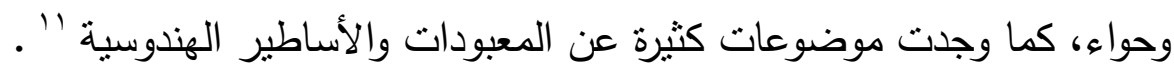

ويعد هذا النوع من التصوير الثُعبي من الموضوعات المهمة في مجال التصوير في الهند خلا العصر الإسلامي خاصة مع ندرة الدراسات المتخصصة لهذه اللوحات، وهو ما خلق صعوبة في معرفة موضوعات التصاوير، وقد تطلب الأمر البحث عن القصص الأسطورية للصوفيين في إقليم البنغال،

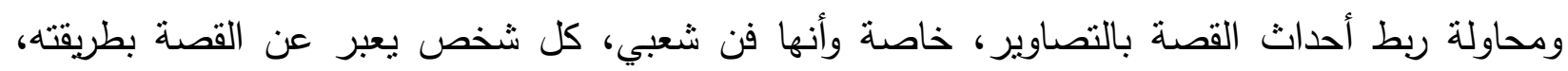
ويضيف أحداثًا من خياله لجذب المستمعين، وكان الهدف الأساس من هذه النوعية من اللوحات الربح

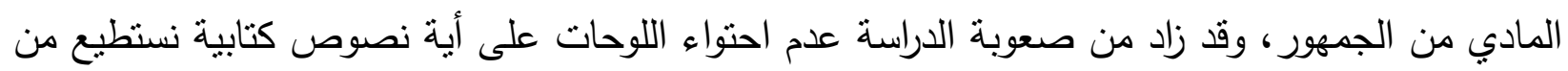

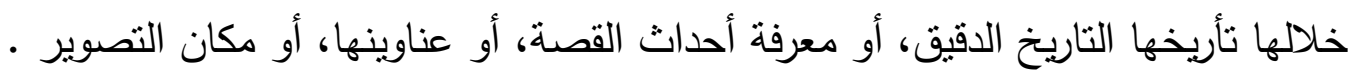
وتهدف الدراسة إلى إلقاء الضوء على هذا النوع من فن التصوير ، بالتطبيق على لوحة "لفافة" غازي بير

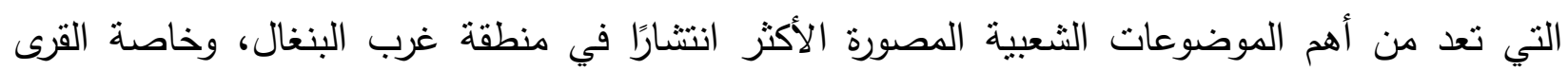

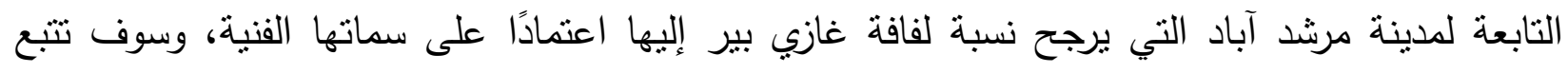

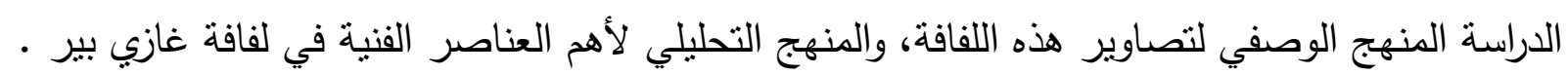
الاراسة الوصفية لتصاوير لفافة "جارانو باتا" غازي بير: تعد قصة غازي بير من القصص المحببة لاى

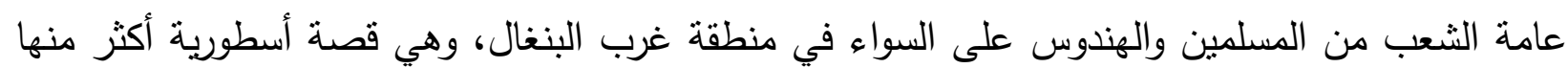

$=$

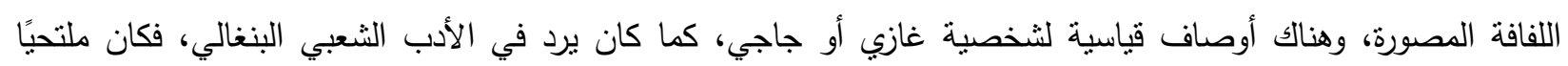

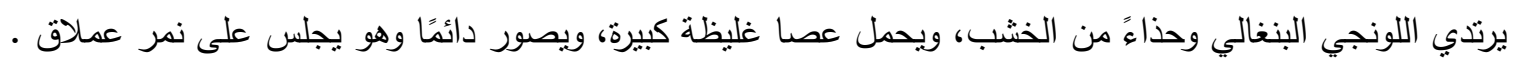
SEN ,B., «Betwixt Hindusand Muslims», Asian Ethnology 76, №.2, 2017, 219-223.

9 مانيك بير أحد المتصوفة البنغاليين الذي نُسجت حوله مجموعة من القصص الأسطورية التي تظهر معجزاته أو كراماته،

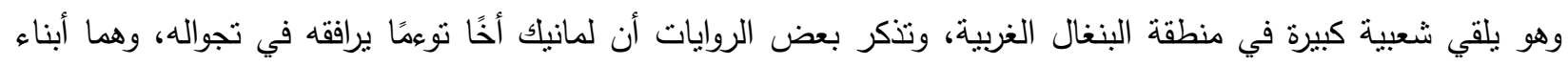

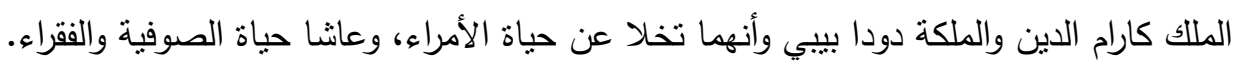
DINESCHANDRA, «Folk Literature of Bengal», 119.

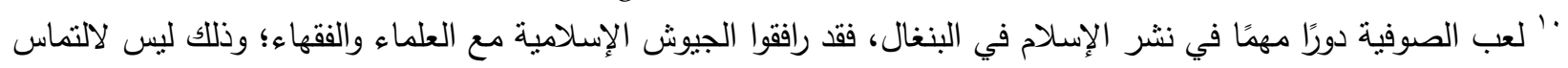

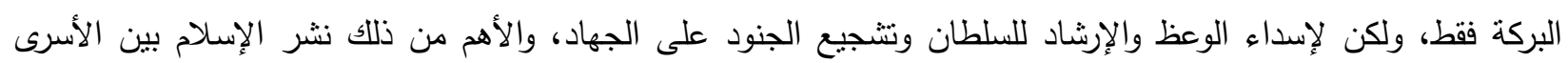

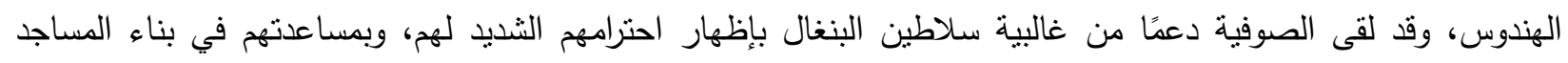

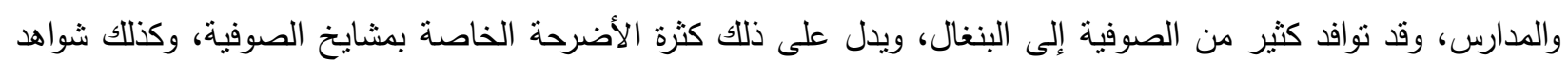

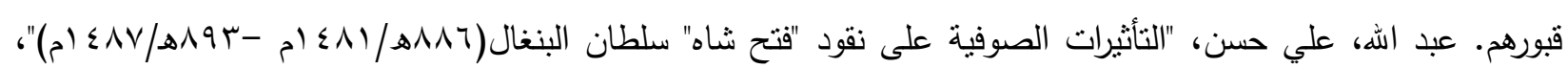

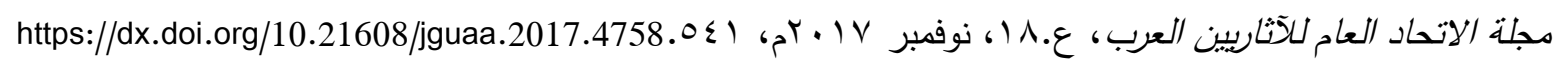
${ }^{11}$ DATTA ,S. «Folk Painting of Bengal», PhD thesis of Pholosophy, Department of ancient indian History and Culture University of Calcutta,1982,29. 
حقيقية حيث نُسجت حول شخصيته مجموعة من المعزات" الكرامات" حول حماية أتباعه من هجمات الحيوانات البرية والوحوش والثياطين في الغابات، ويُقَّس من قبل المسلمين والهندوس، ولا تزال شعبية وقوى غازي بير الأسطورية تؤمن بها المجتمعات في منطقة غرب الهند وبالأخص البنغال، فينطقون باسمه قبل دخولهم الغابات بوصفه الحامي من حيوانات ووحوش الغابات، ويعلقون لفائف الباتا لغازي بير في منازلهم لحمايتهم من تأثير قوى الثر، وقد تعددت الروايات عن ماهية شخصية "غازي بير"، فكلمة غازي تعني محارب أطلقت على المحاربين الذين جاءوا مع الفتح الإسلامي التركي للبنغال، وكلمة بير فارسية الأصل تشير إلى المرشد الصوفي، ونظرًا لإنجازاتهم العديدة ودورهم الريادي في نشر الإسلام، فضلًا عما أثيع عن كراماتهم ومعجزاتهم تحول كثثر منهم إلى صورة أسطورية أخذت مكانها في الخيال الشعبي البنغالي، نجد انعكاساتها في الأدب البنغالي، وكان يُجَّل البير با' وتُقام أضرحة حول قبورهم، وعدها مزارات مقدسة على

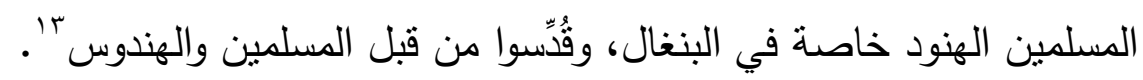

وتعد تصاوير غازي بير باتا من أثهر الموضوعات الدينية والثعبية في المجتمع البنغالي المسلم، وتشكلت أحداثها بناء على التاريخ المحلي للبنغال والحكايات الشعبية والأساطير المتداولة حول شخصية هذا الصوفي الثهير، بالإضافة إلى ما وصفه فنان الباتو من قوى خارقة للطبيعة في القصة التى يروبها في صورة أغنية Pater Gaan

rا تأثر الصوفية في البنغال بالتصوف الهندوسي والبوذي، وذلك عن طريق مؤلفات التصوف السنسكريتية التي ترجمت إلى

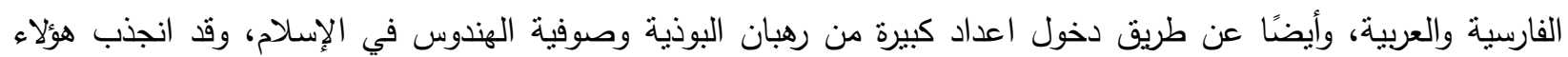

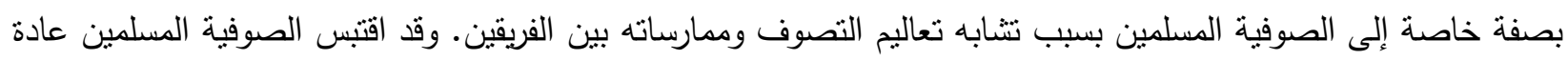
تقديس الأولياء وزيارة أضرحتهم من الهندوس، فأصبحوا يقدسون الأولياء تقديسًا يكاد يرفعهم أحيانًا إلى مرتبة التأليه، وربما

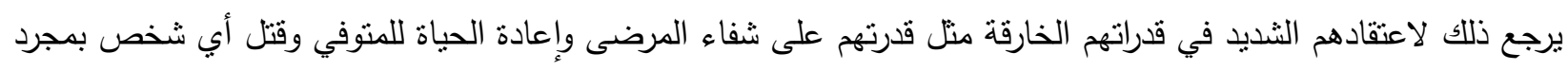

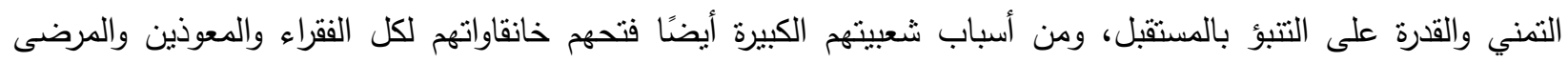

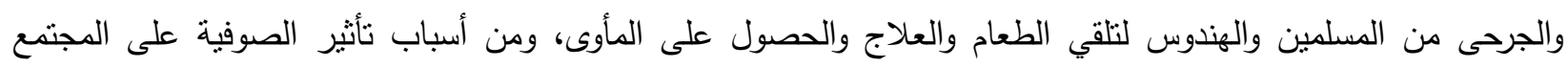
البنغال، انتثارهم بأعداد كبيرة حتى قبل الفتح الإسلامي لها، فلا تكاد تخلو قرية أو مدينة من شيخ من الصوفية قدم ولمن إليها

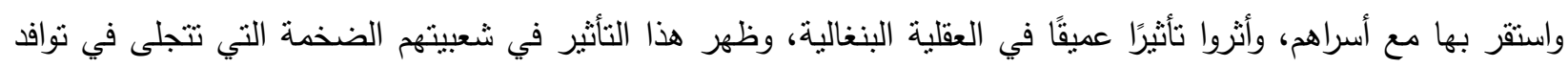

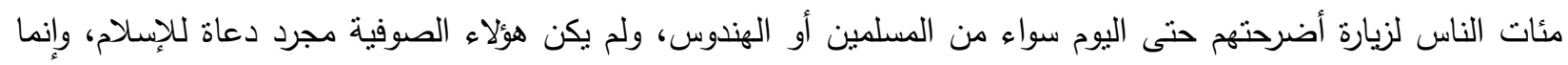

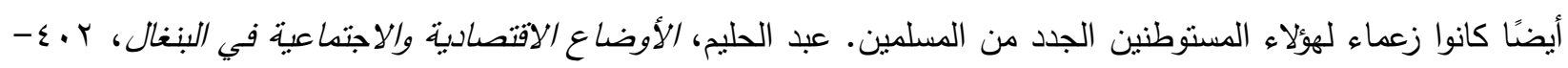

${ }^{13}$ NOORUR RAHMAN, SH.:«Pir Cult Evidence of Hindu-Muslim Amity in Mughal Bengal», Proceedings of the Indian History Congress, Golden Jubilee Session, Vol.50, 1989, 280-282.

14 Bhattacharya, S. \& Narayanaswami, M., Pattachitra: Indian Art in Context, New Delhi, Indian Studies , 2017, .15. 
المختلفة حول التسلسل المرئي للتصاوير، وفي بعض الأحيان تكون أجزاء من القصة غير مصورة، ويقوم

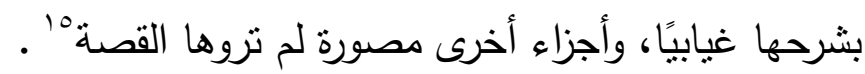

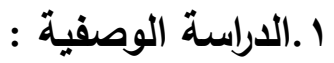

1 , 1, بيانات التصويرة: لفافة غازي بير - محفوظة في الكتحف البريطاني بلندن- عرضت للمرة الأولى عام 919 ام "17 رقم الحفظ: 1955,1008,0.95 الأسلوب الفني: مدرسة مرشد آباد

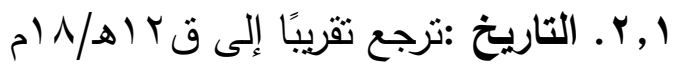

وهي عبارة لفافة رأسية تحتوي على ه ه مشهدًا مصورًا داخل مساحات مستطبلة يفصل بين كل مشهر

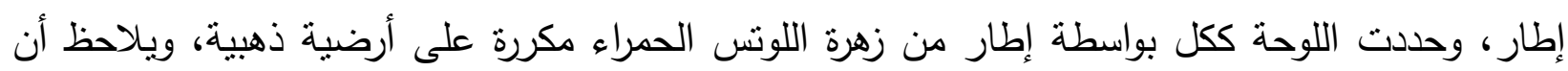

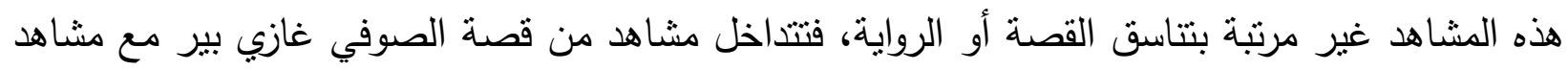

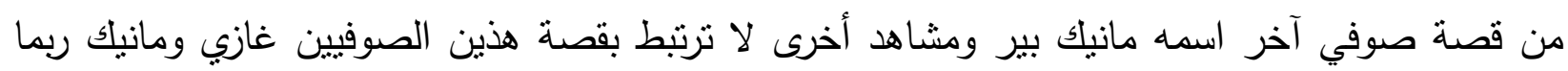

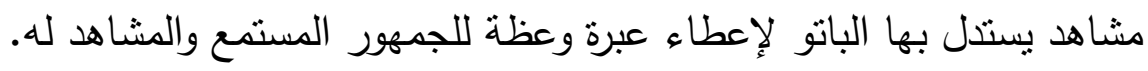

ويلاحظ أن المصور في بعض التصاوير باللوحة يرسم مشهدًا من أحداث القصة ولا يُكمله في

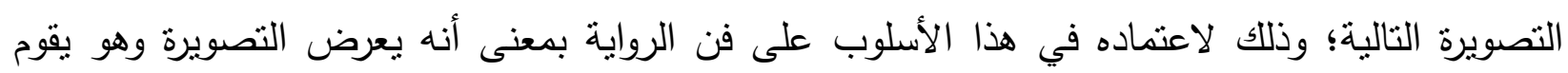

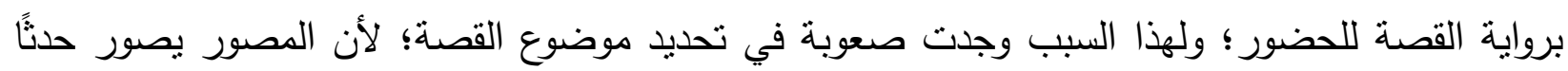

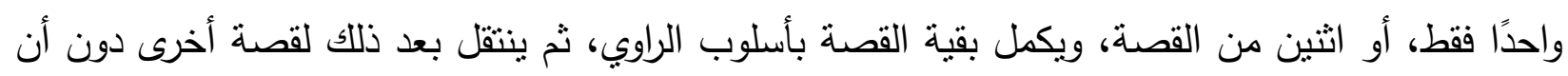

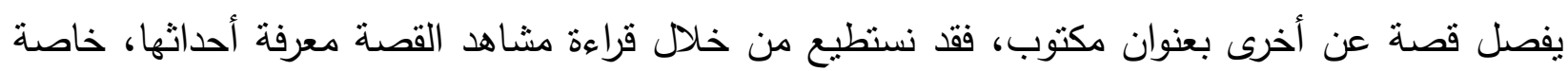

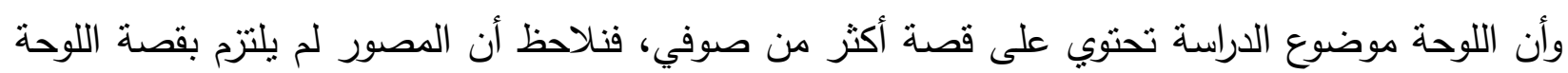

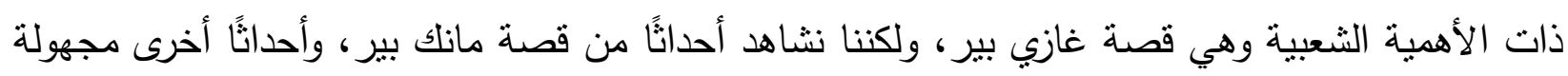

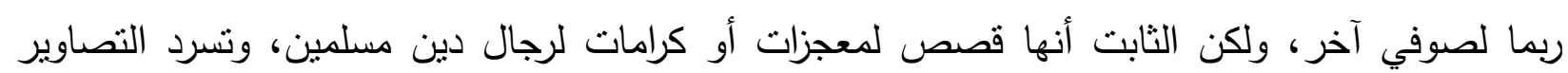
أحداثًا متفرقة عن معجزات الصوفى المسلم غازي بير والصوفي مانيك بير وكراماتهما. تبدأ اللفافة بتصويرة(لوحة //أ) يحبط بها من أعلى وأسفل إطار بشغله زخارف نباتية من فرع

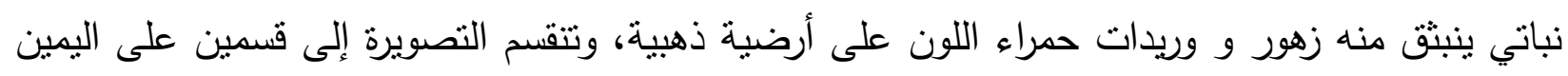
تجلس سيدة داخل مبنى بسيط التكوين من مساحة مستطيلة، له سقف مسطح يستتد على دعلى دعامات مستطيلة

${ }^{15}$ DATTA, «Folk Painting of Bengal », .65.

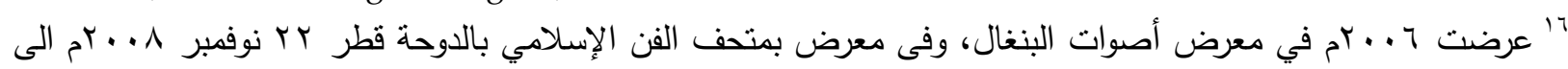

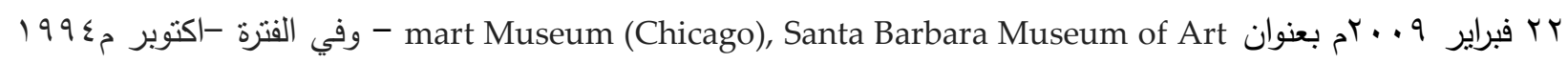

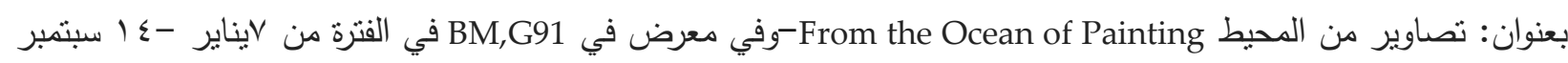

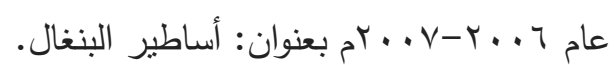
https://www.britishmuseum.org/collection/object/A 1955-1008-0-95(Last visit 12/9/2020) 
يستتد على هذه الدعامات فتحة عقد مفصص الثكل ربما يمنل منزلًا، تجلس السيدة بوضعية جانبية تستتد

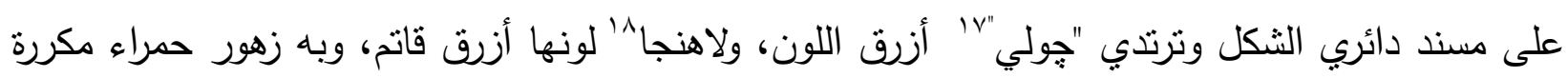

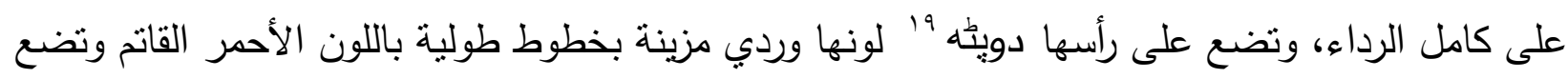
السيدة كامل مجوهراتها من حلي الوجه والأذن والرقبة والذراعين والقدم، وتتير بيدها اليمني تجاه شابة ترتدي ملابس مشابهة لملابس السيدة باختلاف الألوان، وظهر في القسم الثاني من التصويرة وهو يمثل خارج المبني في منظر خارجي حيث تظهر شجرة مرسومة بشكل غير واقعي تتوسط سيدتين ترتديان مالابس مشابهة لملابس السيدة الأولى باختلاف الألوان، وتحمل إحداهما طفلًا صغيرًا على ذراعيها، وعبر المصور في هذا القسم عن السماء والتي تبدو أحداثها بالليل حيث رسم خطوطاً متعرجة لونها أسود وقمراً لونه أحمر. يلى هذا المشهد تصويرة(لوحة /أl) مقسمة إلى قسمين، قسم يظهر به شخص هندوسي يجلس أسفل عقد مفصص داخل مبني بسيط بوضعية جانبية يرتدي ملابس رجل الدين الهندوسى دهوتي أبيض اللون ·r ، وحليق الرأس فيما عدا جزء في منتصف الرأس رافعًا يديه كأنه يرد التحية لرجل يقف أمام المبنى، وأمامه قدور كبيرة الحجم من الفخار، وفي الجزء الأيمن من التصويرة ويمنل خارج المبني يظهر رجل يبدو أنه صوفي مسلم يرتدي من أعلى قميصًا له أكمام طوبلة لونه أحمر ومن أسفل لونجي Lungi أو سارونج sarong لونه أزرق قاتم ويرتدي قلادة من الخيط يتدلى منها حبيبات ذهبية اللون، ويضع على رأسه قلنسوة مثلثة لونها أبيض ويحمل بإحدى يديه عصا صفراء اللون، له لحية وشارب وهو يلقي التحية للشخص V رداء صغير ترتديه النساء يغطي منطقة الثذيين فقط يعرف بهذا الاسم في مناطق الدكن والبنغال، يطلق عليها في مناطق

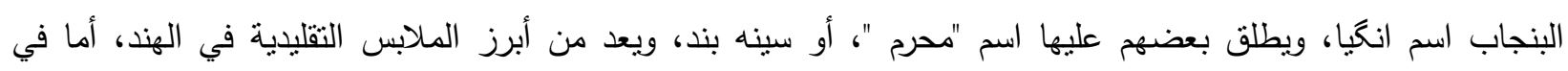
الحجرات فيعرف بين العامة باسم كاجري أو كجوكي، وفي ميسور يعرفه بعضهم باسم كيسيا، ويختلف شكله باختلاف المكان

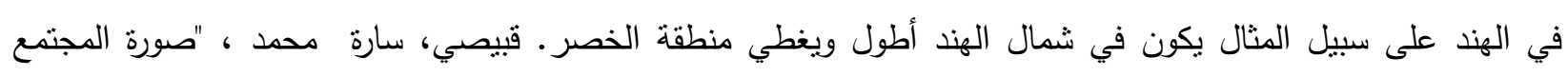

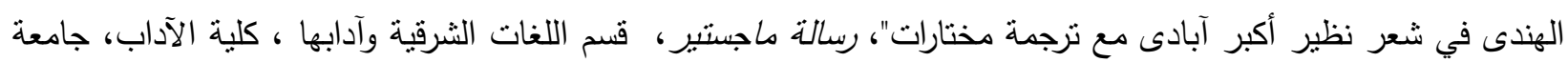

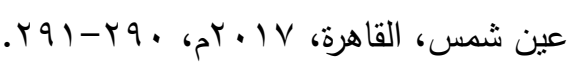
^’ لاهنجا أو الفرارة وهي عبارة عن تتورة (جونلة) طويلة فضفاضة تصل حافتها إلى أسفل حتي تكاد تخفي القدمين والكعبين،

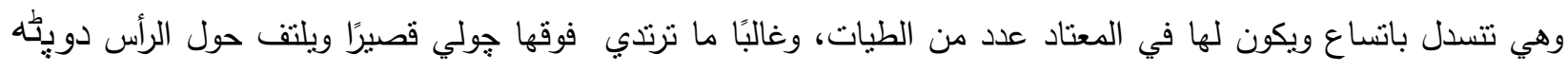

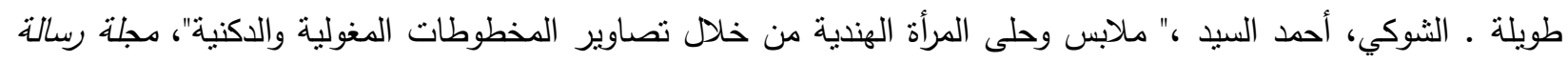

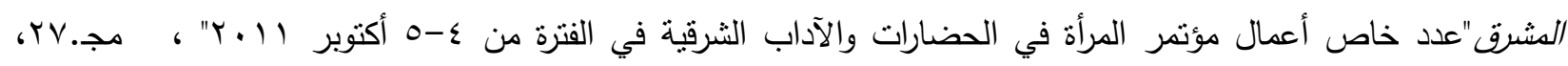

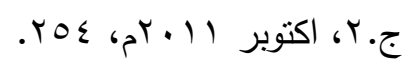
19 دوبيّه عبارة عن قطعة من القماش طولها حوالي ثلاثة أذرع تغطي بها النساء في الهند رؤوسهن وتصل حتي الخصر

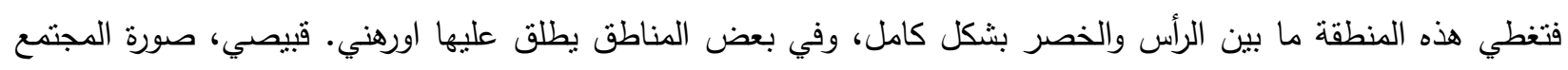

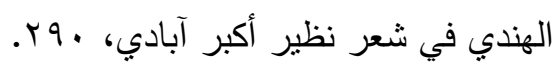
• زي البراهمة ويعرف أيضًا باسم باشا كاشتام (Pacha Kacham) وهو قطعة قماش طويلة غير مخيطة تلتف من منتصف الخصر حتى أسفل القدمين. ACHARYA,P.K., Sacred Complex of Budhi Santani , New Delhi: Concept Publishing Company, 2003 , 82-83. 
الهندوسي، ومن خلال القصة يبدو أن هذا الثخص هو الصوفي المسلم غازي بير، وخلفه رسم المصور شجرة بأسلوب بسيط غير واقعي، وتظهر السماء التي عبر عنها المصور بخطوط متعرجة ملونة بدرجات الأزرق القاتم والأسود ولم يتبع المصور النسبة والتتاسب بين العناصر في التصويرة فالثجرة رسمت بارتفاع الشخص والمبني نفسه.

(تصويرة r/أ): والتصويرة تتبع الأسلوب نفسه في التصويرتين السابقتين فعلى اليمين تجلس سيدة هندوسية أسفل عقد مفصص داخل مبنى بسيط التكوين ترتدي ما يشبه زي البراهمة الدهوتي الأبيض من أسفل ويلتق طرفه حول الكتفين ولا ترتدي من أعلى أية ملابس، وتضع كامل مجوهراتها، وخارج المبني تقف سيدة أخرى تحمل بيدها قدرًا صغيرًا ترتدي من أسفل لاهنجا لونها أزرق قاتم، ولا ترتدي شيئًا في الجزء العلوي من الجسد فيما عدا دوبّه تضعها على رأسها، وتتسدل على كامل ظهرها والكتقين لونها أحمر مزبنة بورود متعددة البتلات باللون الأزرق والأبيض مكررة على كامل الدوبيده، وتتير بيدها إلى الصوفي غازي بير الذي يطلب من السيدة أن تعطيه الحليب وهو يرتدي ملابس مشابهة لملابسه في التصويرة السابقة، ولكنه هنا يرتدي من أسفل سروالًا بدلاً من لونجي.

( تصويرة ع أأ): ويظهر الصوفي غازي بير وهو يجلس على حافة النهر أسفل شجرة وبجواره سيدة ترتدي ملابس السيدة نفسها في التصويرة السابقة فيما عدا اختلاف الألوان تحمل قِدر الحليب وهي تطعم غازي بير "، وعبر المصور عن المياه باللون الأزرق بواسطة خطوط بيضاء متعرجة تشير إلى الأمواج ويظهر بالنهر أسماك وعلى حافة النهر طائر يشرب من المياه.

(تصويرة م/أ): يظهر يمين التصويرة مجموعة من الأبقار تسير في هدوء وسكينة وخلفها صوفي ورجل هندوسي يقبل قدمه، ويبدو أن مصورًا آخر قام برسم هذه التصويرة، حيث رسم غازي بشكل مختلف عن التصاوير السابقة، فهنا لونه داكن، ويرتدي رداء أبيض اللون مفتوحًا من الأمام ويضع على رأسه قلنسوة بيضاء منلثة الثكل، ويحمل بيده عصا مختلفة عن التي كان يحملها في التصاوير السابقة، ويضع علامة صفراء على جبينه، ولونت الخلفية باللون الأحمر بتخلاها شجرتان رُسمتا بشكل بسيط، وعبر عن السماء بشريط من خطوط متعرجة باللون الأسود محددة باللون الأبيض والأزرق.

(تصويرة آ/أ): يظهر في هذه التصويرة شخص يجلس جهة اليمين صور بملامح غازي بير نفسها في التصاوير السابقة والقلائد التي يضعها المتصوفون بالإضافة إلى خيط أبيض يضعه حول نصفه الأعلى، ويرتدي لونجي فضفاضًا لونه أزرق قاتم وكان عاريًا من نصفه الأعلى ويبدو أن مصور هذه التصويرة هندوسي فقد رسمه بهيئة الآلهة الهندوسية له أربعة أذرع ويضع علامة حمراء على الجبين تيكا ويضع قرطًا

DiNESCHANDRA ,S. , Folk Literature of Bengal, Being Lectures Delivered to the Calcutta in 1917 as Ramtanu Lahiri Research Fellow in the History of Bengali Language and Literature, Gyan Publishing House, 2006,63 . 
في أذنه وأمامه آنية دن الفخار بها طعام، ويظهر في الجانب الأيسر كوخ له سقف جمالوني بداخله سيدة تحضر الطعام لهذا الشخص الذي يحمل ملامح الصوفي المسلم من اللحية والثارب والطاقية أو الكُلاه والقلائد واللونجي، وملامح هندوسية تتمثل في التشبه بالآلهة الهندوسية ومعها رجل هندوسي يقف خلف الكوخ ويرتدي دهوتي أبيض ويحمل تحت إبطيه عصا صفراء اللون. (تصويرة V/أ): ظهر السيدة والرجل نفسهما في التصويرة السابقة وهما فاقدان الوعي، حيث ترقد السيدة داخل الكوخ ذي السقف الجمالوني ورقد الرجل خارج الكوخ ويقف غازي بير في يسار التصويرة يشير تجاههم بريش طاووس يحمله في يده، ويرتدي ملابسه المعتادة من قميص أسود اللون، ولونجي أصفر اللون مزين بخطوط زجزاجية حمراء وسوداء اللون، ويرتدي قلادة من حبيبات بيضاء اللون. (تصويرة 1/أ): ومنها تبدأ أحداث قصة أخرى يظهر بها أحد الأثرياء يجلس بداخل قصره الذي تتميز جدرانه بالثراء الزخرفي ومعه زوجته يقدم لله أحد الخدم كأس الثراب بينما تقف جهة اليمين خادمة تحمل في يدها مذبة بَ، يلي ذلك تصويرة (لوحة 9/أ) يظهر غازي بير في منتصف التصويرة يجلس مستندًا على جذع شجرة يرتدي قميصًا أبيضاً مفتوحًا من الأمام وسروالًا أحمراً مزينًا بخطوط طولية سوداء اللون وبضع على رأسه كُلاه بيضاء اللون، وعلى يمينه ويساره كوخان لهما سقف جمالوني تقف أمام الكوخ الأيمن سيدة تتحدث مع غازي بير رُسمت بحجم صغير مقارنة بشخصية غازي بير، ونلاحظ في أعلى التصويرة طريقة تعبيره عن السماء بخط متعرج بعرض التصويرة ملون باللون الأسود ومحدد باللون الأزرق والأبيض، في طرفي هذا الخط المتعرج رسم قمران أحدهما لونه أبيض والآخر أحمر ، ويظهر بعد ذلك تصويرة (لوحة . 1/أ) سفينة كبيرة مقدمتها على هيئة رأس حيوان النمر مكونة من طابقين يجلس في الطابق الأول مجموعة من الأشخاص يظهر من اليسار شخص يجلس على منصة مرتفعة عن باقي الحضور يبدو أنه رجل دين، وهو يتحدث مع شخص يبدو أنه شخصية مهمة أو من كبار التجار وبالبحث في قصة غازي بير ومانيك بير لا تظهر بها هذا الحدث؛ لذلك يبدو أنه ربما لشخصية دينية أخرى من الثخصيات الأسطورية مثل: شخصية سايتا بير بّ رجل الدين المرتبطة قصته بالخروج في البحار للتجارة.

r مذبة من الفعل ذب، والذب الدفع والمنع والطرد، والمذبة يذب بها الذباب والجمع مذبات ومذاب ويطلق عليها منشة أو

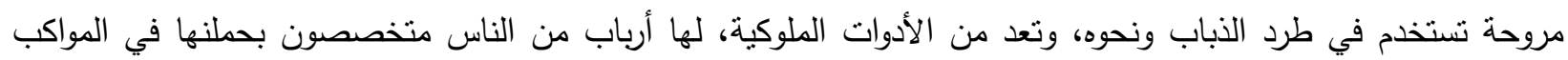
والحفلات. عبد الرحيم، عاطف على، "رسوم المذبات في تصاوير المدرسة المغولية الهندية"، المؤتمر السادس مركز الدراسات

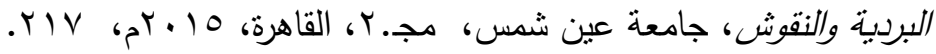

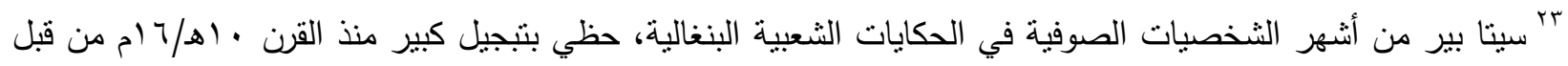
المسلمين والهندوس على السواء؛ وذلك لكثرة الأساطير التي تتاولت قدرته على الحماية من الأمراض والقوي الثيطانية

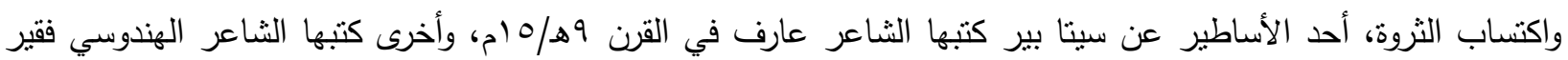

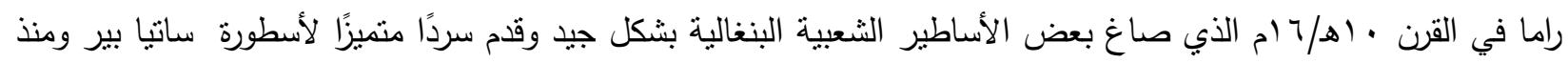


يلي هذه القصة أحداث من قصة الصوفي "الفقير" مانيك بير ، حيث تظهر تصويرة (لوحة (1/أ) بها صوفي فقير يبدو أنه جوبتا أخو مانيك بير يرتدي سروالًا به زخارف زجزاجية باللون البني والأخضر القاتم ومن أعلى عاري الجسد فيما عدا شال أبيض "جاموتثا" يضعه على كتفيه ويضع حول رقبته خيط الصوفية وتحت إبطيه يبدو أنه يحمل ورقة صغيرة بيضاء وفي إحدى يديه عصا، وخلفه سيدة هندوسية عجوز لا ترتدي سوى ما يُشبه دهوتي وتضع طرفه على الكتفين وتسند بإحدى يديها على عصا واليد الأخرى تحمل

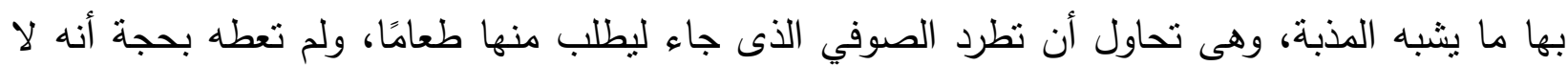
يوجد عندها طعام وإلى الخلف منها بظهر منزلها ذو السقف البنغالي الثهير نتارشالا، وبداخل المنزل مجموعة كبيرة من القدور حيث يعبر المصور بهذه القدر المليئة باللبن كذب السيدة العجوز كما نذكر

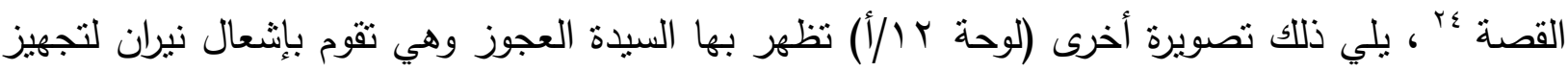
الطعام أمام منزلها، ونشاهد الفقير وهو بختبئ خلف الثجرة وبشاهدها، وهي تطهو الطعام، ثم بظهر في التصويرة التالية(لوحة سأ/أ) النيران وهي نتتعل بمنزل السيدة العجوز ذي الأسقف البنغالية، وبداخلها بقرة، وقد ماتت جراء الحريق، يشاهد في التصويرة التالية (لوحة؛ //أ) مجموعة كبيرة من الأبقار قد ماتت كلها، ثم في التصويرة التالية(لوحة 0 /أ) أولاد السيدة العجوز كينو غوش وأخوه كانو، وهما يحمان الحليب ويرتديان

ذلك الحين ينقل عنه كل شعراء البنغال، وأخرى كتبها الثشاعر الهندوسي سانكاراثاريا ترجع إلى عام بأحداث مختلفة حول شخصية الصوفي المسلم سايتا بير .

DINESCHANDRA, Folk Literature of Bengal, 85.

عَ قصة مانيك وبائعى الحليب بإيجاز وتذكر القصة أن مانيك وأخاه وصلا إلى قرية جوكول وهناك وجدا منزلاً لبائعي الحليب وهما الأخوان كانو وكينو غوس وطلبا منهما إعطائهما بعض اللبن لأنهما لم ينتاولا الطعام منذ V أيام؛ ولأن السائلين مسلمون

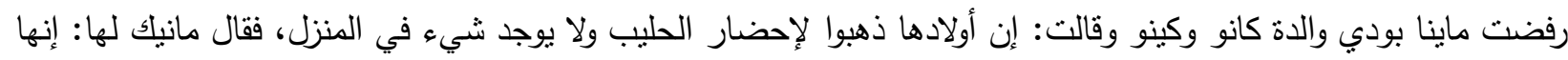

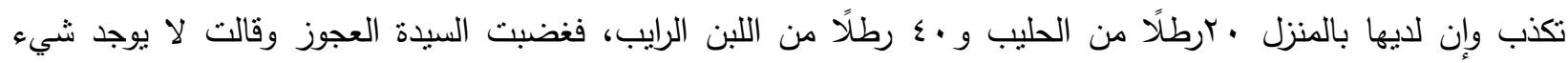

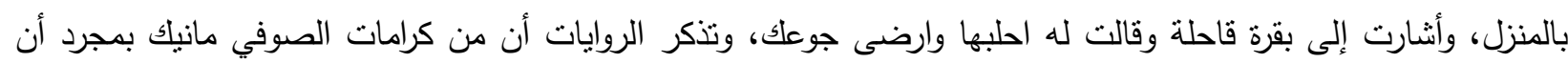

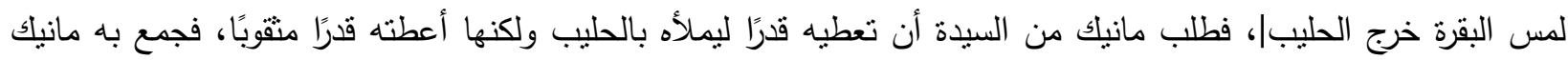
اللبن في القدر الذي لم يعد يسرب وكأن لم يكن هناك ثقوب، ولكن السيدة العجوز غضبت من الأخوين وقالت: إنهما استولا

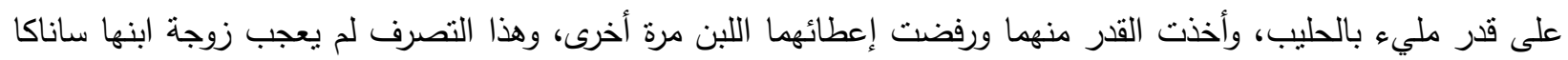
وقالت: لماذا أخذت الحليب الذي حصلا عليه بقوتهما الخارقة؟ فصاحت العجوز وهي غاضبة تسميها معجزة لقد أحضرا

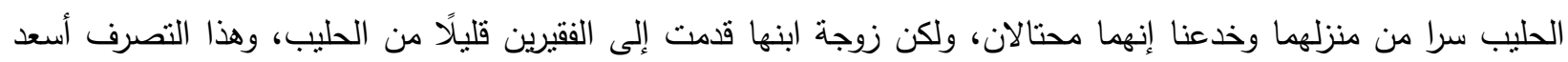

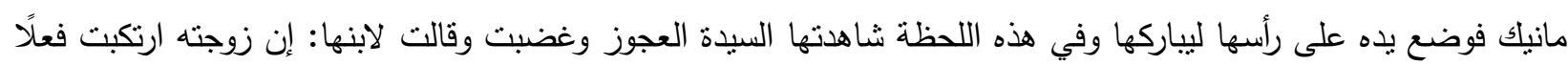
غير أخلاقي، فاندفع كانو واعتدى على الفقيرين بعصا خشبية، فذهبا وهما غاضبان وعلى إثر ذلك اثتعلت النبران بمنزل

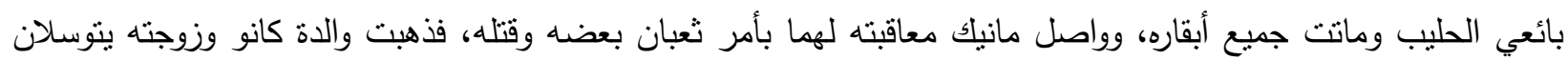

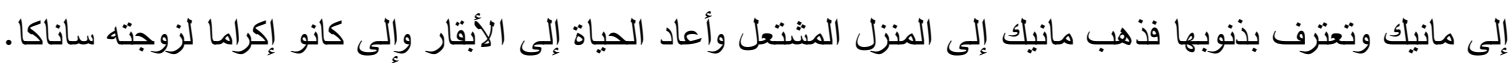
AHMED, S.I. , « Performing and Supplicating Manik Pir: Infrapolitics in the Domain of Popular Islam», TDR The Drama Review53, №.2,2009, 54-55.

Dineschandra, Folk Literature of Bengal, 119. 
الدهوتي الأبيض ويحلقون رؤوسهم ويضعون أقراطًا ذهبية في أذنيهم، وفي هذه التصويرة يتعرض كانو للاغة حية ضخمة تظهر خلفه جهة اليمين فيسقط على الأرض، ثم يظهر في التصويرة التالية(لوحة 7 ألمأ) الصوفي مانيك بير ذو البشرة البيضاء وشارب ولحية بيضاء اللون يرتدي قميصًا أسوداً من أعلى ومن أسفل لونجي أبيض اللون مزين بخطوط طولية سوداء ويحمل بيده عصا وورقة بيضاء تحت إبطيه ويضع قلائد بعضها من الخيط الأبيض والأسود ويضع على رأسه قلنسوة مثلثنة وتظهر زوجة كانو واسمها ساناكا وهي تتوسل إلى مانيك بير فتظهر وهي راقدة على الأرض في محاولة للاعتذار إلى الصوفي، ويظهر بالتصوير خلف السيدة شجرة رمان وخلف مانيك نخلة، وقد رسم مانيك بير بطول يقارب طول الشجرة والنخلة، وجاءت السماء بنفس طريقة رسمها في كل تصاوير الدراسة عبارة عن شريط في أعلى التصوير من خطوط متموجة باللون الأسود والأزرق والأبيض وبتخلاها رسم للقمر، ثم يظهر في التصويرة التالية(لوحة V//أ) كرامات مانيك بير، حيث يقف بهيئته نفسها مع اختلاف طفيف في تصويره هنا بشارب ولحية سوداء أمام منزل السيدة العجوز بعد أن أعاد لها المنزل بعد احتراقه كما كان وعالج ابنها من لدغة الحية، وتجلس بداخل منزلها ذي السقف البنغالي (تثار شالا) في طمأنينة ومعها ابنها وزوجته وخلفها قدور اللبن ويتحدثون مع البير الذي يقف أمامهم جهة اليمين ويقوم بتوديعهم، ويرتدي الثلاثة دهوتي من أسفل، السيدة العجوز دهوتي لونه أبيض، وكانوا دهوتي لونه أصفر وزوجته دهوتي لونه زيتي منقوش بزهرة صفراء ومن أعلى يضع الثناثثة شالاً يُعرف في غرب البنغال باسم جامونتا، وبظهر مانيك بير طوله بارتفاع المنزل نفسه. ويظهر في التصويرة التالية (لوحة ^ / أأ) إحدى كرامات الصوفي مانيك بير المشهور بها في البنغال وهو يقف في المنتصف بهيئته نفسها المعروف بها الوجه الأبيض والثارب واللحية البيضاء، ويرتدي قميص الصوفية المرقِّع وسروالًً مزينًا بخطوط طولية وقلادة من الخيط الأسود ويحمل في يده كثكول الصوفيين، وصور وهو يلمس وجه البقرة القاحلة وبمجرد أن لمسها أصبحت تدر اللبن بغزارة وخلفه في الجهة اليسرى تجلس بقية الأبقار في سكينة وهدوء، وتظهر في التصويرة التالية(لوحة 9 و/أ) الزوجة الثابة وهي تقدم قدرًا به اللبن للصوفي مانيك بير الذي يجلس خارج المنزل بجوار الشجرة وفى الجهة المقابلة تجلس السيدة العجوز بداخل منزلها وهي غاضبة لما تفعله زوجة ابنها (ومن المفترض أن التصويرتين السابقتين كانتا تأتيان قبل حرق المنزل على حسب نتاسق أحداث القصة ولكن كما سبق وذكرنا أن المصور لا يلتزم بتصوير الأحداث متتابعة) وبذلك تتتهي أحداث قصة مانيك وبائعي اللبن.

(لوحة • ب/أ) وتمثل تصويرة على مستوبين مقسمة بالنصف يظهر بها في منتصف المستوى الأعلى قبر على هيئة تركيبة مستطيلة الثكل وضع فوقها شال أبيض جاموتشا من ملابس المسلمين المتصوفة في البنغال وفوق القبر مظلة يتذلى منها شراشيب من القماش الملون، ومعلق بها فرع من الورود الملونة وعلى يمين القبر ويساره قائمان معلق بكل منهما هلال لونه أحمر، وبجوار القبر وضع سبف له مقبض ذهبي اللون، وهن هذه الأدوات نستطيع أن نقول: إن هذا القبر هو للصوفي والمحارب غازي بير. وأمام القبر 
يجلس شخص مسلم يرتدي لونجي لونه أزرق قاتم ويضع على كتقيه شالًا أبيض "جاموتثا" وطاقية بيضاء اللون "كُلاه"، وخلفه يقف شخص آخر يرتدي دهوتي أبيض ويحمل في يده طبقًا أبيض صغيرًا، وفي الجزء

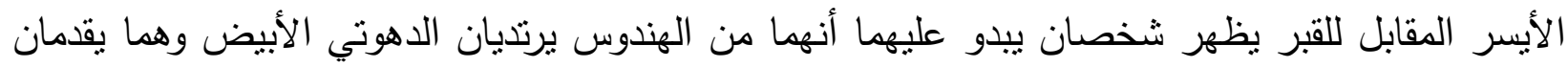

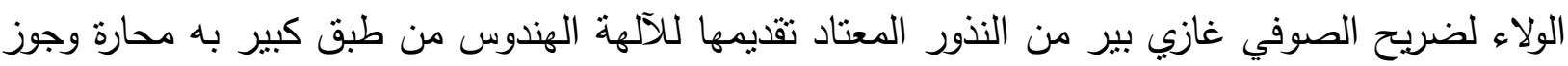

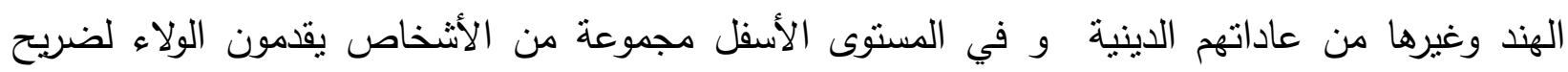

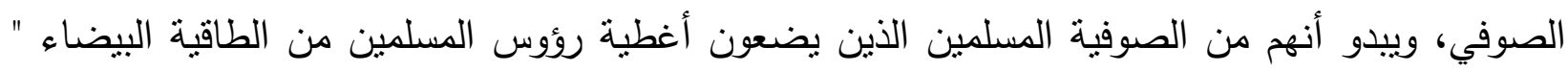
الكُلاه "، وبالمتل في الجانب الأيسر يظهر مجموعة من الهندوس بعدئ الهد المسلمين نفسه في الجانب الأيمن

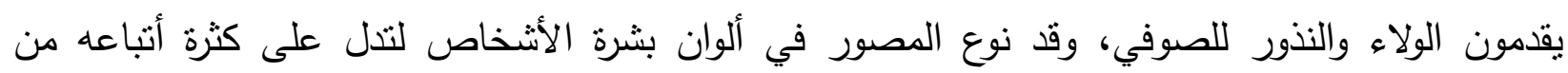
المسلمين والهندوس على اختلاف طبقاتهم ومعتقدهم الديني.

يلي ذلك تصويرة (لوحة (ب/أ) يظهر بها جهة اليمين الإلهة الهندوسية كريشناو رداها فيظهر كريشنا بلونه الداكن يحمل تحت إبطيه ورقة بيضاء منلما يصور الصوفي المسلم في باقي تصاوير اللوحة، وتسير

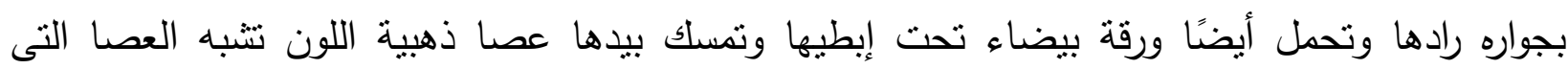
يحملها الصوفي المسلم متجهين إلى يسار التصويرة حيث تجلس سيدة معها طفلان أحدهما يقف خارج الكوخ والآخر طفل رضيع تحمله السيدة داخل كوخ له سقف نتار نتشالا.

يلي ذلك تصويرة(لوحة r ب/أ) شخص يمنطي صهوة حصان لونه بني يرتدي هذا الثخص ذو اللحية

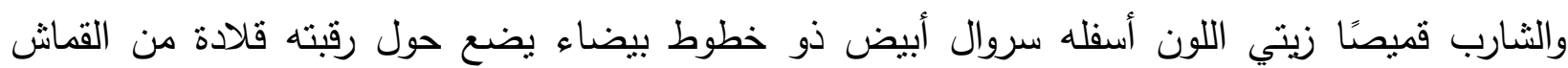

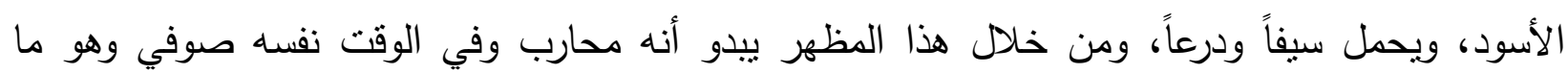
ينطبق على شخصية الصوفي والمحارب غازي بير، ويتجه جهة اليمين حيث يوجد مبنى مكون من ثلاثنة

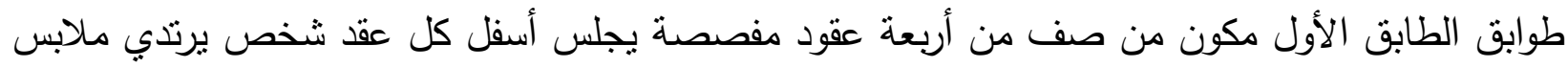

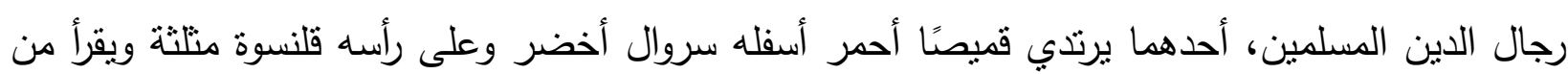
ورقة يمسكها بيده، يليه شخص يقرأ من كتاب موضوع على كرسي رحل ربما يقرأ القرآن ويرتدي رداءً أسود

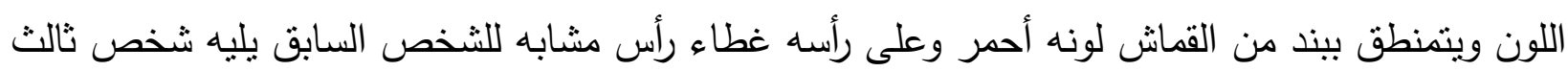

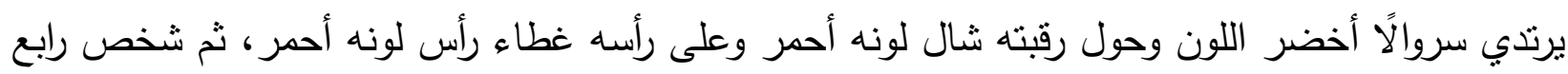

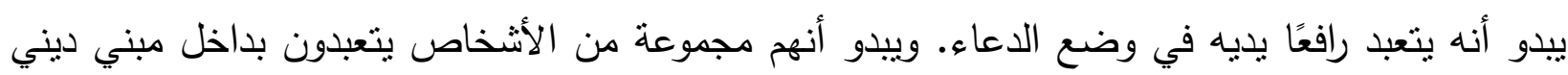
المفترض أنه مسجد ولكنه مرسوم على هيئة المعابد الهندوسية.

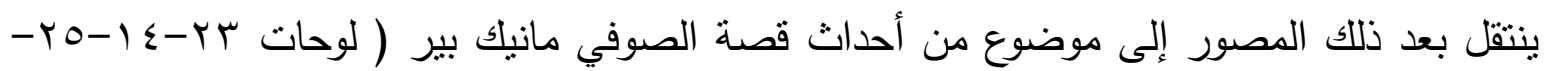

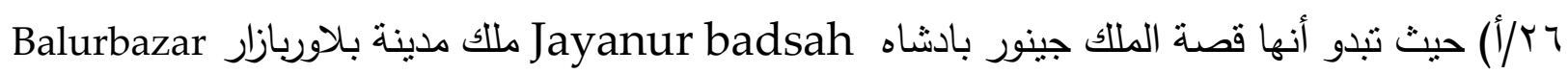
وتروي القصة أن مانيك بير طلب مقابلة الملك وأبلغه أن أبناءه لن يحافظوا على مملكته وطلب منه تقديم

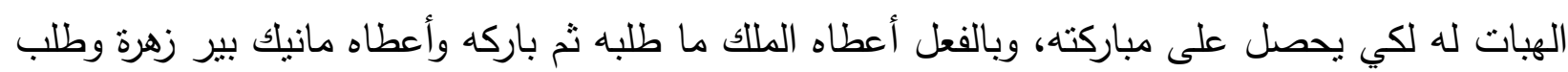


من زوجته الملكة الصغيرة تارا بهانو التى لا تتجب أن نأكلها لكي تتجب له ابنًا سيكون خليفة له ويحافظ

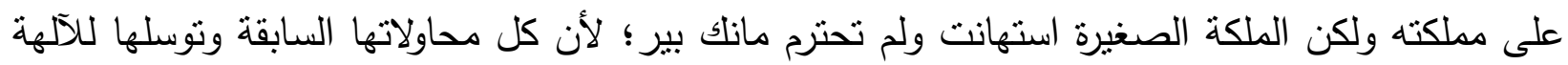

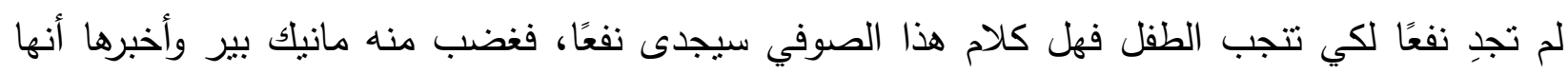
بالفعل ستتجب ولدًا بسمي تاجال ولكنها ستعاقب وستتفى إلى الغابة ويمرض زوجها (وللقصة بقية ولكنها

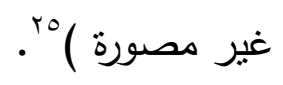

ويظهر في التصويرة (لوحة سب/أ) مانيك بير يقف أمام الملك يرندي رداءً قصبرًا لونه أزرق قاتم مفتوح

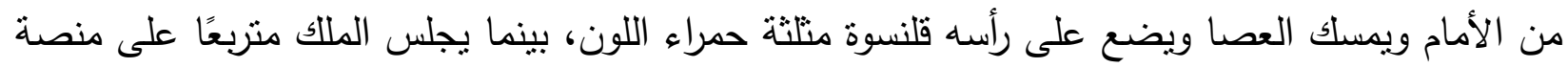
مرتقعة قليلًا عن الأرض وفوق رأسه مظلة بيضاء اللون، يرتدي رداء لونه أخضر قاتم يزين بزهرة لونها

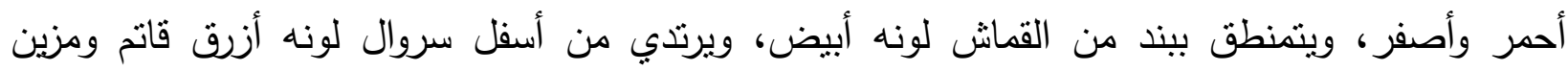
بخطوط زجزاجية باللون الأسود ويضع على رأسه عمامة بيضاء متعددة الطيات، ويشير الملك إلى المئل الملكة

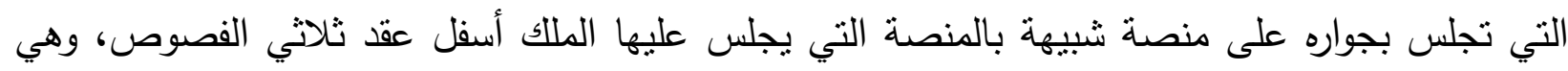
ترتدي ملابس مشابهة لملابس النساء في التصاوير السابقة وتربط شعرها من الخلف وتمسك بإحدى يديها

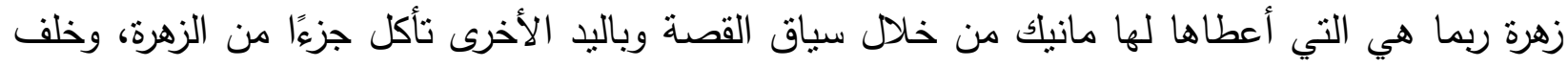

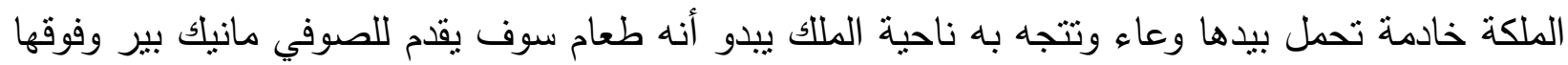

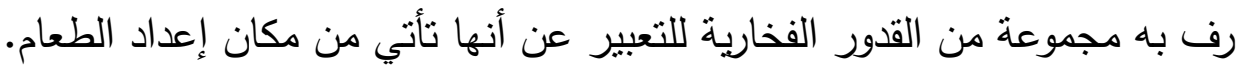

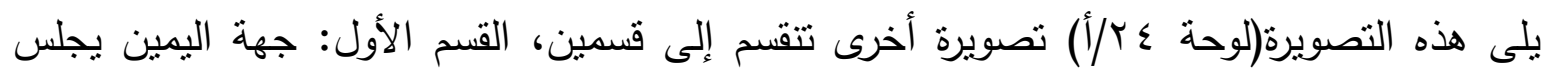
الملك على منصة مرتفعة أو كرسي العرش خلفه مسند أحمر اللون برتدي الملك من أعلى قميص له له أكمام

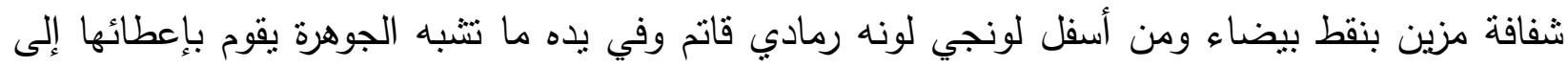
مانيك بير الواقف أمامه ويرتدي قميصًا فقط ذا أكمام قصيرة، حول رقبته قلائد من الخيط إحداها سوداء

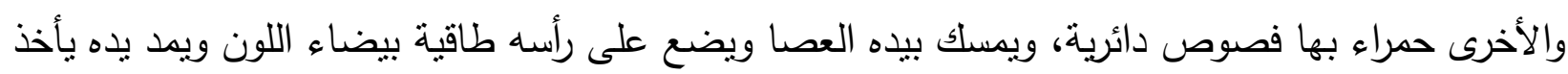

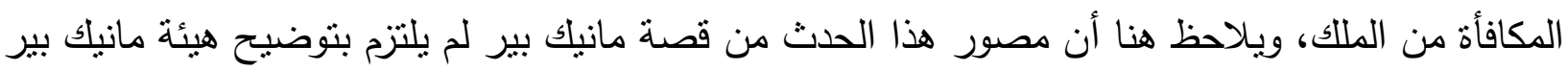

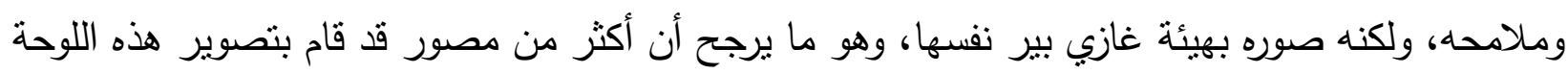
وهذه طريقته في التعبير عن الصوفي سواء كان غازي بير أو مانيك بير فلا يجيد التتوع في ملامح الوجوه

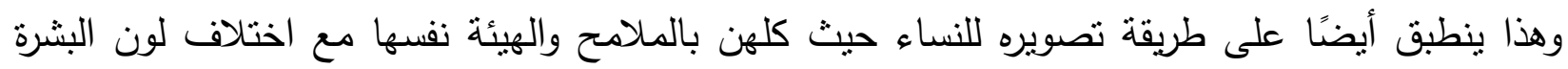

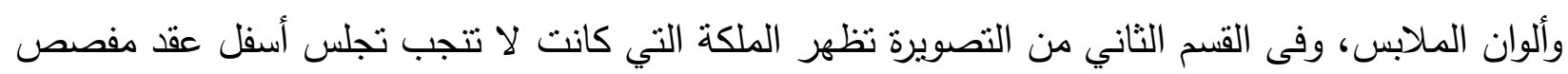
وبيركة مانيك بير قد قامت بولادة ابنها الذي تحمله سيدة تجلس أمامها وخلفها خادمة تمسك الملكة من

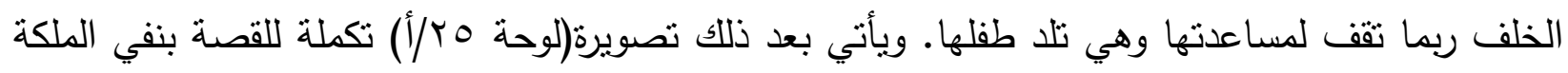

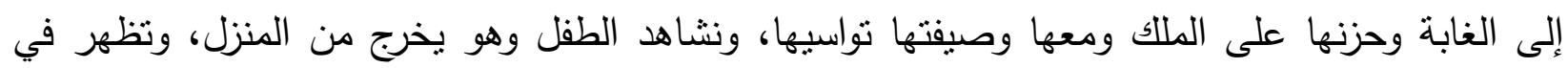


التصويرة التالية (لوحة جب/أ) وهى تتوسل إلى مانيك بير لرجوع ابنها وشفاء زوجها، وتصويرة أخرى

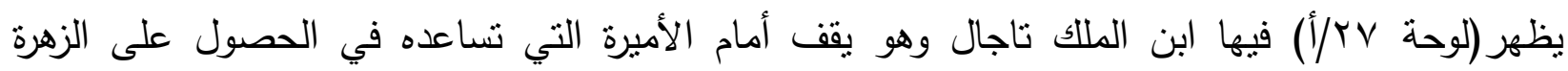
السحرية التي تساعد في شفاء والده الملك بعد أن أخبره مانيك بير بأنها سوف تساعده في شفاء والده، وخلفه يجلس على الأرض مانك بير أمام كوخ له سقف جمالوني ويمسك بإحدى يديه العصا الذهبية اللون وباليد

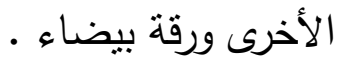

ثم ننتقل إلى قصة أخرى من قصص الصوفي غازي بير (من لوحة و؟- هـ/أ) وهنا يظهر عدم

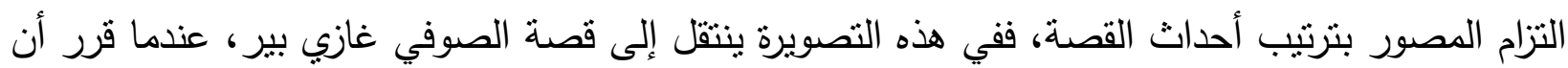

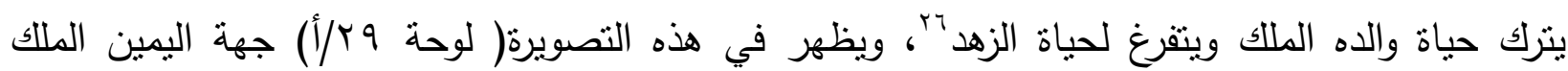

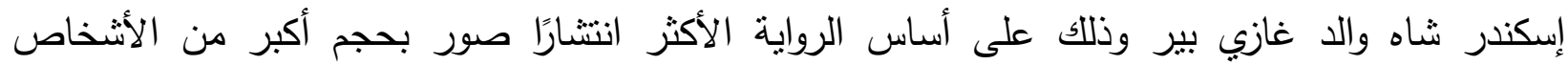

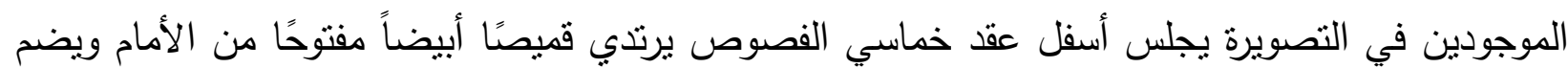

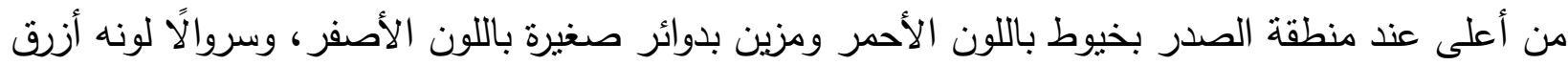

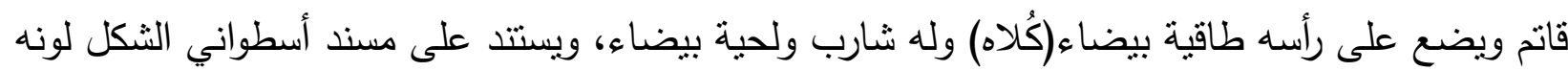
أحمر ومزين بنقاط صفراء اللون، أمامه كرسي رحل عليه كتاب مفتوح ويجلس أمامه غازي بير أسفل عقد ولداء

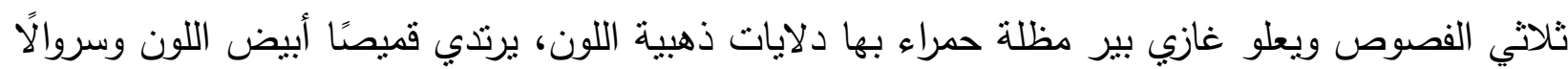

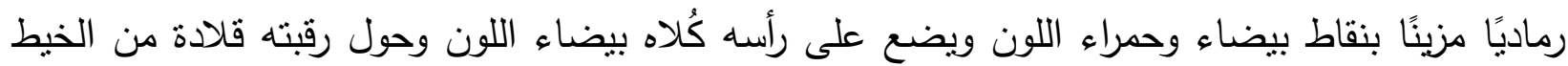

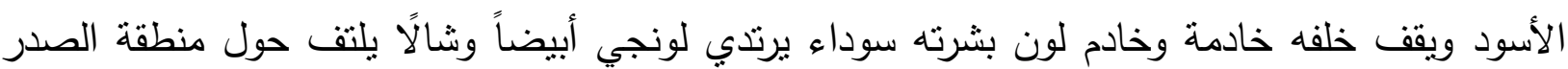

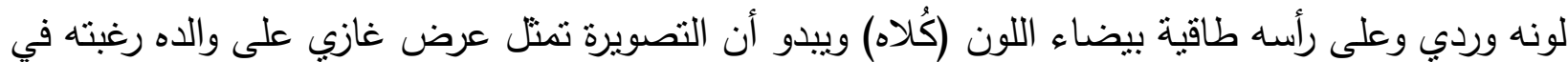

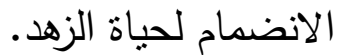

rr ويظهر إسكندر شاه وقد نظر إلى ابنه بأنه سيكون خليفته للعرش، لكن ميل غازي الى الزهد أدى لغضبه الثديد وحاول

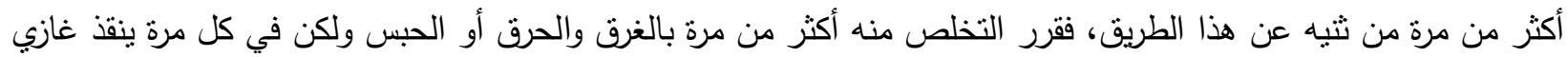

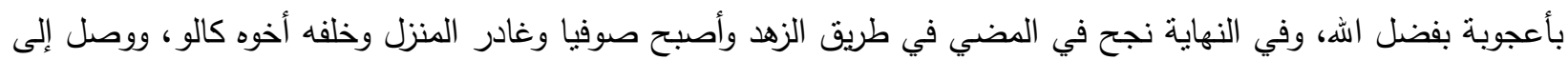

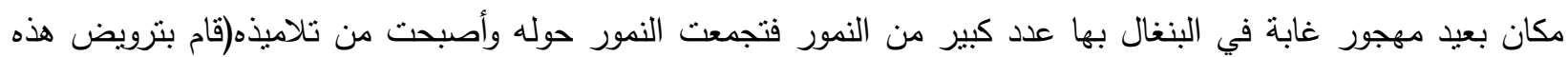
النمور)، بالإضافة إلى قصته مع ملك هندوسي طردهم من الغابة فاحترقت الغابة وأدظله غازي في الإسلام، وقصته مع المالك

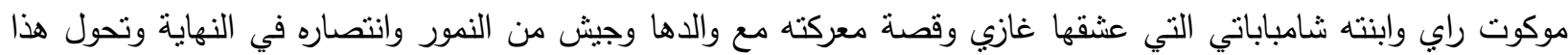
الملك إلى الإسلام وزواجه من شامباباتي .

؛ SARKAR, S.Ch., The Sundarbans: Folk Deities, Monsters and Mortals, New Delhi, 2010 , .55-58.

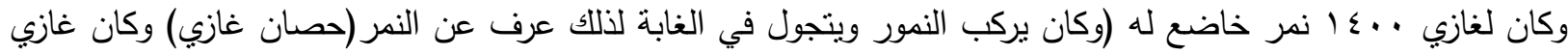

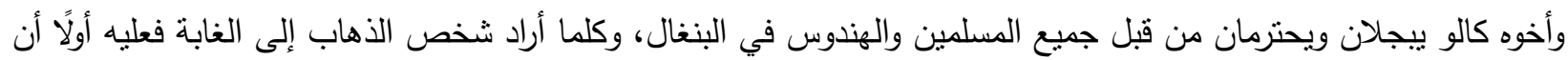

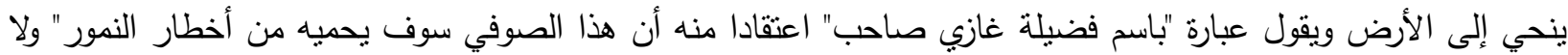




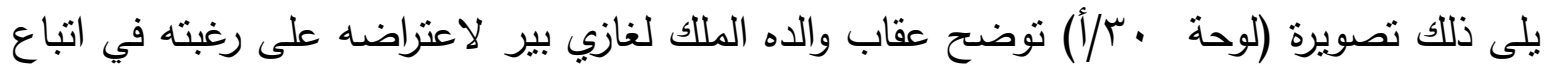
طريق الزهد، ومع ذلك نجاه الله من هذه المهالك كما تذكر القصة، والتصويرة مقسمة إلى ثلاثة أقسام يوضح القسم الأول غازي بير في البحر الذي عبر عنه المصور بخطوط متعرجة مع تتوعه في درجات اللون الأزرق والأبيض، وفي القسم الثاني غازي بير في محبسه، والقسم الثالث فيه غازي بير يُحرق وحوله النبران

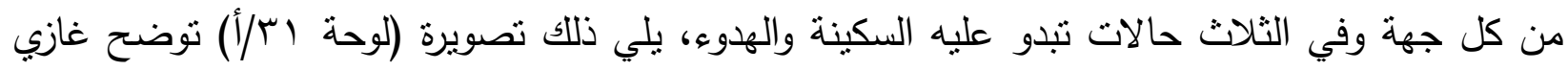
بير يجلس منربعًا أمام منزله المكون من كوخ له سقف شالا المشيد على صفة نهر وتقف أمامه سيدة تتحدث

يلى ذللك تصويرة(لوحة r//أ) يظهر فيها غازي بير وأخوه كالو وهو يودع والدته الملكة دون رغبة

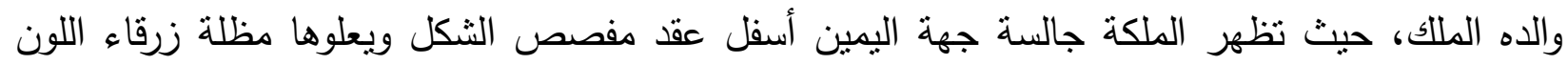
وتجلس متربعة الجسد في وضع المواجهة بينما الوجوه جانبية الثكل، ترتدي رداء ذا أكمام طويلة أحمر الثراه

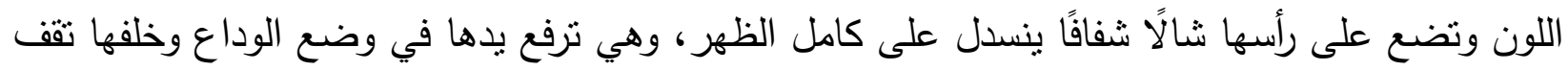

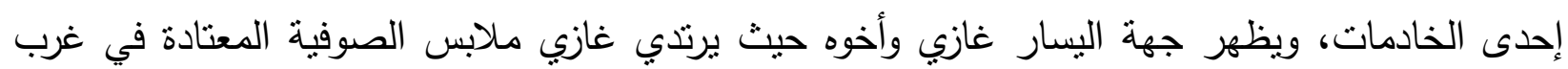

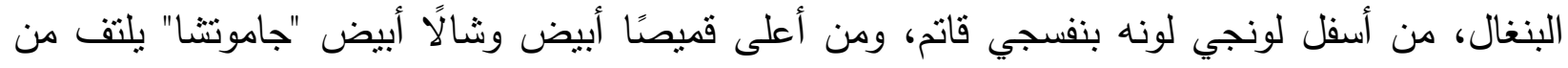

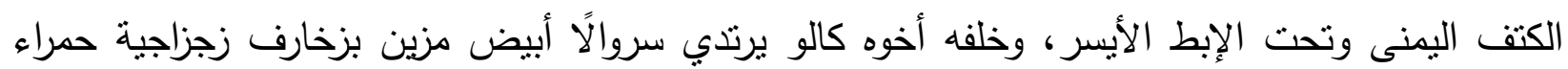
اللون ومن أعلى قميصًا أسوداً يربط على الوسط بيند من القماش لونه أحمر ويضع الاثثان على رأسهها كُلاه

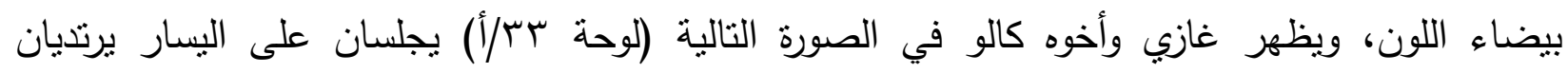

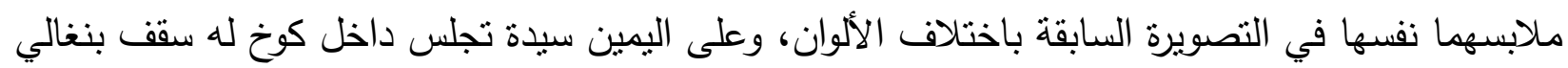

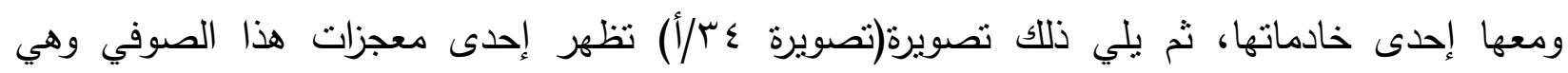
ترويضه للنمور حيث يقف في الغابة وأمامه نمران أحدها يركع أمامه وآخر يقف على بلى رجليه الخلفيتين،

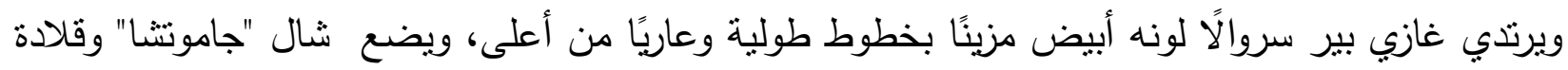

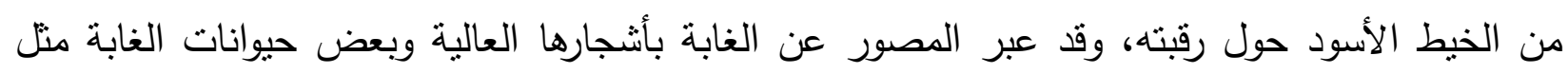

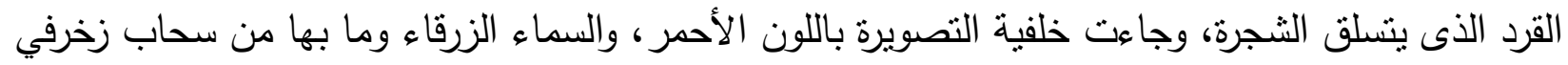
يتخذ أنشكالً غير منتظمة بخطوط متعرجة بدرجات اللون الأزرق والأسود. وفى التصويرة التالية (تصويرة هم/أ) يظهر غازي بير وأخوه كالو وهما بركبان سفينة لها مقدمة على بلى

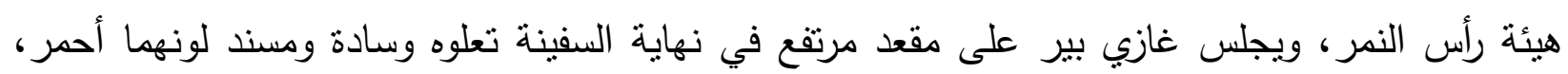

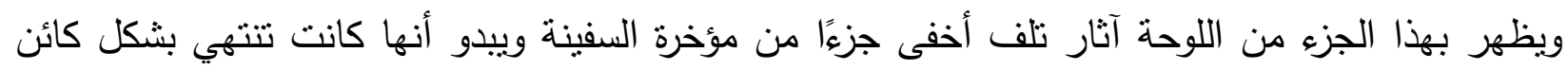
مجنح تظهر أجنحته فقط، وتظهر المياه عبارة عن خطوط منموجة تتدرج ألوانها من الأزرق القاتم والفاتح وخطوط باللون الأبيض يعبر بها عن حركة الأمواج. 
ويلي ذللك تصويرة(لوحة جس/أ) يظهر بها ضريح أحد المتصوفة والضريح له سقف "تثار شالا"

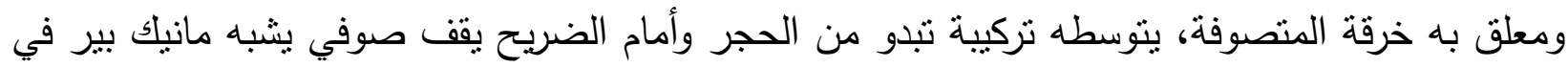

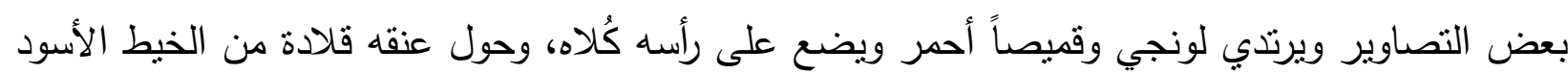

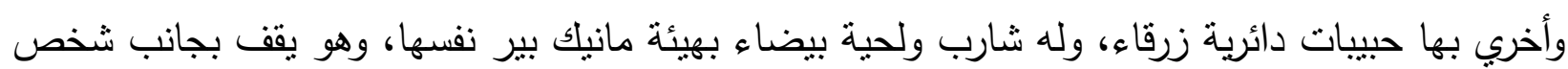

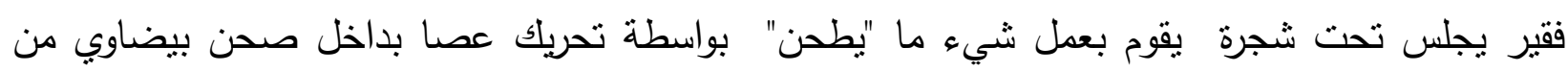

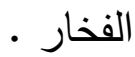

وفي التصويرة التالية (لوحة Vr/أ) يظهر شخص يرتدي دهوتي قصيرًا أبيض اللون يحمل على رأسه صحنًا كبيرًا يبدو به طعام ويسحب ماثيتين من حبل مربوط في رقبتهما، وأمامه سيدة تحمل طفلًا صغيرًا

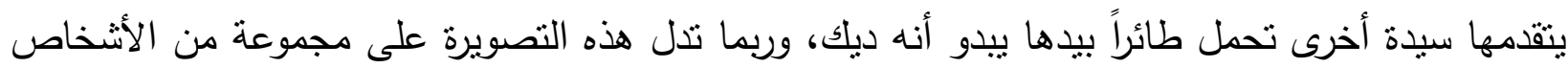

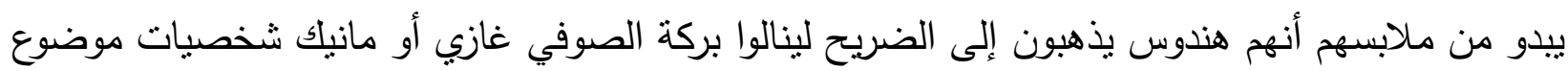

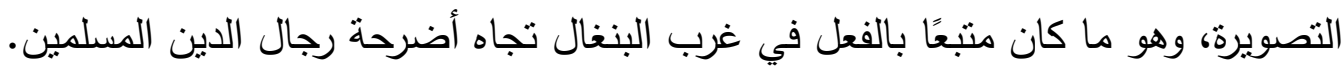
ونتنقل في التصويرة التالية (لوحة م/r/أ) إلى حدث من قصة غازي بير وأخيه أثناء تجوالهم وهما

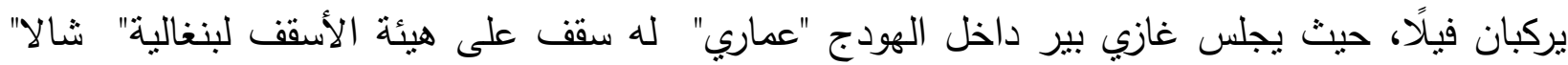

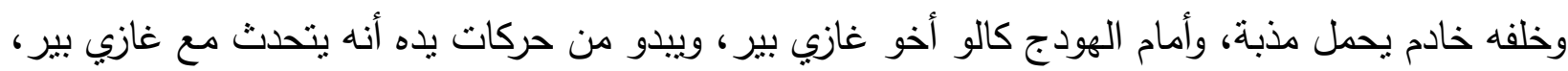

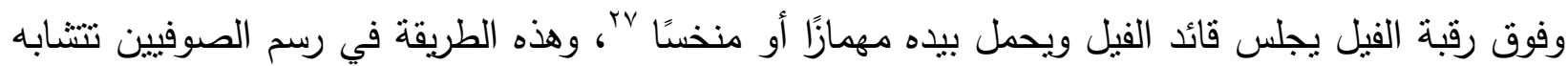
مع رسم مواكب الثخصيات المهمة والحكام في التصوير المغولي الهندي، وجاء رسم الفيل كبير الحجم بهيئة قريبة من الواقع بكامل زينته، وجاء الإطار الذي يفصل بين هذه التصويرة والتصويرة التالية مزينًا بتكوين

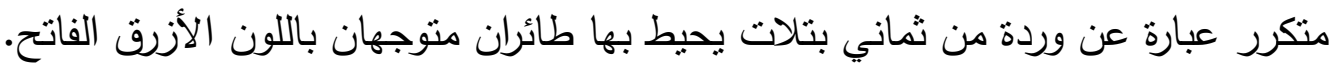
يأتي بعد ذلك تصويرتان(لوحة و ه/أ- . \&/أ) بهما أحداث غير واردة في قصة غازي بير أو مانيك

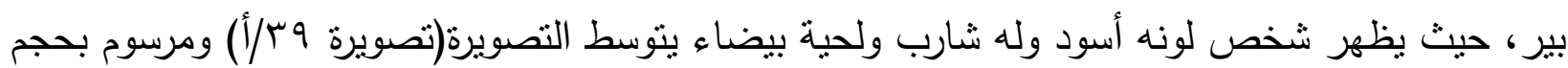

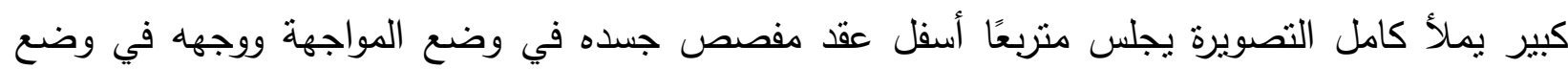
جانبي خلفه وسادة بيضاوية كبيرة الحجم، يضع حول رقبته قلادة من الخيط الأسود وأخرى من حبئنسات

rv المهماز عبارة عن وسيلة وخز مزودة برأس مدبب أو ناخسة يوضع في دولاب الفارس، والثكل المبكر من هذه الألة يأخذ

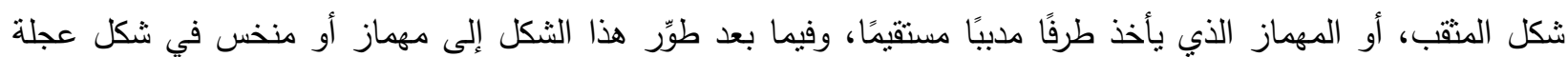

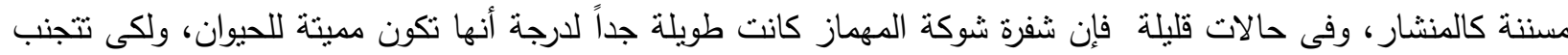

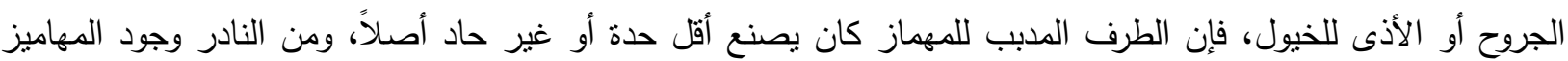

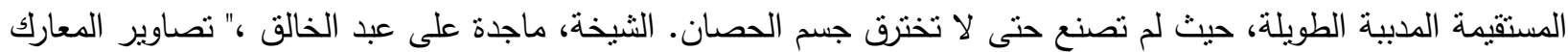
الحربية للجيش المغولي الهندي من خلال المخطوطات والتحف التطبيقية"، رسالة ماجستير، قسم الآثار الإنلامية، كلية

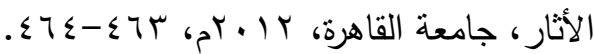


دائرية بيضاء اللون وأساور من حبيبات صفراء اللون، ويمسك بيده كأس شراب صغير الحجم، وقد بدأ بتذوقه وأمامه يقف خادم يقدم له الثراب، وخلف هذا الثخص خادم بلفاء آخر يمسك بإحدى يديه قارورة الثراب وباليد

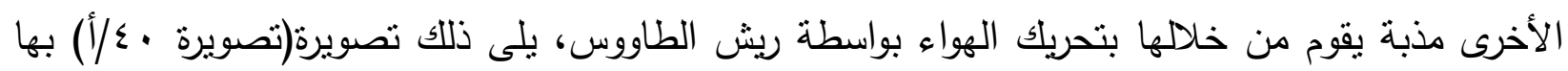
سيدة تجلس أسفل عقد مفصص لبناء له سقف مسطح ترتدي جولي أحمر اللون ولاهنجا لونها أزرق قاتم

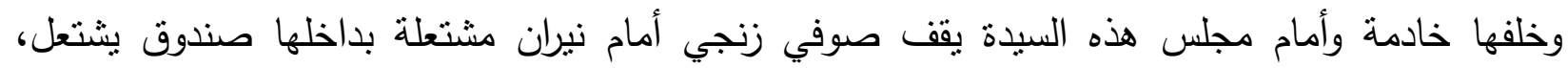

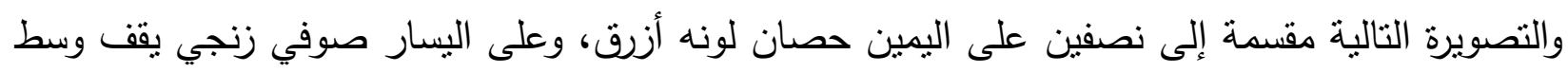

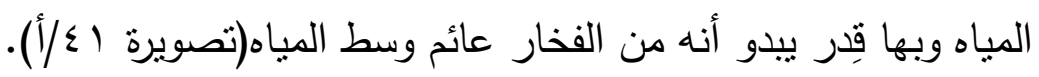

يلى ذلك (تصويرة بـ/أ) يظهر بها ضريح له سقف بنغالي نتشارشالا بداخله معلق خرقة الصوفي،

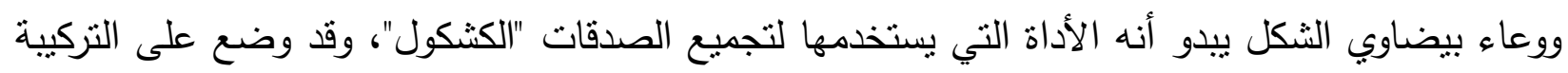

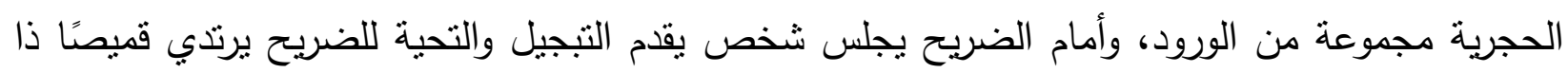

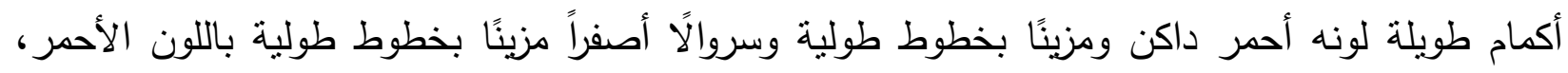

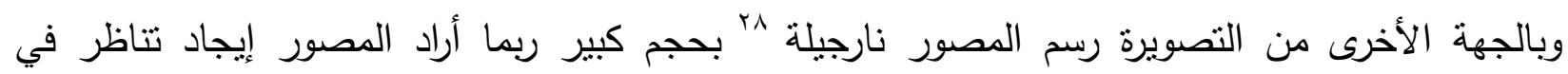

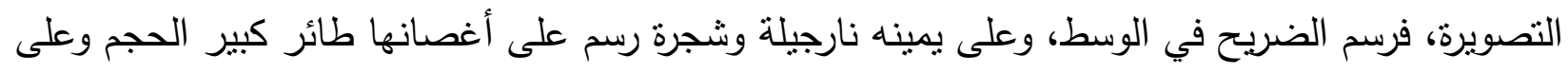

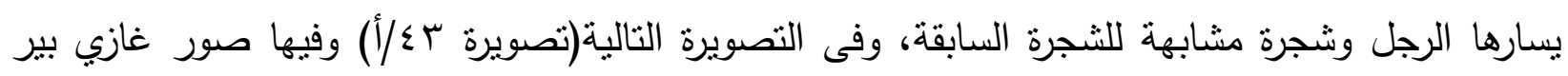

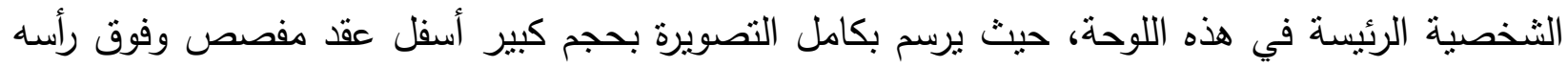

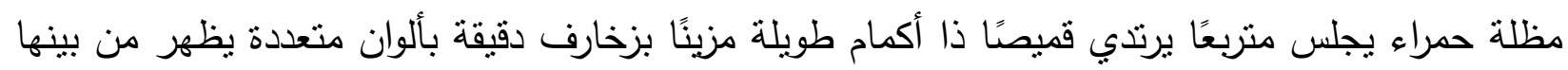

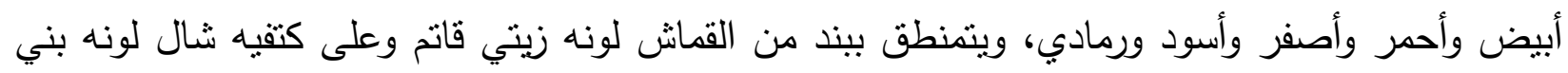

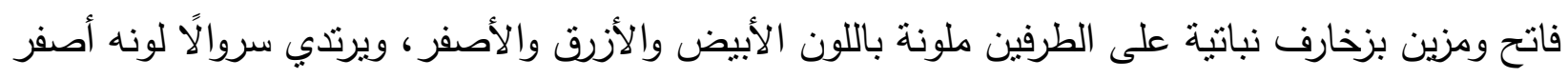

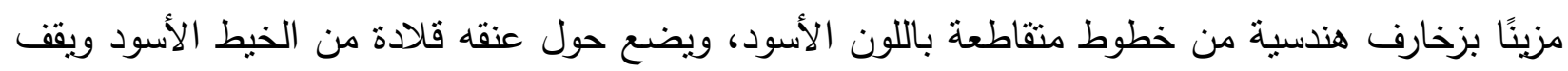

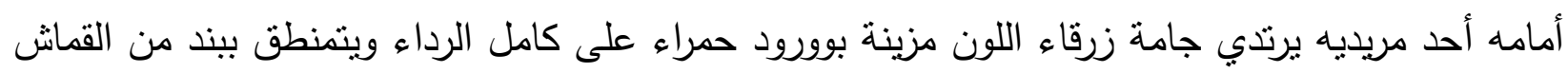

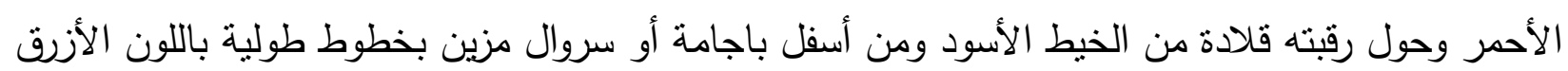

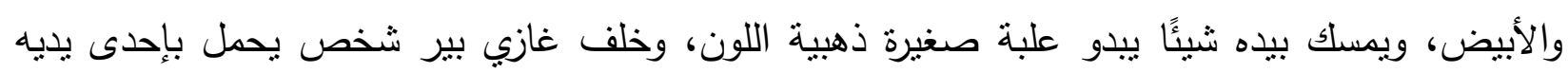

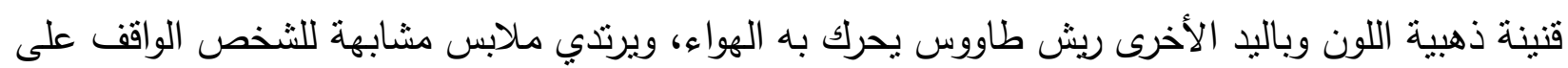

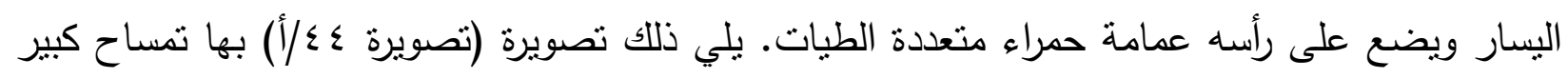

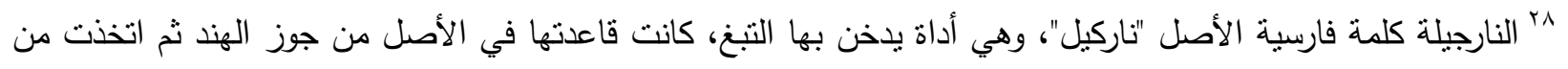

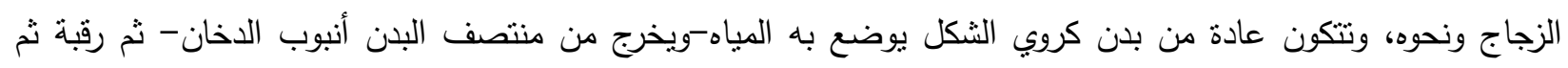

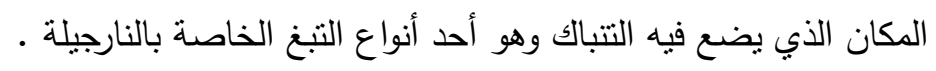
RUDGLEY,R. The Encyclopedia of Psychoactive Substances, New York: Great Britain - Brown and Company, 1999, 196. 
الحجم عائم على المياه فاتح فمه وذيله يلتف بشكل موازٍ لجسمه وفوق ظهره سمكة كبيرة وأمامه سمكة أخرى أصغر حجمًا من السابقة.

يلى ذلك الثكل الأكثر شهرة التي يعبر به عن شخصية غازي بير ، ولا تخلو أية لوحة من لوحات

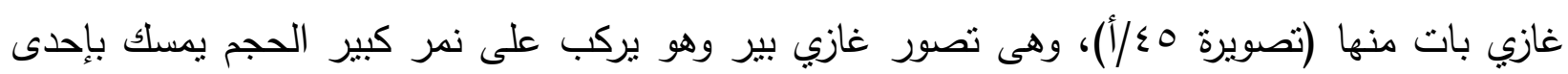

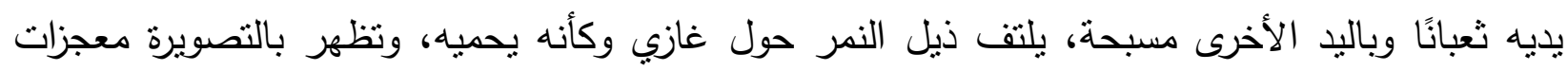

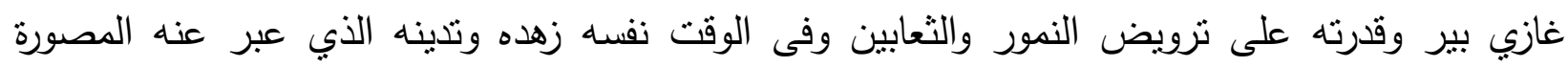

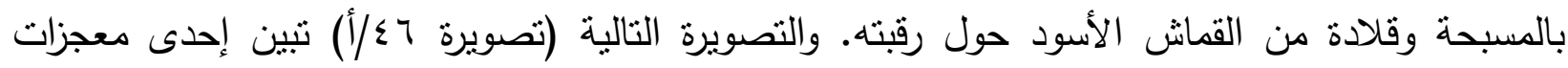

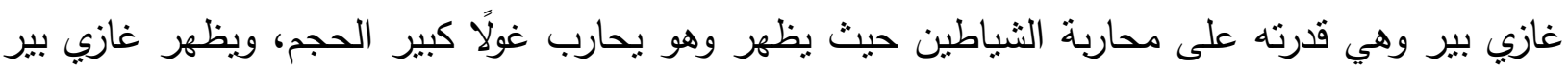

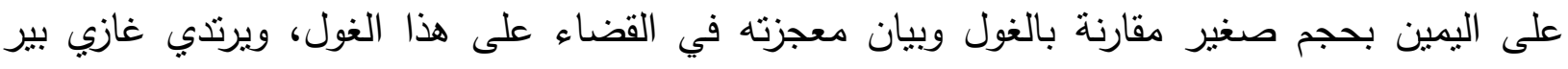

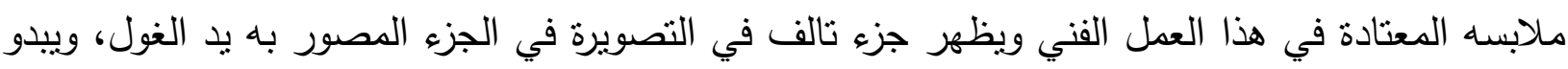

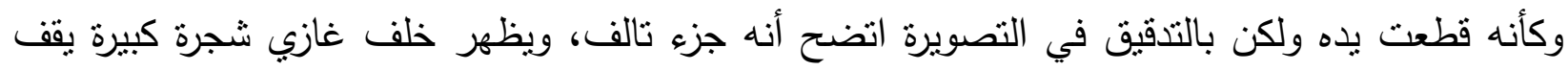

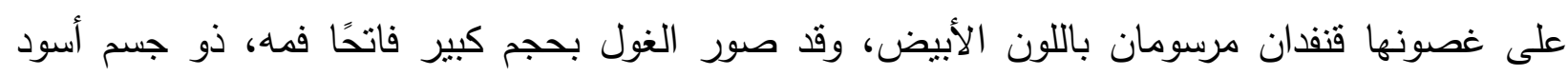

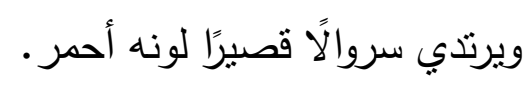

ثم يلي ذلك تصويرة(تصويرة V٪/أ) تصور مجلس غازي بير بهيئة بلاط الملوك حيث يجلس في مكان

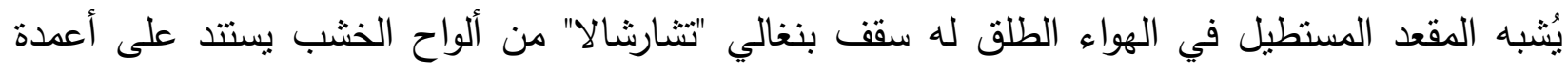

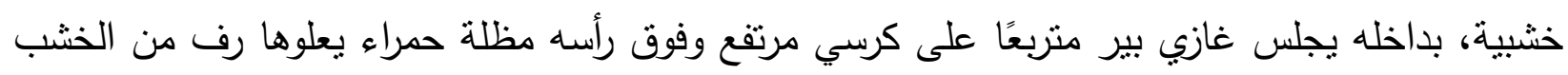

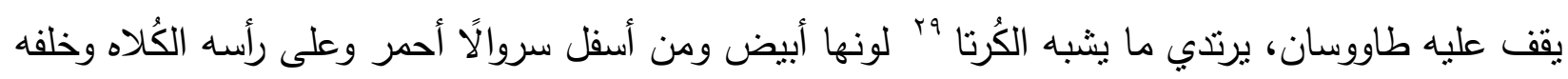

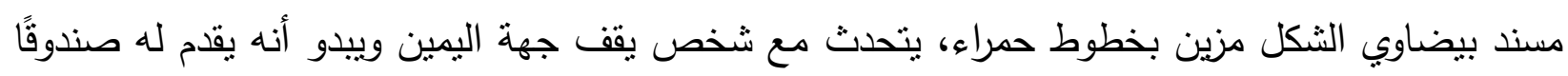

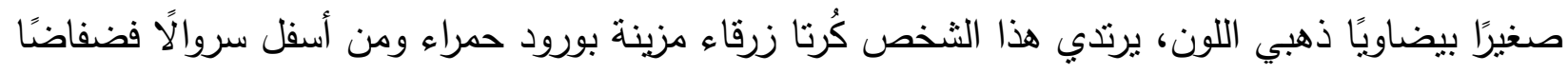

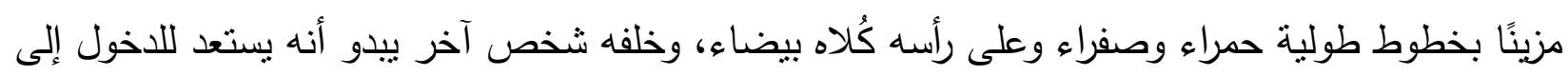

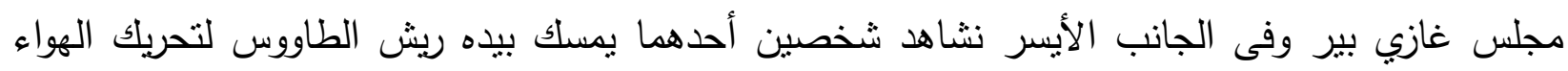

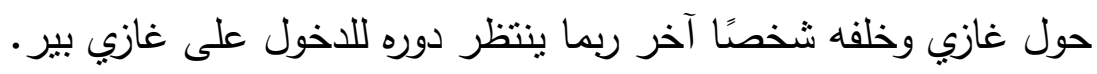

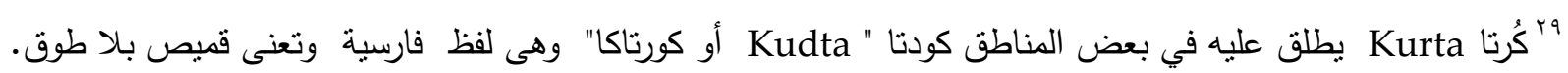
GHURYE,G.S., Indian Costume, Bombay, 2nd.ed., 1966, 156.

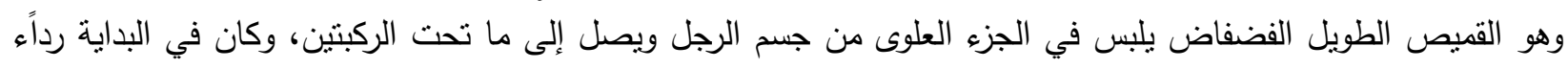

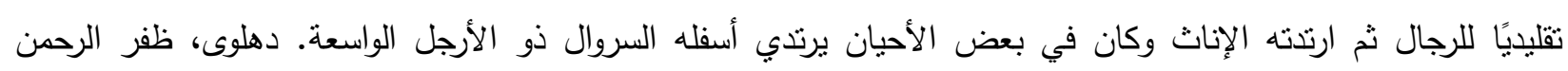

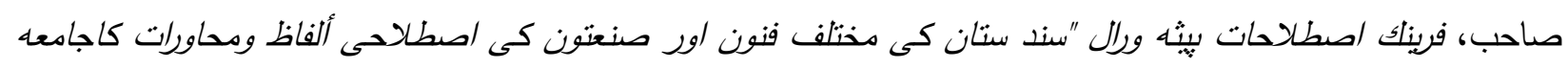

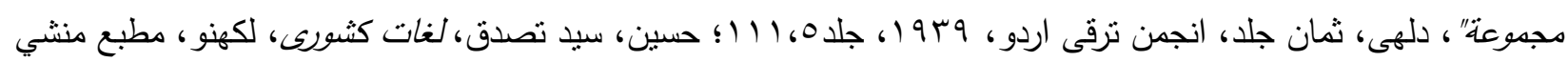


وفى التصويرة التالية (تصويرة ^^/أ) تظهر سيدة نقوم بإطعام التماسيح حيث تقام إلى التمساح ما

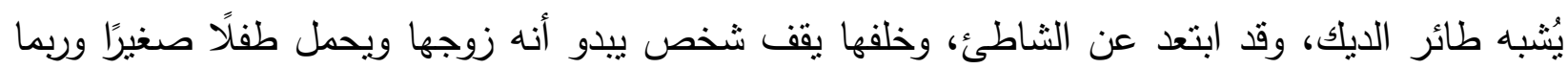

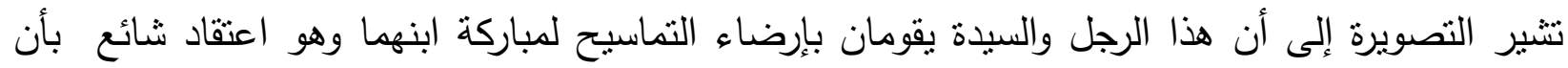
غازي بير حامي سكان البنغال من التماسيح والنمور ، كما كان للتمساح دور في قيادة مركب غازي بير فير في في

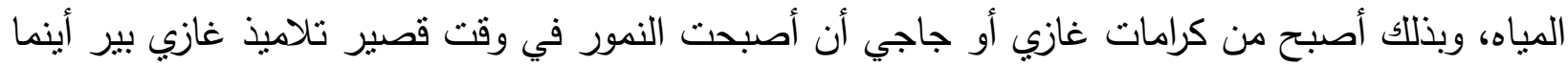

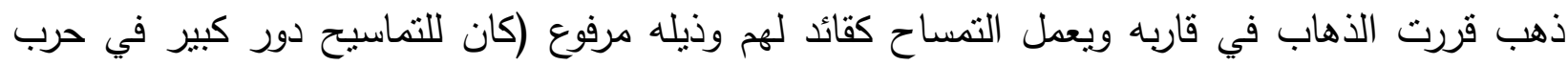

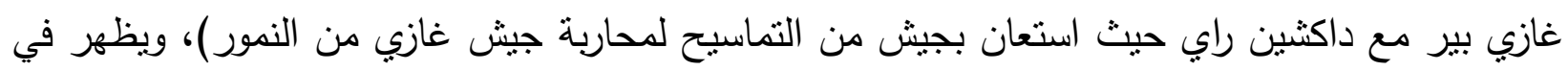

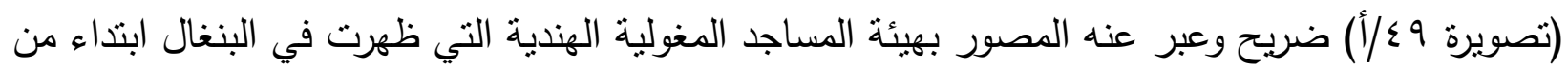

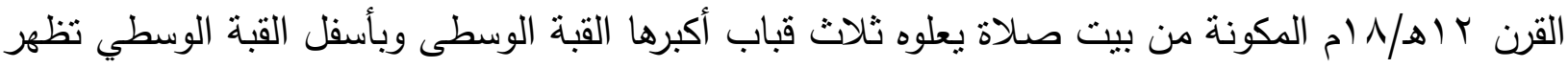

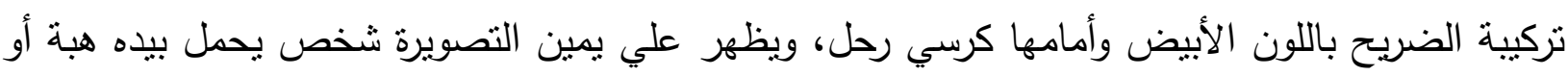

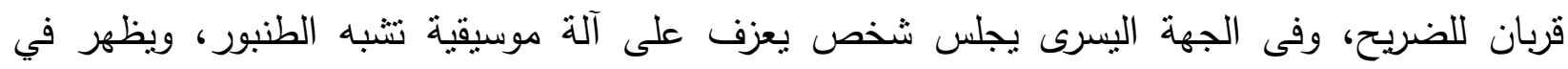

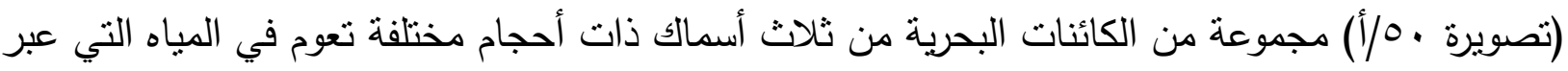
عنها المصور في باقي التصاوير من خلال خطوط متعرجة تظهر في مقدمة التصويرة بدرجات اللون الأزرق

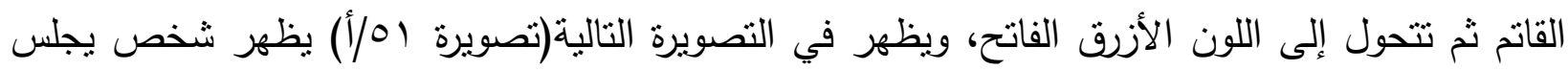
يتعبد بداخل سفينة في منتصف النهر، وأمامه كرسي رحل يقرأ من كتاب وضع عليه، وعلى يساره ويمينه رسم سمكتين متماتلتين في الثكل والحجم ربما لخلق تماثل بين عناصر التصويرة، والتماتل سمة مديزة نجدها في كل تصاوير اللوحة.

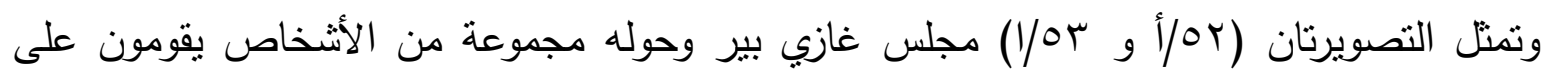

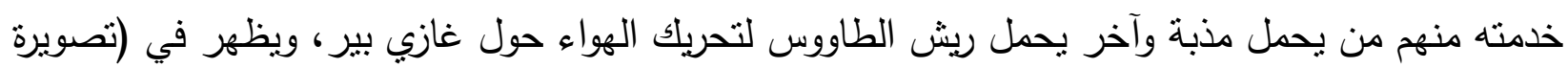

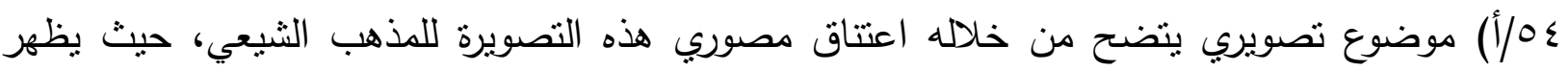
الكائن الأسطوري "البراق" بهيئته المعروفة في التصوير الإيراني من وجه آدئ آدي على رأسه تاج ذهبي وأجنحة

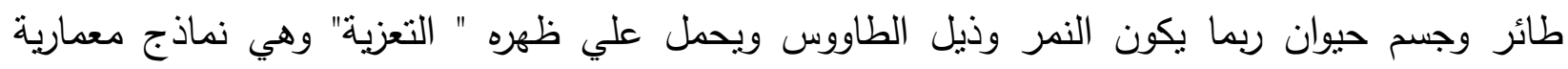

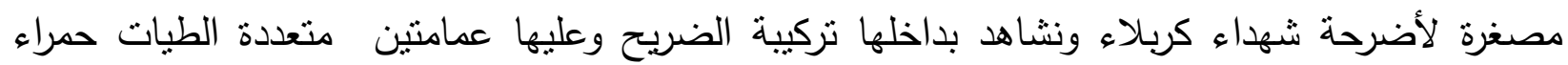
اللون، ومثبت بها ترس دائري معلق به سيف ذهبي اللون، وقد رسم هذا الكائن بحجم كبير يتضح من خلهاه

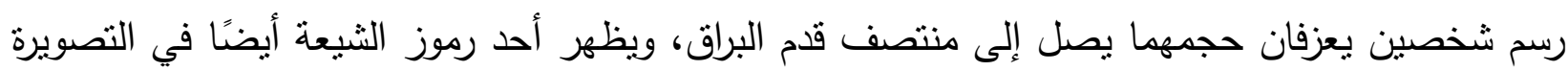

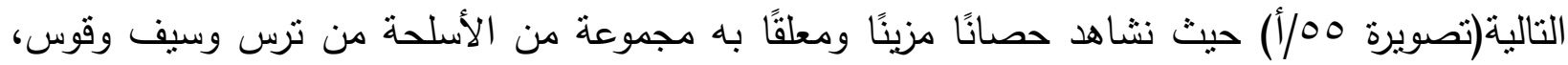

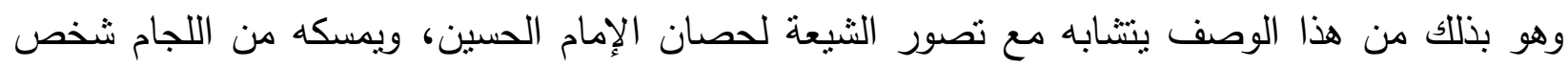

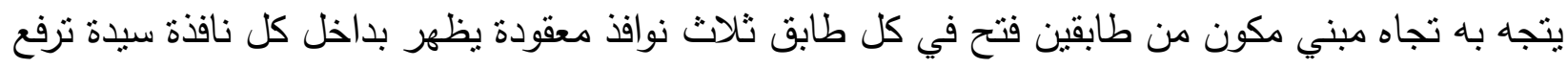

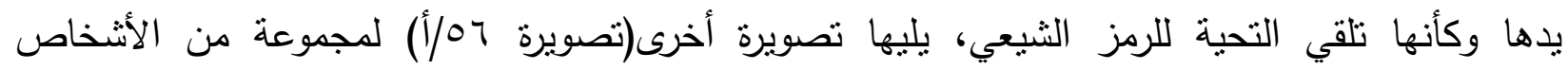


يتجمعون حول أحد الأعلام البيضاء اللون وهي أيضًا تعد من الرموز الثيعية التي تُشتخدم أثناء احتفالات

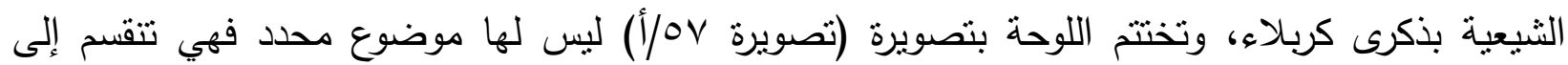

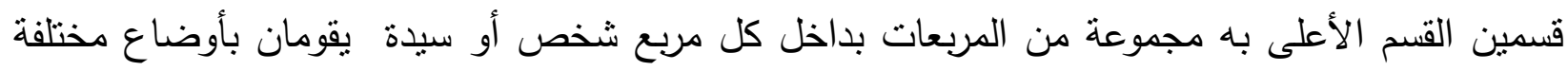

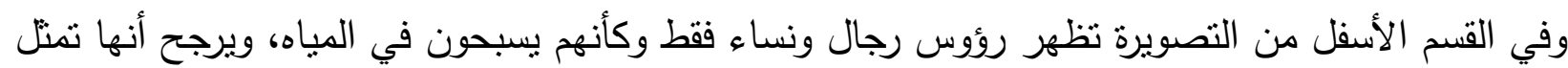
مجموعة من الأشخاص يغتسلون في نهر الجانج المقدس لديهم، حيث يعتقدون بأن الاغنسال في الملتقي

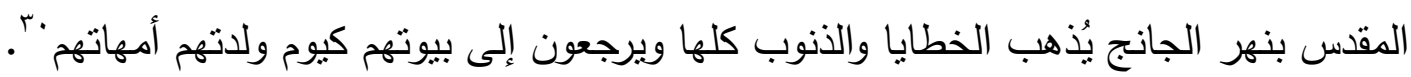
r.الدراسة التحليلية: تتضمن الدراسة عدة نقاط رئيسة تتحصر فيما يلي:

$$
\begin{aligned}
& \text { 1- نشأة وتطور لوحات الباتا "لفائف الباتا". } \\
& \text { r- مصوري لوحات الباتا "الباتو ". } \\
& \text { ب- أنواع تصاوير الباتا في غرب البنغال. }
\end{aligned}
$$

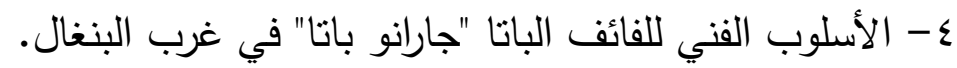

0- السمات الفنية المميزة للفائف الباتا "جارانو بانا" بالمركز الفني بمدينة مرشد آباد.

$$
\text { צ r ـ مراكز إنتاج لوحات الباتا في غرب البنغال. }
$$

الباتا عبارة عن لفيفة من الورق أو القماش مصورة بمشاهد سردية للنصوص والأساطير والحكايات

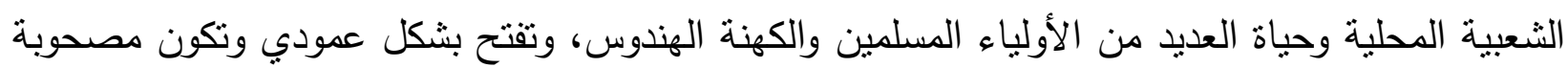
بأغنية تروي قصة الصور في لحن إيقاعي "، أثثاء عرض الصور عن طريق فتح اللفافة بيد واحدة، صورة

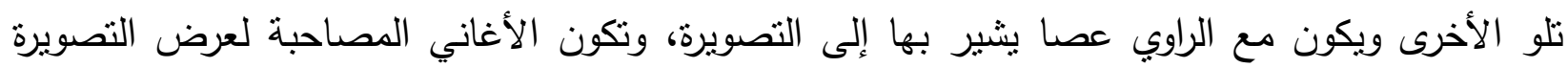

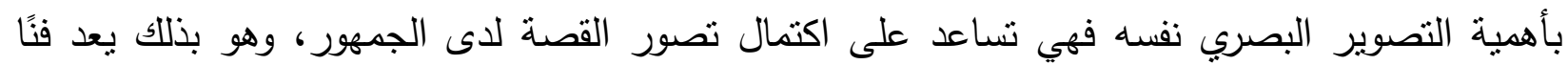

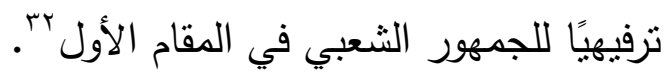

وباتا كلمة سنسكرينية تعني قطعة القماش، ومصطلح باتا Pata أو Pot بالبنغالية بصفة عامة يشير إلى لوحة مرسومة على القماش بrاب، حيث كانت بداية هذا النوع تتم بالرسم على أوراق سعف النخيل ثم استبدل

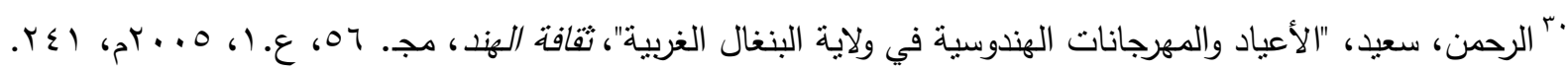
${ }^{31}$ MAJUMDER ,R.: «Disappearing Traditions , The Narrative Songs of Bengal Pata Painting» , KalakalpaIGNCA Journal of Arts IV, №. 2, $2020, .38$.

32 MAJUMDER, Disappearing Traditions, . 40 .

33 GUPTA,S . D. , «Village to Naya, Pingla, Traditional Art, Chitrolekha International Magazine on Art and Design 1, №. 3, 2011, 6. 
القماش به، وبعد ذللك أصبح يرسم على الورق ثم يلصق في كثير من الأحيان على القماش، وهو بذللك يرتبط

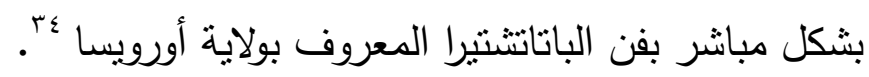

يوصف تصوير الباتا أو تصوير اللفافة بأنها لوحات تصور قصة ملحمية يتجول بها الباتواس

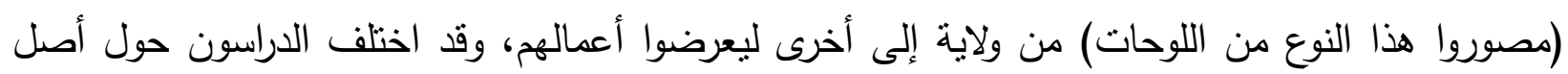

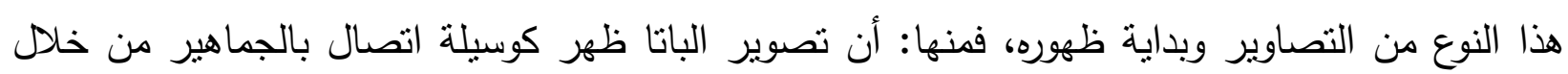

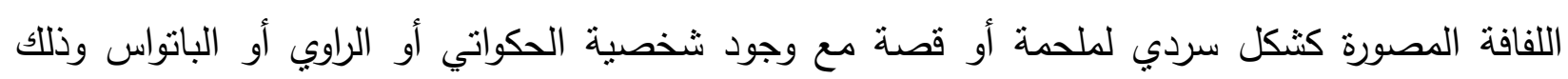

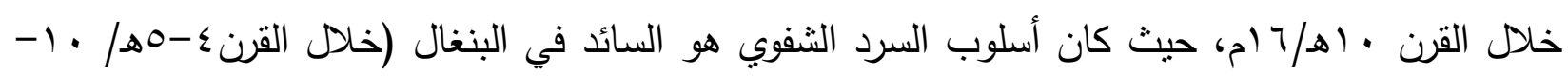

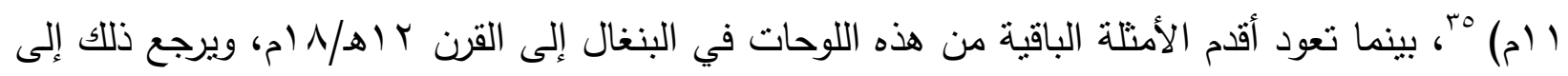

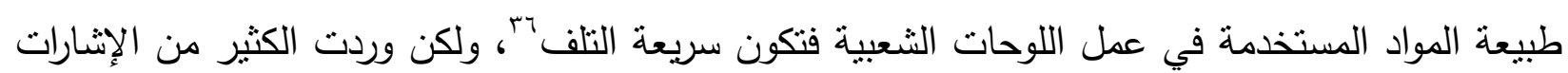

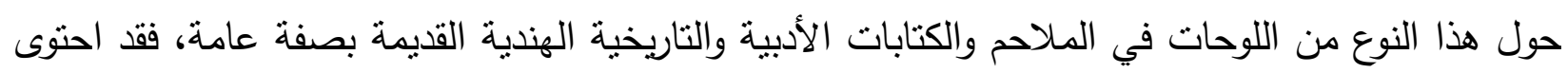

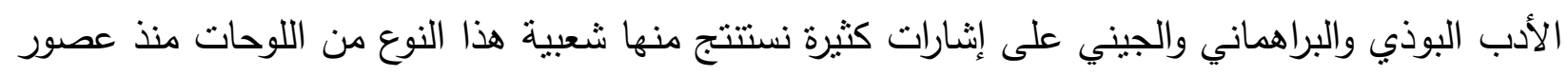

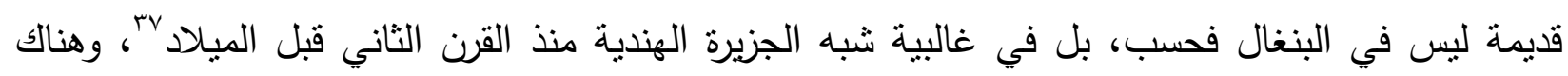

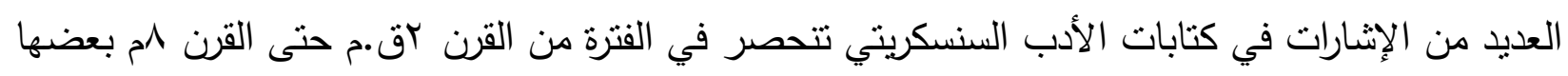

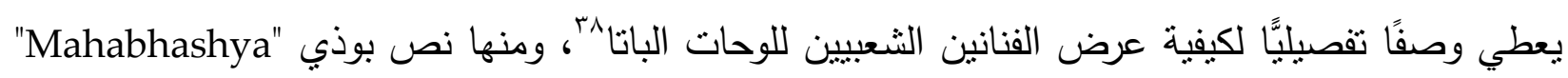

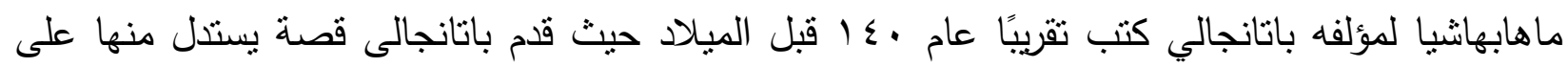

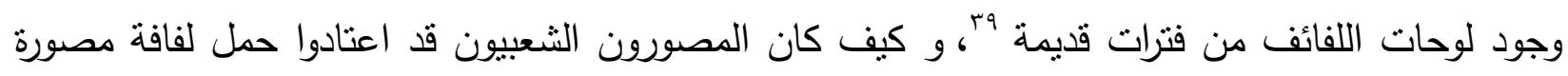

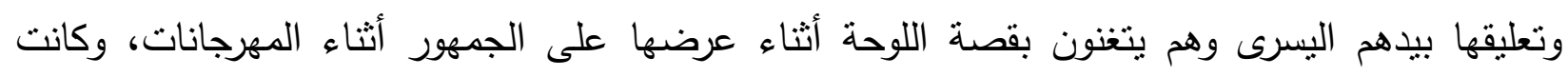

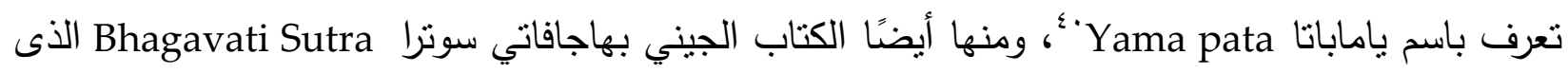
يؤرخ بالقرن آم، ويشير إلى فن عرض القصص المصورة المعروفة في الأدب الجيني باسم مانخا

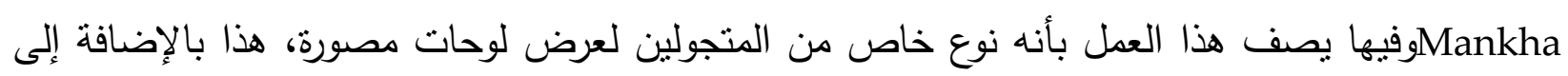

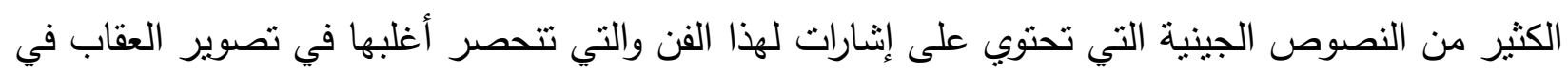

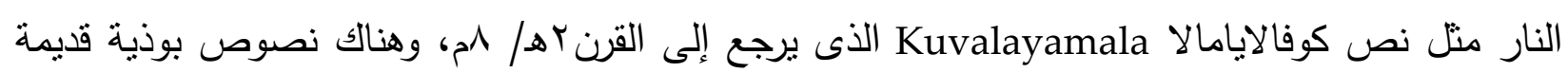

${ }_{34}$ PALIT, S. and Datta, D. B. , «Transformation from Performativeaer to Demonstrative art : A Survival Strategy for Patachitra», Asian Journal of Multidisciplinary Studies, vol.4, №. 2, 2016, 220.

${ }^{35}$ BHATTACHARYA, and Narayanaswami, , Pattachitra: Indian Art in Context , .6.

${ }^{36}$ DATTA, Folk Painting of Bengal , 10.

37 JAIN,J., «The Art of Indian Picture Showmen : Tradition and Transformation», Storyelling and Puppet traditions of India, Dhurjjati Sarma, New Delhi: Indira Gandhi National Centre For the Arts, 2010 , 15.

${ }^{38}$ DATTA, Folk Painting of Bengal , 7

${ }^{39}$ DeHejIA, V.: «On Mode of Visual Narration in Early Buddhist Art», The Art Bulletin 72, №. 3, Sep.1990, 377.

${ }^{40}$ JANA, Th.: «Educational Marginality : A Crisis Among the Patuas at Naya, West Bengal», Chitrolekha International Magzine on Art and Design 6, №.2, 2016, 91. 
مثل Samyutta Nikaya وتتير إلى نوع من الفن اسمه شارانا شيتا charana chitta وهي عبارة عن لوحات متحركة بها رسوم توضيحية لعقوبات في النار اء.

ويعتقد البعض أن فن تصوير الباتا كانت شائعة بين كثير من القبائل الهندوسية القديمة مثل سانتال وموندا وكانت تستخدم في تصوير القادة والزعماء القدامى، ومع انتشار البوذية استخدم الملوك والرهبان البوذيون اللفائف المصورة على نطاق واسع؛ وذلك لنشر تعاليم الديانة البوذية الجديدة في ذلك الوقت، وخلال هذه الفترة انتشر فن الباتا إلى البلاد المجاورة مثل التبت وماليزا وجاوة وبالي وسربلانكا، ومع الفتوحات الإسلامية وانتشار الإسلام اعتتق كثير من مصوري الباتا "الباتو أو تشيتراكار" الدين الإسلامي بـ. وكانت الأشكال القديمة من باتا البنغال غالبًا ما تأخذ شكل لوحة واحدة مربعة أو مستطيلة تُعرف باسم Chauko pata وتكون غالبًا بتكوين واحد لصورة واحدة لمعبود هندوسي أو شخصية أسطورية، وكان بطلق عليها أيضًا لوحات Yama Pata وذلك لارتباطها بالموت ومشاهد العقاب والعذاب لتحذير الناس من الأعمال السيئة، وبصفة عامة كان الجانب الأخلاقي والوعظ السمة المميزة في معظم أعمال باتا المبكرة، ومن المرجح أن شكل لوحات اللفائف التي تمتن في كثير من الأحيان بطول عدة أمتار هي تطور لاحق لهذه اللوحات، ووفقًا لبعض الدراسين فإن هذا التسلسل السردي لأحداث القصة المصورة هو فرع من الثقافة الموروثة للبنغال في العصور الوسطى، حيث اعتقادهم بالأساطير والقصص الشعبية المحلية التي سيطرت على ثقافة عامة الشعب، فكانت القصص المصورة بشكل تسلسلي وعرضها تدريجيًا من قبل المصورين مع الأغنية التوضيحية عن القصة نتاج طبيعي لهذه الثقافة، وعدَّ بعضهم "باتا أو باتثيترا البنغال" نتاج اندماج الثقافة

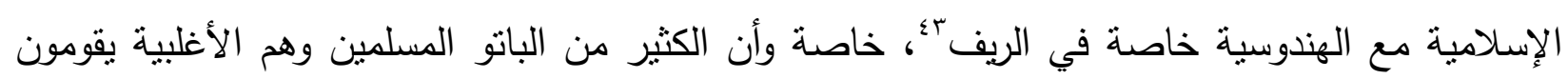
بتصوير موضوعات للمعبودات والثخصيات الأسطورية الهندوية، كما يصور بعض الباتو الهندوس الموضوعات الإسلامية؛؛ وتحتوي معظم باتا البنغال على قصة واحدة ثُرتبِّ الأحداث بالتتابع بطريقة سردية حتى يصل إلى المشهد الرئيسي وهو إما أن تتتهي اللوحة أو يتبعها بعد ذلك لوحتان تعليميتان عادة ما تكون بان مشاهد العقاب في النار أو تأليه الثخصية الرئيسة (إعطاؤها صفة الألوهية)؛؛

${ }^{41}$ JAIN, The Art of Indian Picture Showmen : Tradition and Transformation ,15.

42 Sayantani, and Narayanaswami, Pattachitra; Indian art in context, 3.

${ }^{43}$ MAJUmdAR, S.N.: «Bengal Pata Chitra: Painting, Narrating and Siging with Twists and Turns», Strangi Bengal Patachitra, New Delhi, 2018. 14.

؛؛ اعتبر الباتو قديمًا من طبقة المنبوذين في الترتيب الطبقي الهندوسي؛ لأنهم انتهكوا قواعد الرسم التي وضعها الكهنة البراهمة، ومع انتتار الإسلام في البنغال اعتنق الكثير منهم الإسلام فرفع من مكانتهم الاجنماعية. BANU ,U., Pattcitra of Bengal ; An Emotion of Community, New Delhi, Strangi Bengal Patachitra , 2018 , 34. ${ }^{45}$ JAIN, The Art of Indian Picture Showmen, .17. 
وجدير بالذكر أن لوحات اللفائف السردية كانت تتتج أيضًا في إقليم راجستان والكجرات ب؛وعُرف لوف بعضها في إقليم هضبة الدكن r r r. r. rصورو لوحات الباتا "الباتو":

يطلق على مصوري هذه النوعية من التصاوير مصطلح باتو وهم فئة من الرواة يقومون بتوضيح

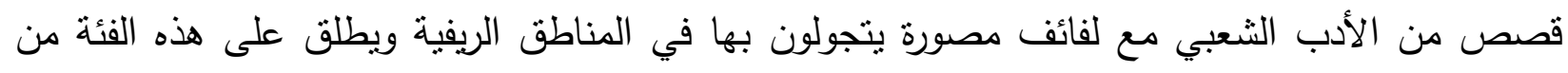
المصورين مصطلح آخر وهو تشيتراكار Chitrakars وتعني مصور ، وجاء هذا المصطلح في تقرير التعداد

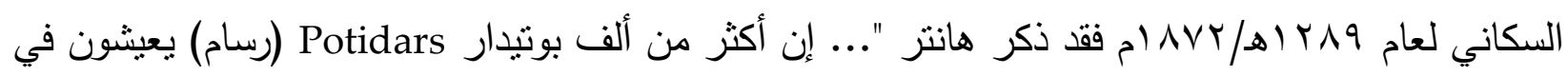

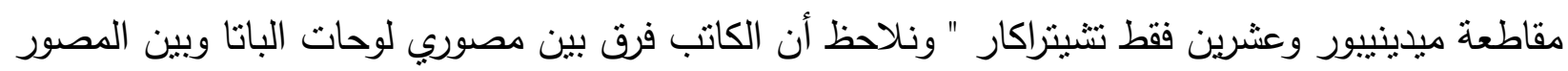

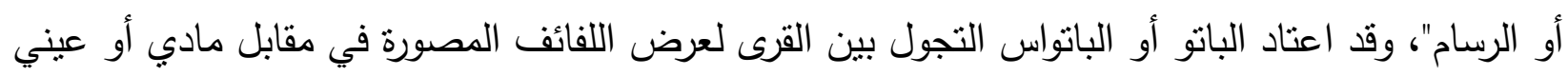

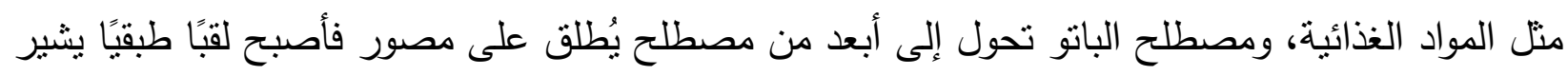

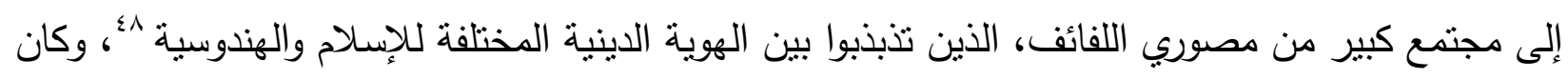

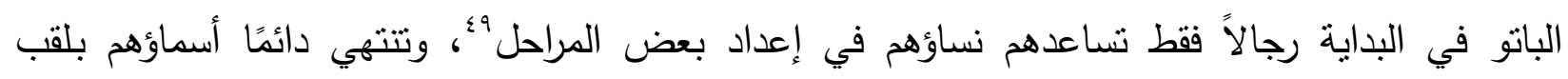

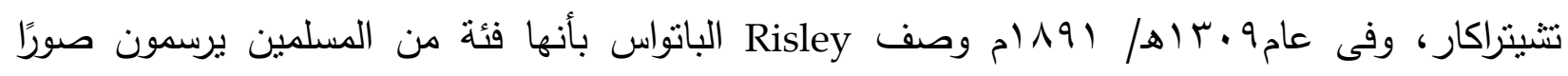

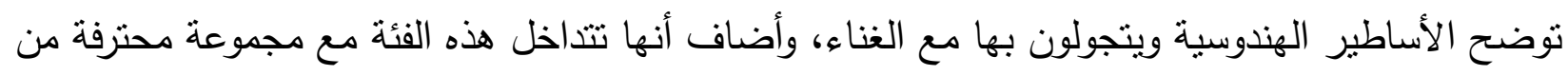
الرسامين تُسمى باتوا تُعرف أيضًا باسم Patu, Pota, Putua, Patudar وبذلك عدَّ الباتواس والتيشركار فئتين

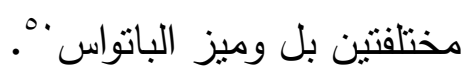

وكانوا قديمًا يتمتعون برعاية العديد من الملوك والنبلاء، حيث استقبل الأثرياء الباتو الذين كانوا

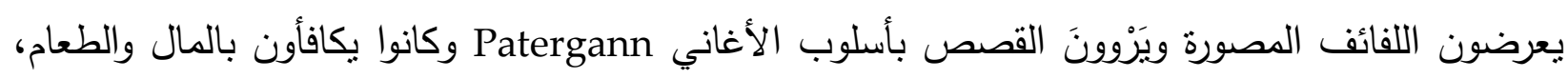

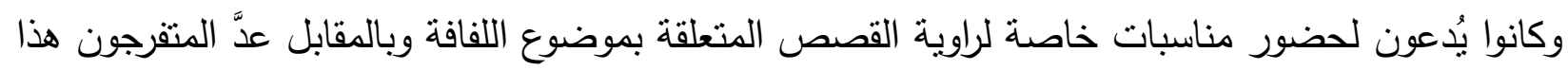

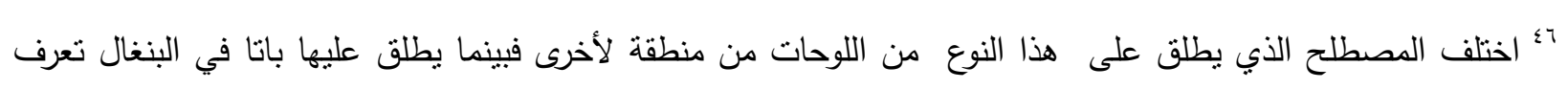

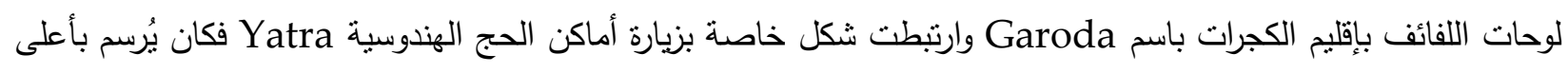
هذه اللوحات شكل معبد وتحمل هذه اللوحات باعتقادهم بمثابة معبد متتقل. Jain, The Art of Indian Picture Showmen , 17.

بينما تعرف في إقليم راجستان باسم Phad وأغلبها تكون موضوعات للمعبود فيشنو وتكون لفائف من القماش والمصور

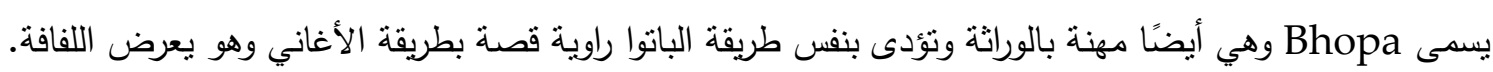
MANDAL, R.: «Historical Ornamentation of Chinese Scroll Painting and Bengal Pata Painting», The Chitrolekha Journal on Art and Design, vol.2, №.3,2018, .95

${ }^{47}$ JAIN, The Art of Indian Picture Showmen , 15.

${ }_{48}$ MAJUMDER, Disappearing Traditions, The Narrative Songs of Bengal Pata,38.

${ }^{49}$ GUPTA, S.D.: «Village of Painters:A Visit to Naya, Pingla», Chitrolekha International Magazine on Art and Design1, №. 3,2011, 6.

${ }^{50}$ HAUSER,B., «From Oral Tradition to "Folk Art": Reevaluating Bengali Scroll Paintings», Asian Folklore Studies61, №.1,2002,108. 
الأداء مقدسًا، حيث كانوا يلتزمون الصمت للاستماع إلى رواية الباتو "، وحاولوا أن يقدموا أنشطتهم إلى

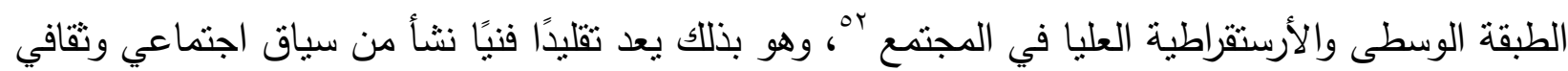
ريفي

ومع ظهور التقنيات الحديثة لفن الرواية، أدى ذلك إلى انخفاض رعاية البلاط العالي والأثرياء إلى الثى تزفيه الثخص العادي خلال المهرجانات والتجوال في الريف، وهكذا من تصاويرها المتقنة والأداء المتميز

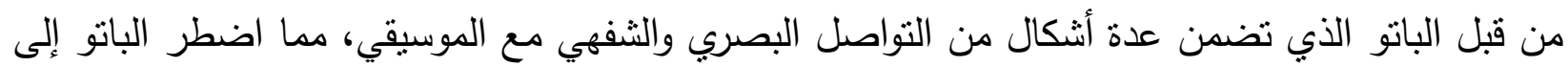

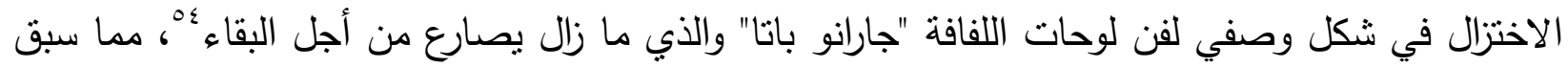

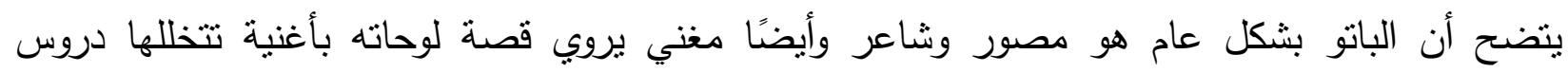
أخلاقية .

\section{r,r. أنواع تصاوير الباتا في غرب البنغال :} تعددت أنواع لوحات الباتا في غرب البنغال على النحو التالي:

"جارانو بانا" Rolling Pat Jarano: وتعني تصاوير اللفائف وفيها يتم تصوير القصة بنسلسل الأحداث وموضوعة بطريقة رأسية ومحاطة بإطار مزين بزخارف نباتية ولكل صورة إطار يحبط بها ويفصلها عن بن

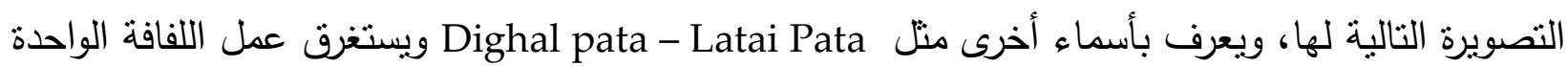

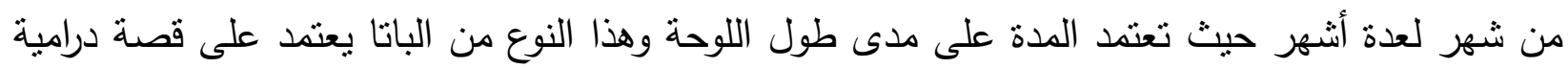

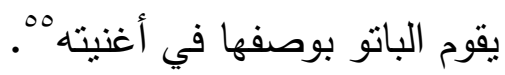
Arelatai Pat

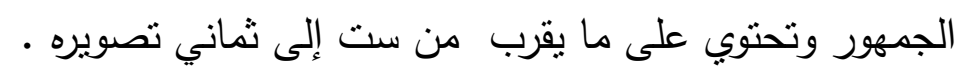

Choukosh pat

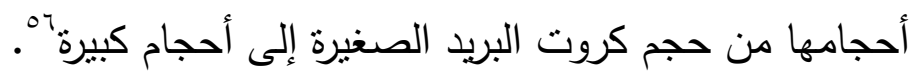

كاليغات باتاتثيترا: وهو نوع من لوحات الباتو الموجود بالقرب من معبد كاليغات بكالكوتا، حيث تمركز

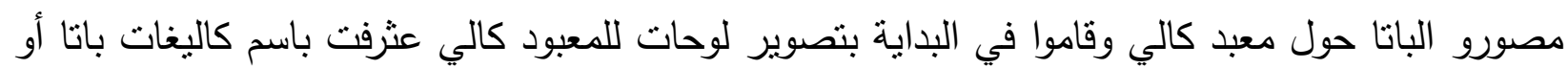

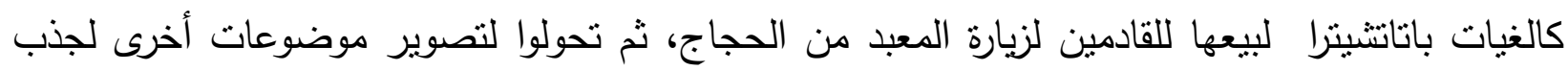

${ }^{51}$ BHATTACHARYA, and Narayanaswami, «Pattachitra: Indian Art in Context,6.

52 BANU, «Acritical Study of The Progressive art movement in Bengal», PhD of Philosophy in Fine Arts , Department of Fine Arts Aligarh,2018, 58.

53 MAJUMDER, Disappearing Traditions, The Narrative Songs of Bengal,38.

54 PALIT \& DATTA, Transformation from Performativeaer ,218.

55 BAJPAI : «Intangible Heritage Transformation - Patachitra of Bengal Exploring Modern New Media», International Journal of History and Cultural Studies (IJHCS), vol.1, №. 1,June 2015, 2.

56 BHATTACHARYA, \&Narayanaswami, Pattachitra: Indian Art in Context, .26. 
السياح له ومع الوقت احتوت علي تصاوير للرموز الدينية الإسلامية والهندوسية، حيث احتوت على رسم لحصان الإمام الحسين والبراق وغيرها من الأساطير الإسلامية المتداولة هذا بجانب رسوم للمعبودات والأساطير الهندوسية، وتميزت بكثرة التأثيرات الأوروبية على لوحاتها^ه. وهنالك أنواع أخرى من تصاوير الباتا في البنغال تُعرف باسم القربة التي تقوم بإنتاجها منل باتانتيترا ميدنابورى Midnapuri بيربهوم Birbhum

ومن حيث موضوعات باتا البنغال فقد تتوعت ما بين موضوعات دينية وأسطورية ثم أضيف إليها لاحقًا الموضوعات الاجتماعية ثم التاريخية، وبذلك لعبت باتا البنغال دورًا رئيسًا في ترفيه الجماهير وتثقيفهر

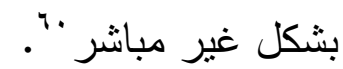

جدير بالملاحظة أن وجود لوحات ممتدة أفقية أو رأسية وتحتوي على أكثر من مشهد تصويري وجدت بمفهوم قريب من موضوع الدراسة في اليابان يُطلق عليه "يامتاتو "Yamato-e ويصور قصصاً شعبية سردية ترجع إلى فترة العصور الوسطى في اليابان، وقد انتقلت إلى اليابان عن طريث الصين حيث ظهرت لوحات اللفافة أو التمرير في الصين وتعود أقدم إثارات معرفة الصين بلوحات اللفافة إلى القرنعم واهتمت في البداية بتصوير موضوعات الأخلاق والتقاليد البوذية "“، ثم طورت في القرن اهـ/ Vم وأصبحت تهنم بالمناظر الطبيعية، كما أصبحت تُعرف باسم ماكيمونو Makimono وبلغت قمة تطورها في القرنينع-0هـ| • 1-1 ام بَ، وتتدر الدراسات التي تتتاول العلاقة بين شكل لوحات اللفائف في الهند ووجودها في الصين ثم

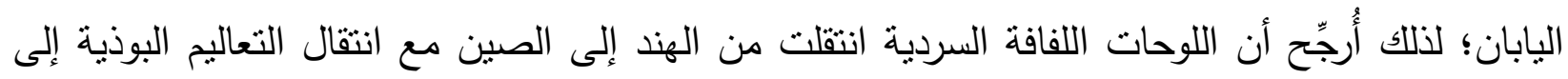
الصين خاصة وأن أقدم الإثارات الأدبية في الهند ترجع إلى فترة انتشار التعاليم البوذية، وإذا انتقلنا إلى الصين نجد أن بداية معرفتهم بهذه اللوحات كانت لتوضيح التعاليم البوذية ومع مرور الزمن أصبح لها

57 JefFERSON,P., The Art of Survival Bengali Pats Patuas and Evdution of Folk Art in India, New DeLHI, Independent Study Project (ISP) Collection,2014, .7.

58 MANDAL, Historical Ornamentation of Chinese Scroll Painting ,95.

${ }^{59}$ KOLAY, \& Roy : «The Designing alternative Paradigm for Traditional Visual Storytelling, ICORD'15» Indian Institute of Science, Bangalore, 7-8 January,2015,3.

${ }^{60}$ BHATTACHARY, and NARAYANASWAMI, Pattachitra: Indian Art in Context,26.

" وصلت البوذية إلى الصين في النصف الثاني من القرن الثاني الميلادي في أواخر حكم أسرة هان Han من طريق

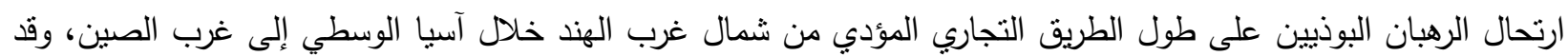

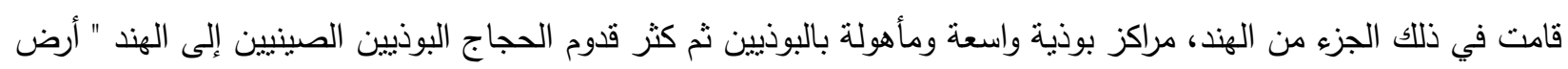
بوذا المقدة" وكان من بينهم مجموعة جاءت للبحث عن النصوص المقسة ومعرفة الطقوس البوذية وكان ذلك في فترة

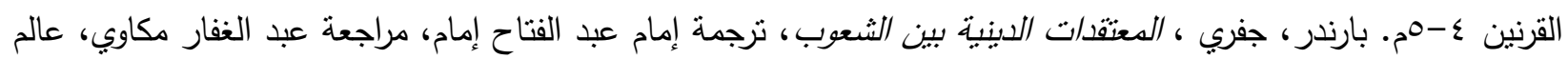

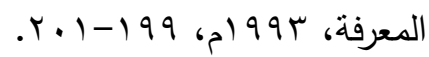

${ }^{62}$ MANDAL, Historical Ornamentation of Chinese Scroll Painting, 90-91. 
استخدامات وأثكال أخرى، لذلك من المرجح تأثر الصينيين بهذا النوع من اللوحات لنشر التقاليد البوذية من خلالها. وعرفت أيضًا اللفائف المصورة خارج الهند متل بلاد فارس، ولكن اختلف استخدامها في بلاد فارس عن

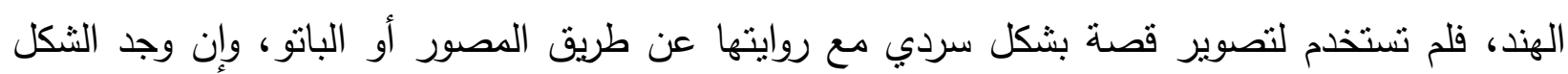

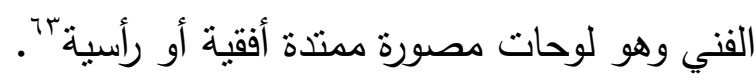

\section{r , ـ ـ الأسلوب الفني للفائف الباتا "جارانو باتا" في غرب البنغال:}

ترجع أصول فن التصوير في البنغال إلى فترة حكم أسرة بالا (القرن ب-7ه/و-Y (م) حيث نشأت

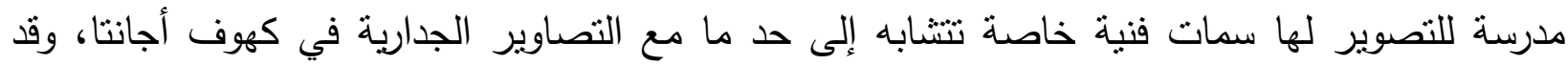
وصلنا من عصر أسرة بالا مجموعة من مخطوطات سعف النخيل، وعلى الرغم من وجود مدرسة فنية

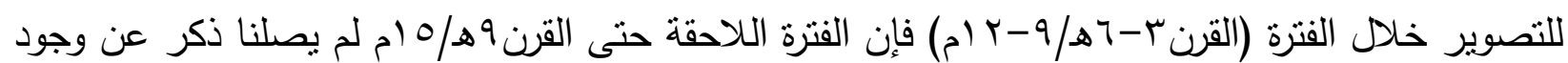
مدرسة للتصوير خلال هذه الفترة، وخلال القرن 9 هـ/0 ام بدأ ينتشر الأسلوب الفني لباتا البنغال في الريف

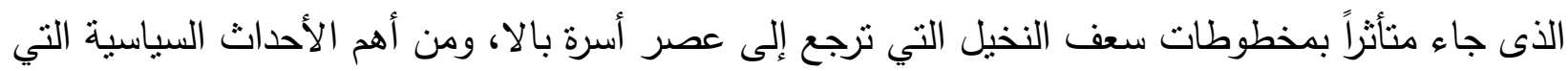

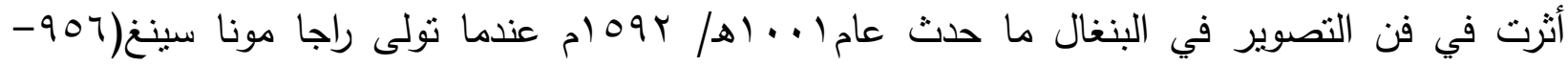

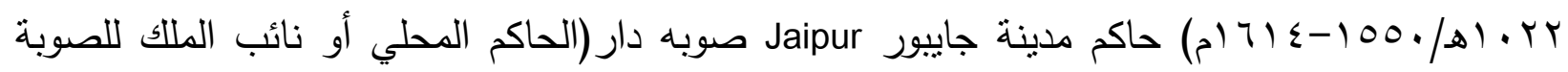
وتعني المقاطعة) البنغال وبيهار من قبل الإمبراطور الدغولي گ، وهو ما نتج عنه حدوث اتصال ثقافي وفني

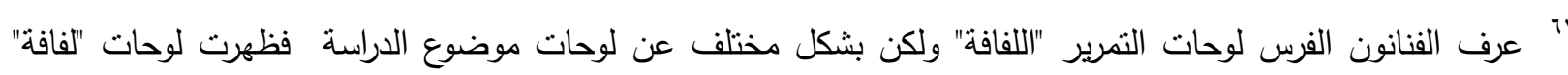

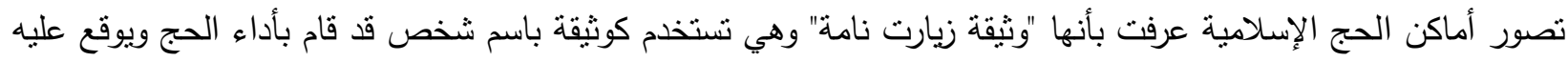

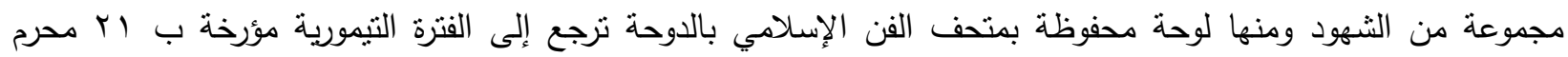

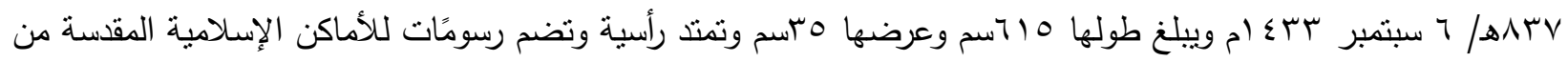

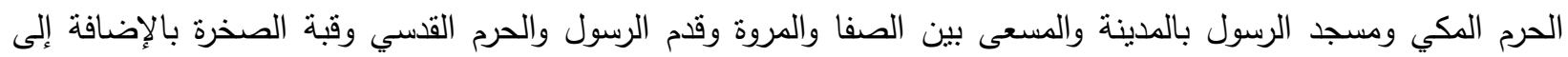

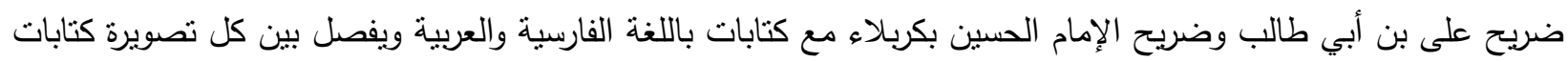

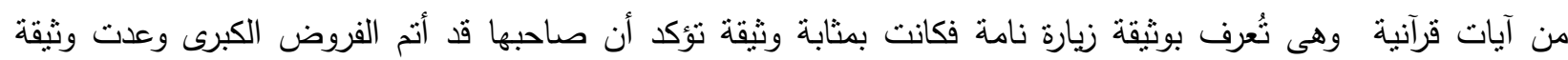

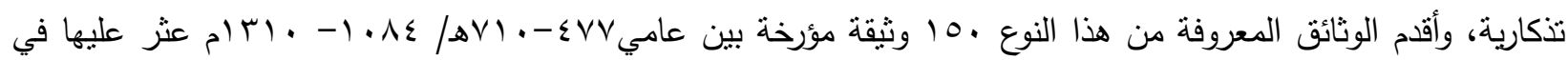

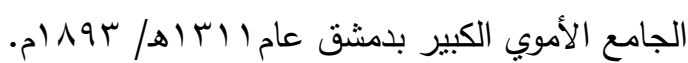
ABUDAYA,M.CH., \& others .: «Sayyid Yusuf's 1433 Pilgrimage Scroll (Ziyaratnama) in The Collection of the Museum of Islamic Art Doha», Muqarnas, vol.33,2016, 345-348

" ع" الأمير راجا مان سينج أحد أمراء مدينة أمير والتي عُرفت بعد ذلك باسم مدينة جايبور ، أصله راجبوتي من وسط الهند، وقد

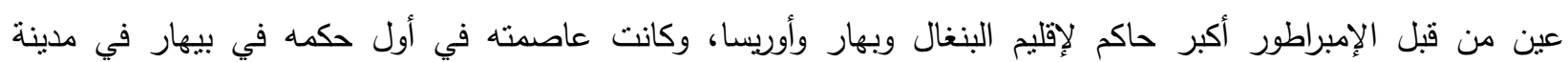

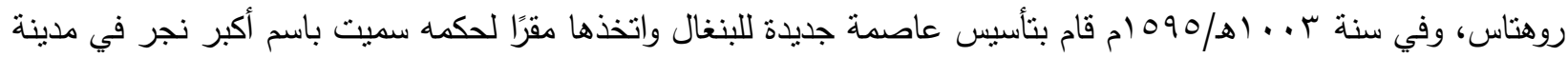

RoY, history of Bengal: Mughal period, , Calcutta: Nabharat publishers, 1968,30.

داكا (جنوب غور الحالية). 
بين راجستان والبنغال، حيث قدم من راجستان مجموعة من التجار والفنانين والنحاتين إلى البنغال وبيهار وكان لهذا الاتصال أثز في انتقال سمات التصوير الراجبوتي المبكر على فن التصوير في البنغال فامتزجت مع سمات التصوير المحلي لمدرسة البنغال والتي تعود إلى مدرسة التصوير في عهد أسرة بالا، وكونت أسلوبًا خاصًا بها ظهر بشكل خاص في لوحات باتا البنغال خاصة التي ترجع إلى مدرسة التصوير الثعبي بمدينة مرشد آباد والقرى التابعة لها، هذا بخلاف بعض سمات التصوير المغولي الهندي التي كانت سائدة في مدرسة التصوير في بلاط نواب البنغال في العاصمة مرشد آباد خلال النصف الأول من القرن

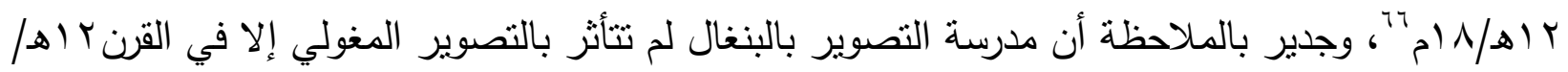

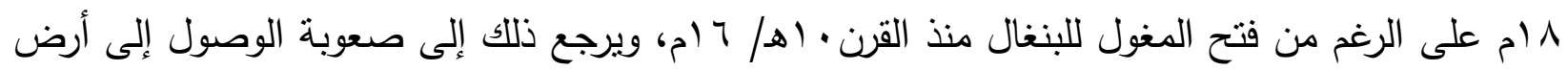
البنغال ذات الغابات الكثيفة لّ؛ لذلك نجد أن الأسلوب المغولي الهندي لم ينتشر كثثرًا في لوحات باتا البنغال فغلب الأسلوب المحلي الثعبي خاصة في ريف غرب البنغال، ويلاحظ عدم مواكبة تصوير باتا البنغال لتطور قواعد التصوير المعاصرة من عدم اتباعها لقواعد المنظور والبعد الثالث، وحفاظهم على موروثهم المحلي الذي يتميز ببساطة الأسلوب الفني دون إدخال سمات فنية جديدة من المدارس الفنية المعاصرة المحيطة بهم، كما يلاحظ اقتصار المصور على عدد قليل من خطوط الأرضية وربما نجد في بعض مئ التصاوير خط أرضية واحد ثُرسم عليه جميع عناصر التصويرة، وسادت هذه السمات كل المراكز الفنية لتصوير الباتا في البنغال، وعلى الرغم من انتشار فن لوحات الباتا في كثير من مدن البنغال الغربية، إذكان لكل مدينة أو قرية سمات فنية مميزة لها، فإن هناك اختلافات طفيفة في الأسلوب الفني لكل مدينة تظهر في الرسوم الآدمية والعناصر المعمارية والملابس، ومما زاد من صعوبة تحديد سمات خاصة لكل مدينة أن كل

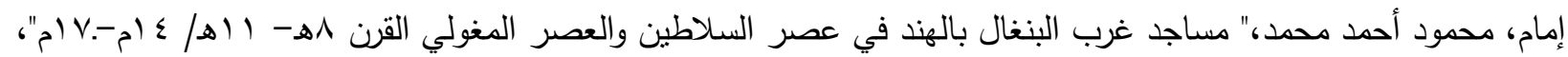

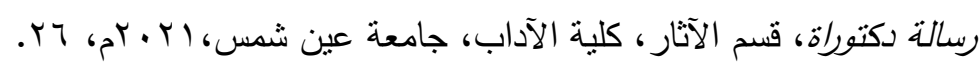
${ }^{65}$ DAS,N.: «Importance of Linearity in Indian art with special reference to Eastern Indian folk paintings», PhD thesis of Philosophy, Department of arts, Assam University,2014 , 40.

$$
\text { "1 لمعرفة المزيد عن فن تصوير البلاط في مدينة مرشد آباد المعروفة باسم أسلوب مرشد آباد انظر : }
$$

LOSTY, J.P., 'Towards a New Naturalism: Portraiture in Murshidabad and Avadh 1750-80', in After the Great Mughals: Painting in Delhi and the Regional Courts in the 18th and 19th Centuries, Bombay: ed. B. Schmitz, 2002, 34-55.

LOSTY, J.P.: «Early Views of Gaur and Pandua by the Indian Artist Sita Ram», Journal of Bengal Art1, 1996, 189-205

LOSTY, J.P.: «An Album from Bengal 1795-1810» in F. Galloway, Imperial Past: India 1600-1800",London, Francesca Galloway sale catalogue 2011, 66-87.

"َّ يرجع بعضهم عدم وصول سمات التصوير المغولي إلى البنغال إلى أن المغول عدوا البنغال منطقة ذات جغرافية وعرة أو

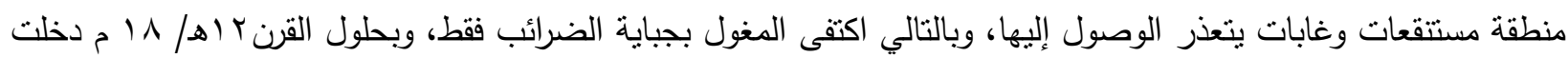
إمبراطورية المغول في مرحلة الضعف والتدهور فظهرت ممالك مستقلة مثل البنغال وفى ظل صوبه دار مرشد قولي خان استطاع إدخال ثقافة المغول وآداب البلاط . GHOSH,I : «Murshidabad's Darbari Culture and the Incipient Nawabi of Bengal c.A.D. 1704-1740», Urbanisation in India: Past and Present: Professor Nisith Ranjan Ray Birth Centenary Volume, Edited by Chittabrata Palit, Institute of Historical Studies,2009,341-342 


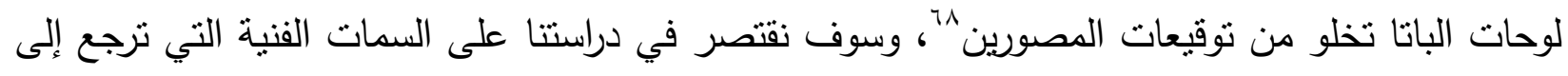

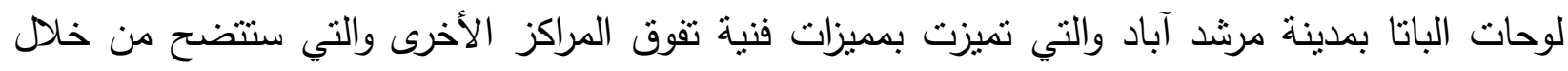
دراستتا التحليلية للوحات موضوع الدراسة.

r. r.السمات الفنية المميزة للفائف الباتا "جارانو باتا" بالمركز الفني بمدينة مرشد آباد:

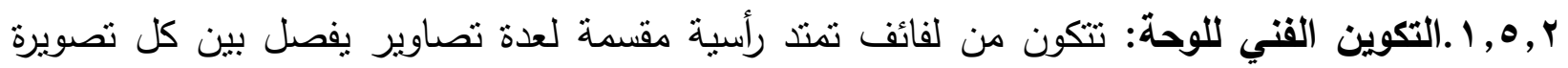

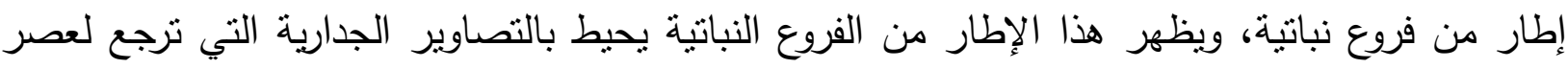

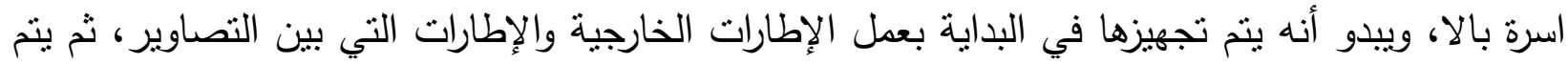

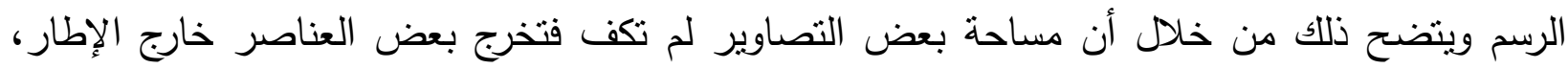

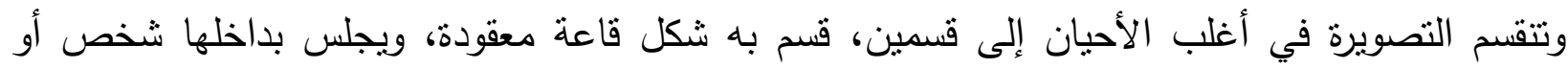
أكثر، والقسم الثاني يعبر عن منظر طبيعي خارج المبنى، يظهر به شجرة ضخمة وستارة في أعلى التصويرة

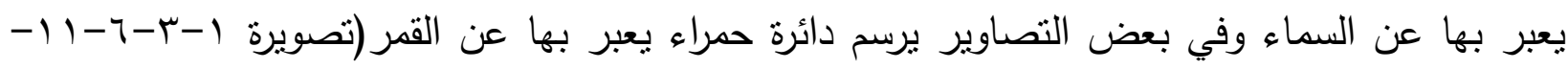

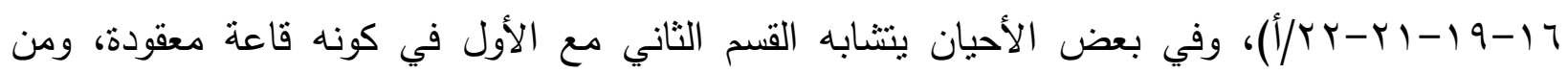
الجدير بالملاحظة مراعاة المصور التمانل بين عناصر التصويرة بصورة كبيرة ونشاهدها على سبيل المثال

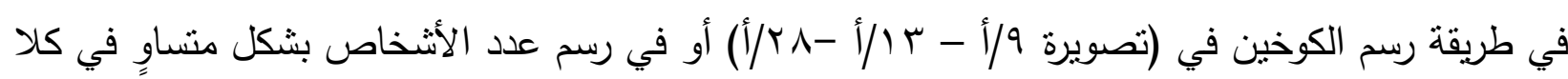

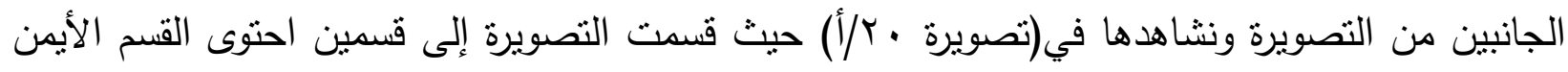

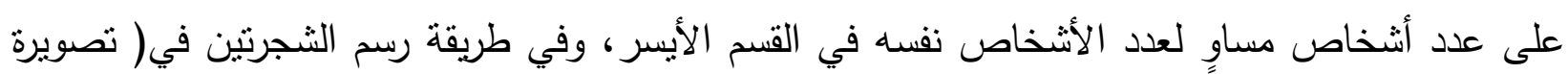

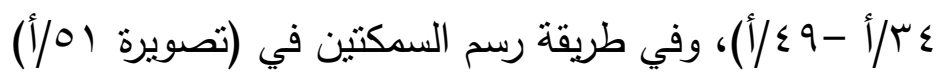

وجدير بالملاحظة أن التكوين الفني لتصاوير اللفافة يتشابه مع تصوير مدرسة راجستان

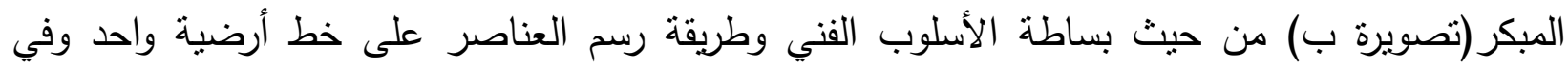

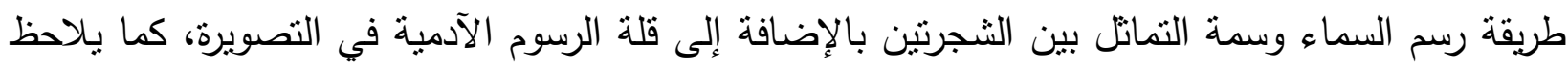

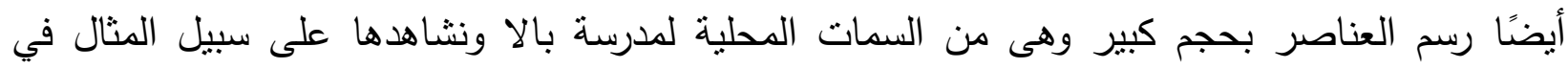
تصويرة من مخطوطات مدرسة بالا (تصويرة ج).

ويعد فن لوحات الباتا بصفة عامة فنًا ثنائي الأبعاد لا يظهر به قواعد المنظور، يهتم بزخرفة الإطارات

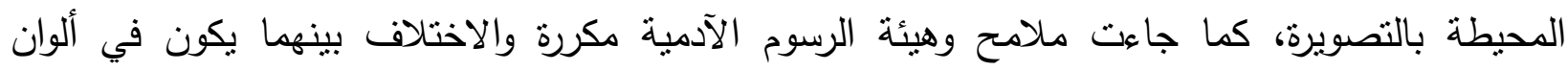

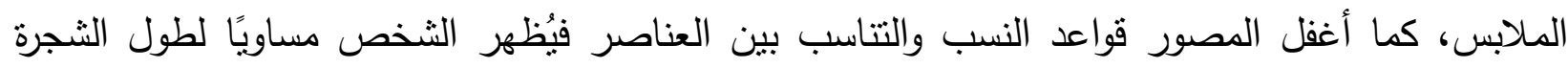

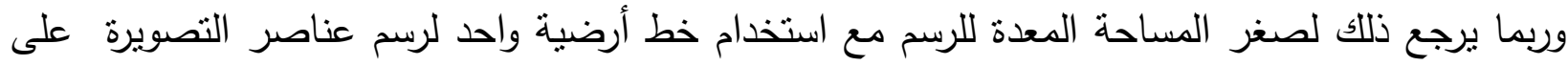

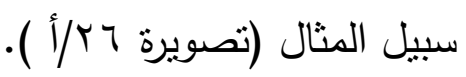


r, Y, r. الرسوم الآدمية: تنوعت الرسوم الآدمية الواردة بالتصاوير موضوع الدراسة ما بين رسوم لرجال

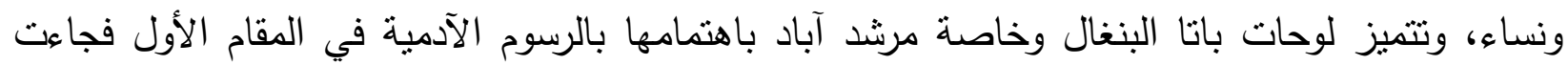

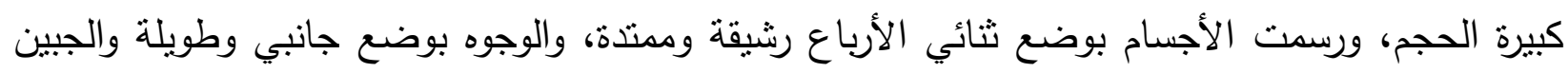
عريض وحواجب كثيفة وعيون واسعة مفتوحة وأنف مدبب وذقن صغير والأطراف طويلة والأصابع نحيلة

وهناك بعض الآراء التى تذكر أن شيوع الوضع الجانبي بدأ في مدارس التصوير المحلية وخاصة

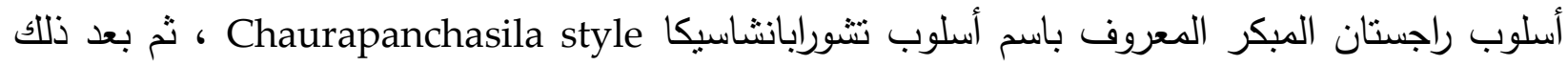
انتشر في باقي المدارس المحلية كتأثير لمدرسة راجبوت المبكرة مثل الددرسة الجينية، كما تأثرت به المدرسة

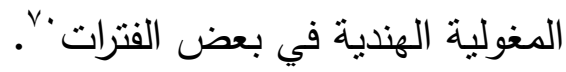

وجاءت جميع الرسوم الآدمية حافية القدمين، كما تميزت بتوضيح الاختلاف بين المسلمين والهندوس من خلال الثكل والملابس سواء للرجال أو النساء على النحو التالي:

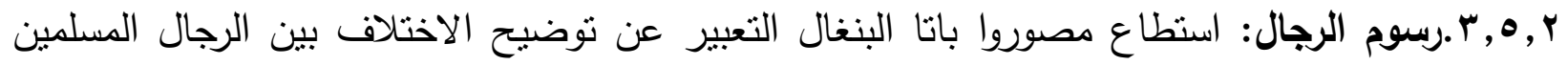

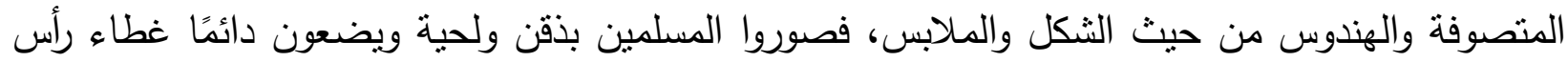

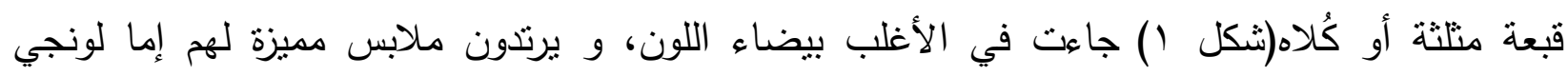
(Lungi)

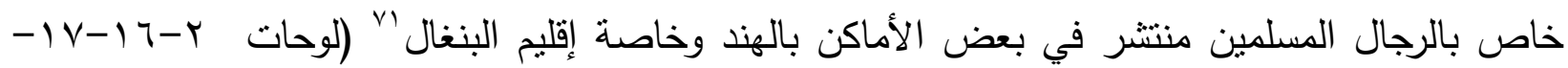

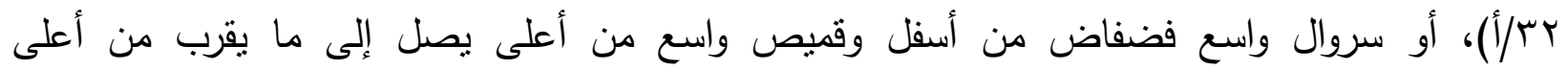

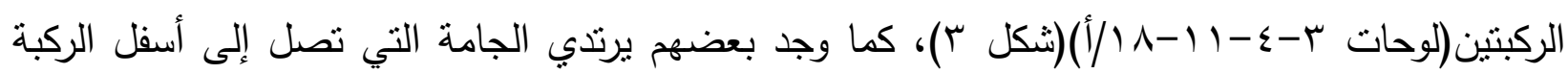

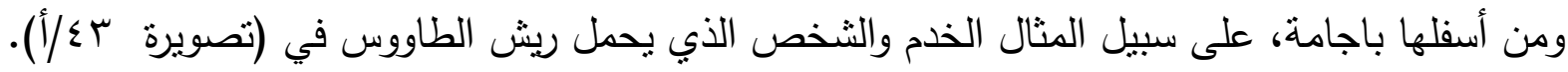
كما ميز المصور رجال الدين المسلمين وخاصة الزاهدين(البير) بسمات خاصة، فيظهرون وهم يضعون قلادة من الخيط إما سوداء أو حمراء أو الاثثين معا والمسبحة وعصا في يده وفي بعض الإن الأحيان

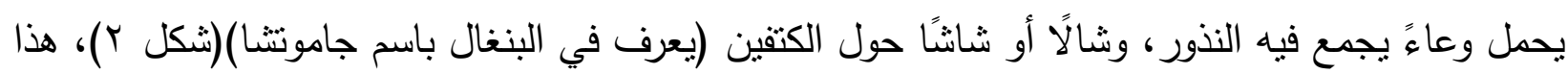

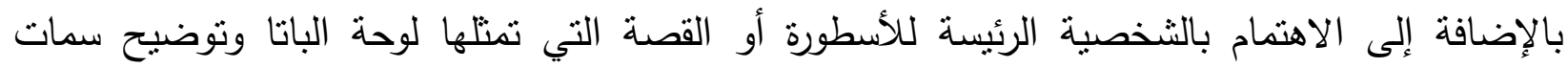

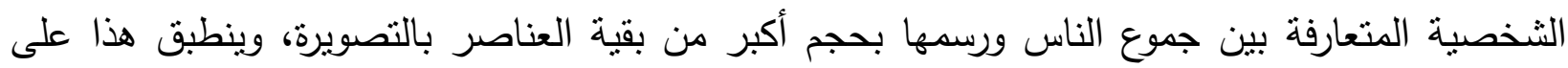

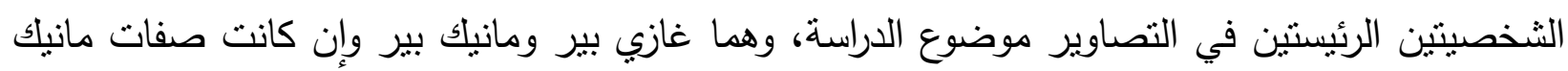

${ }^{69}$ DATTA, Folk Paintings of Bengal",109.

${ }^{70}$ AtSUSHI,I .: «Profiled Figures: The Modes of Representation of Faces in South Asian Painting», Kyoto Bulletin of Islamic Area Studies 10, March2017, 68.

71 SCHENDEL, W.V., The Bengal Borderland : Beyond State and Nation in South Asia, Delhi: Anthem South Asian Studies,2004, 334. 
بير هي الأكثر تداولًا في الأساطير الشعبية، إذغالبًا ما يصور ببشرة فاتحة يشبهه الكثيرون" بأن بشرته فاتحة

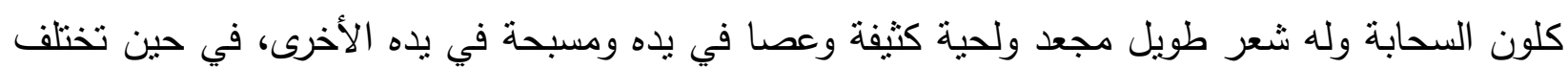
ملابسه ولكنها غالبًا ما تكون ملابس بسيطة بوصفه صوفيًا، ويغلب على ملى ملامحه هو وغازي بير التقوى الصوفية مبابسه

وجدير بالملاحظة أن المصور في بعض التصاوير لا يميز بين ملامح شخصية الصوفي غازي بير

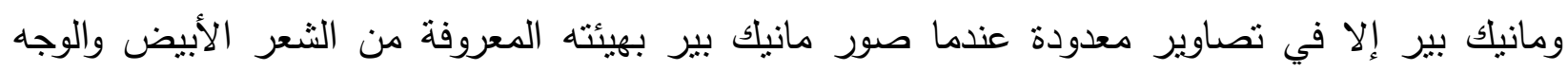

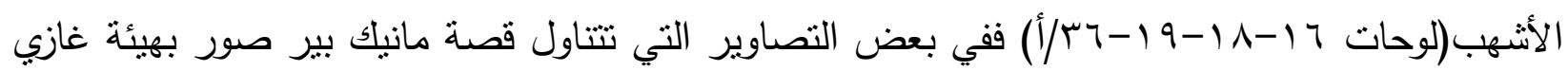

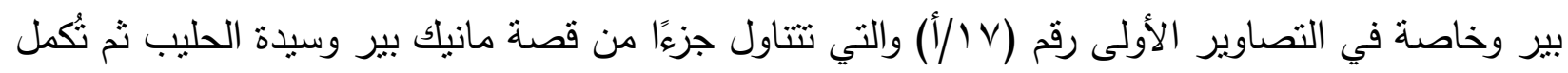

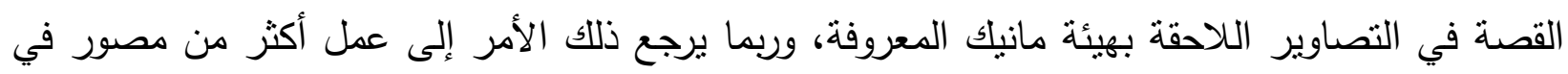

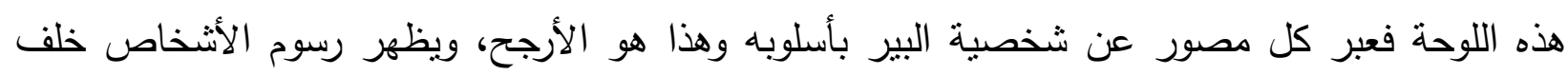

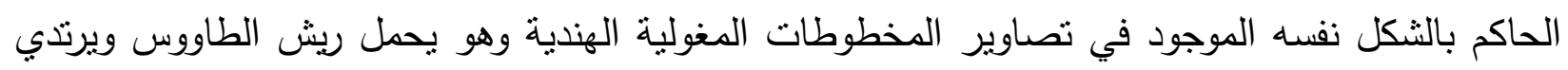

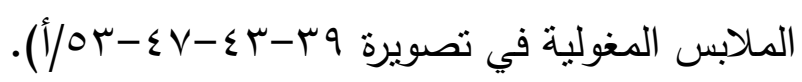

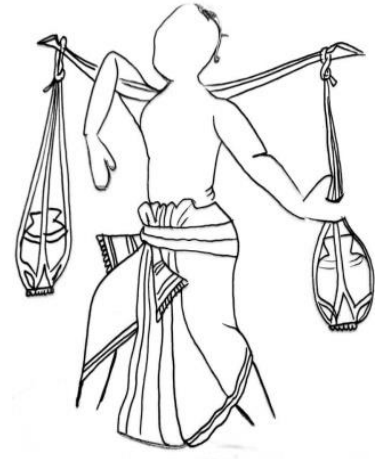

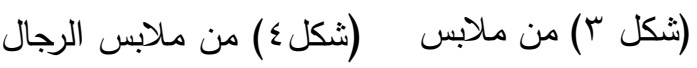

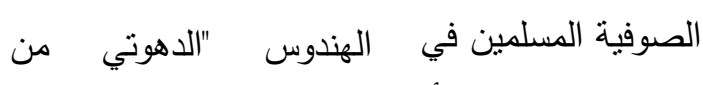

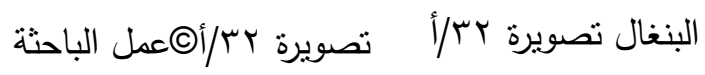
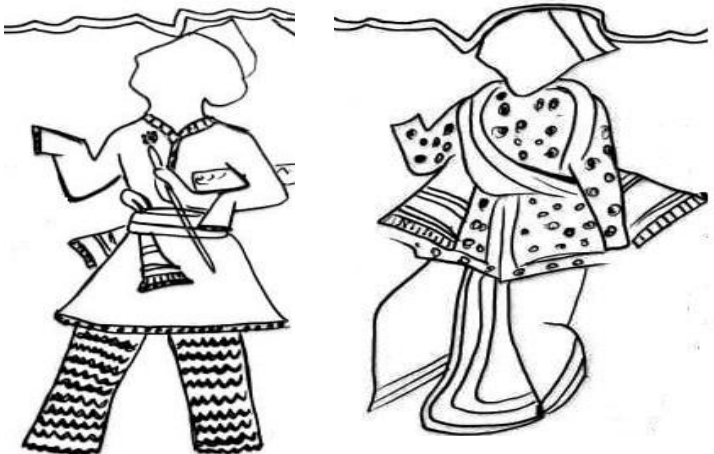

(شكل r) زي اللونجي

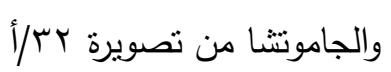
(1) عمل الباحثة

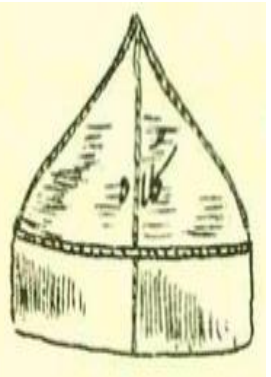

(شكل ( )غطاء رأس

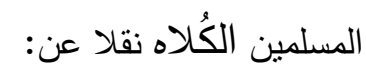

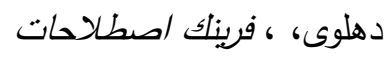

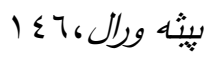

أما الرجال الهندوس فصوروا حليقي الوجه بدون لحية وشارب، حليقي شعر الرأس فيما عدا جزء

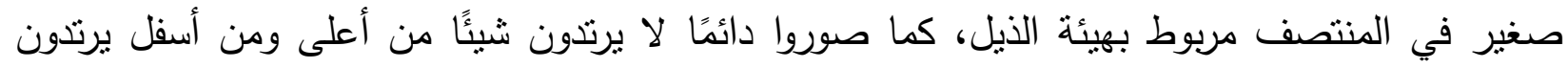

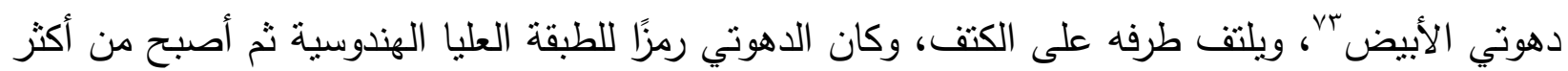

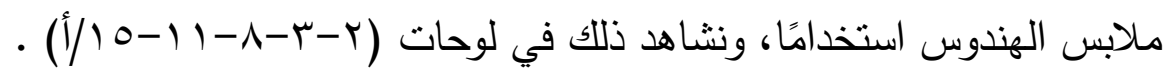

72 StewART, T.K.: «The Tales of Manik Pir-Protector of cows in Bengal, Tales of God's Friends», Islamic Hagiography in Translation, ed. John Renard, Berkeley: University of California Press,2009, 313.

"نيعرف زي البراهمة باسم باشا كاشام (Pacha Kacham) والمعروف أيضًا باسم "دهوتي" وهو قطعة قماش طويلة غير

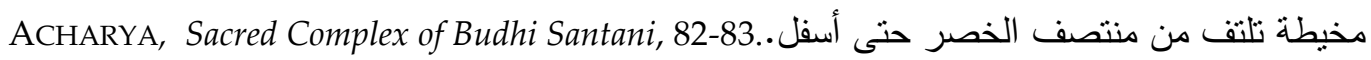


ץ , ه, ـ .رسوم النساء : تميزت رسوم النساء بحفاظها على تقاليد مدرسة التصوير المحلية منذ عصر أسرة

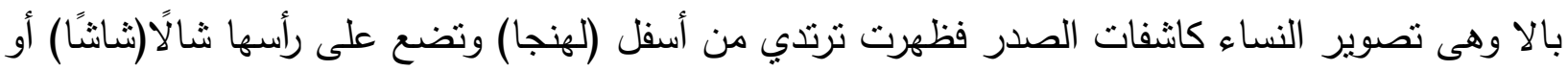

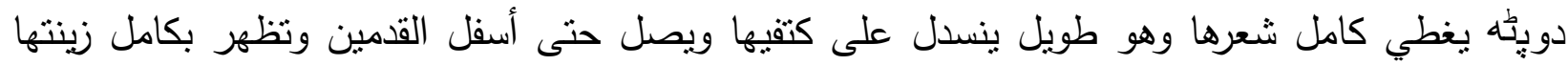

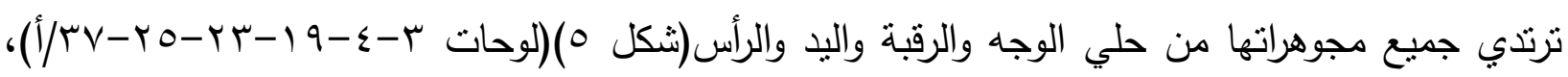

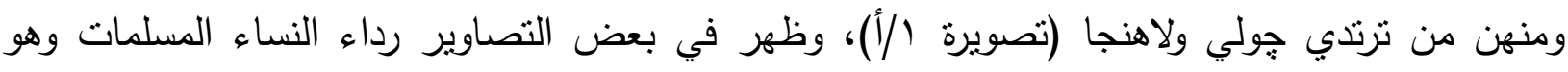

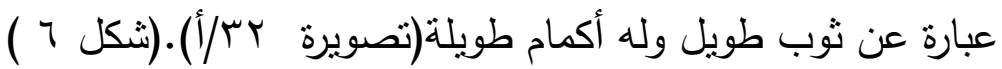
أدوات البير: العصا: وتكون ملازمة للبير وهي رمز السلطة والوقار والهيبة وغالبًا ما تكون ملازمة للزاهدين

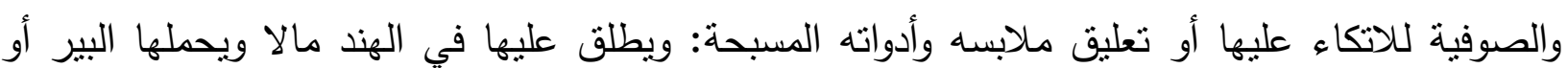

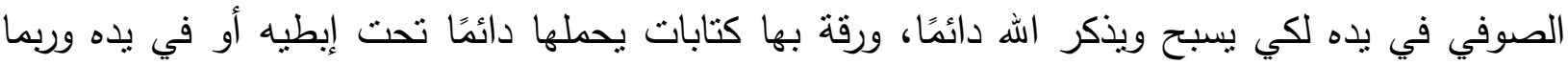

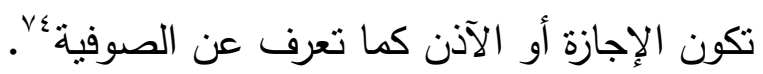
كما يلاحظ أن المصور كان يميز الثخصية الرئيسة بوضع ما يشبه المظلة فوق رأسها وتكون عبارة عن

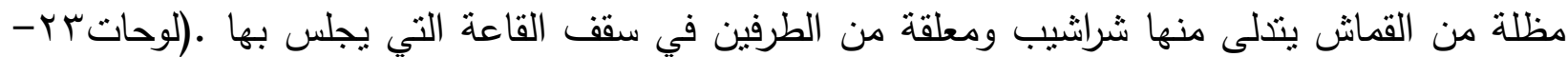

$$
\text { .) (I/ } \mid \leqslant \Lambda-\varepsilon r-r r-r r-r)-r q
$$

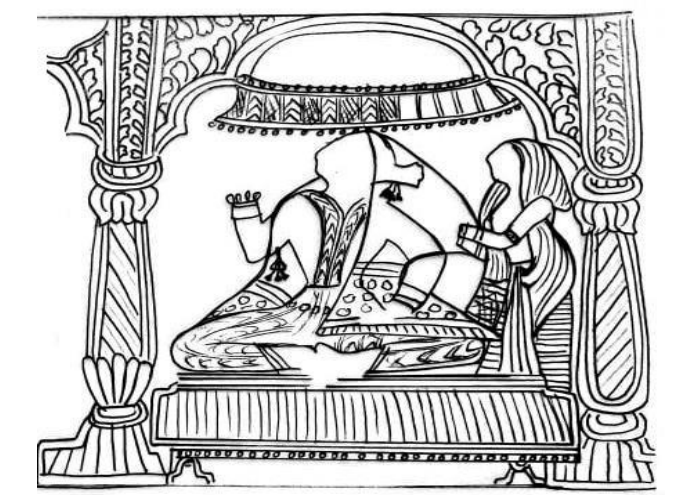

$$
\text { T) زي النساء المسلمات- العقد الخماسي- منلة }
$$

(عمل الباحثة)

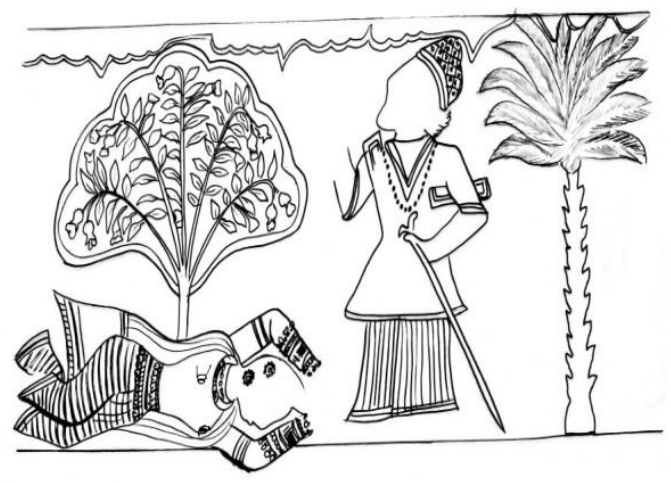

0) زي الرجال المتصوفة- زي النساء (ثكل

الهندوس- التماتل-من تصويرة 17 (عمل الباحثة)

ع 1أبرز آداب الثيخ الصوفي التي أوردها أعلام الفكر الصوفي في رسائلهم ومؤلفاتهم، أن يكون صاحب علم شرعي يؤهله

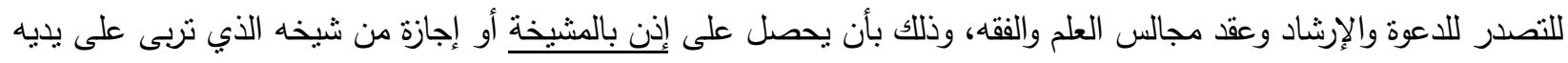

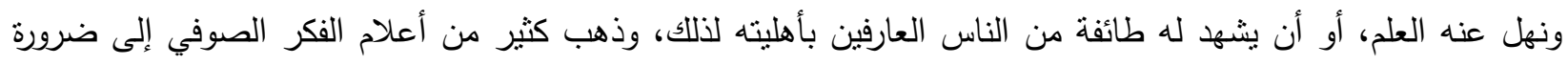

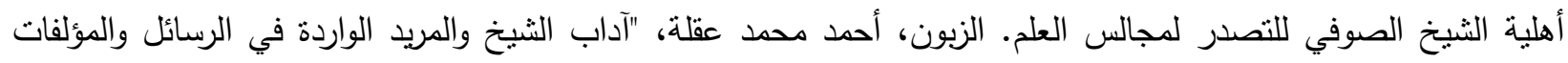
الصوفية في الفترة الزمنية الممتدة من القرن الثالث إلى السابع الهجريين "دراسة تحليلية ونقدية في ضوء الكية الكتاب والسنة"، المجلة

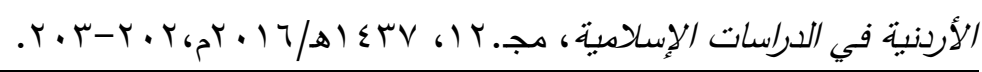


Y, Y.العناصر المعمارية : ظهرت بالتصاوير موضوع الدراسة أسلوب تغطية لرسوم العمائر مستوحاة من

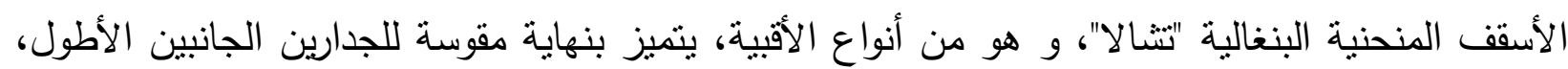

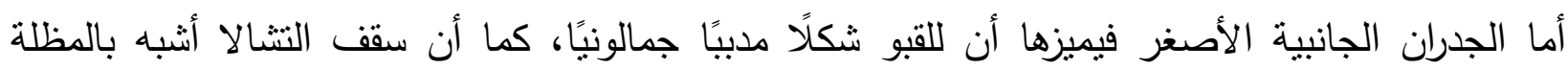

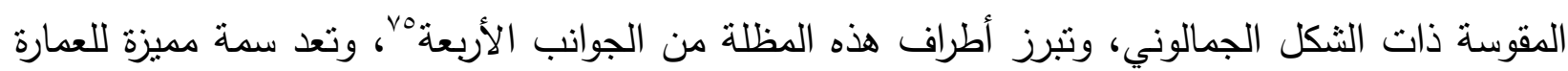

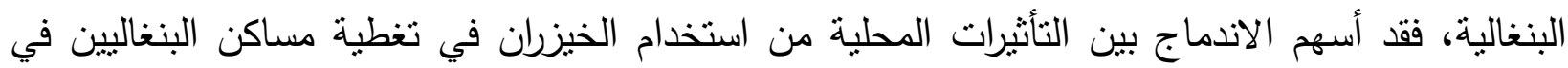

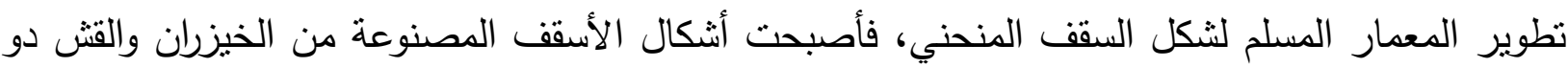

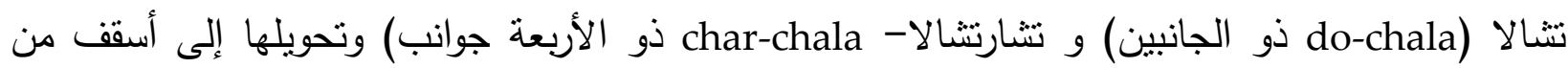

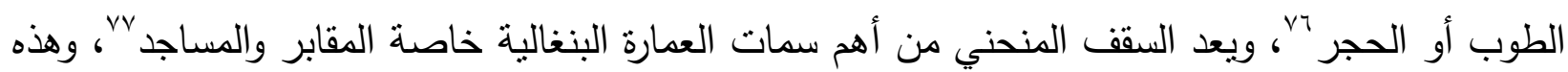

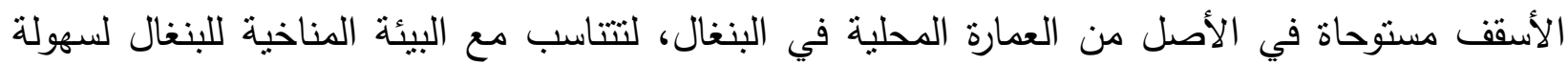

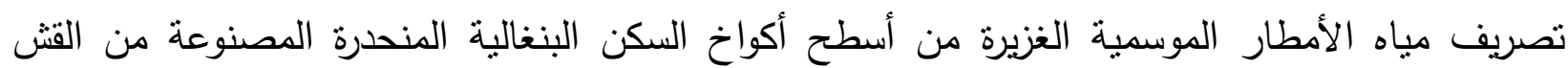

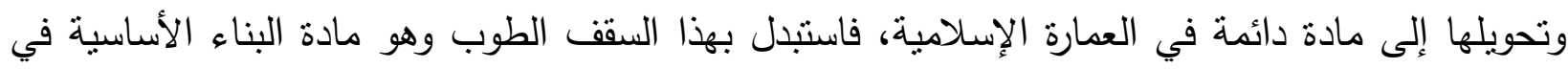

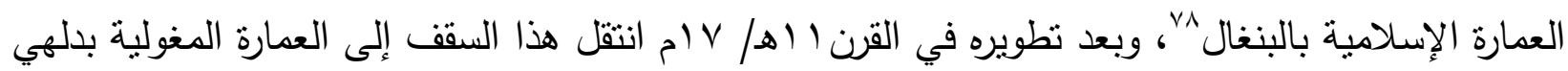

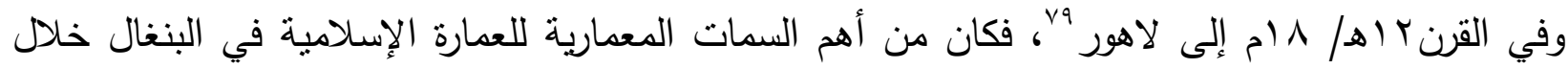

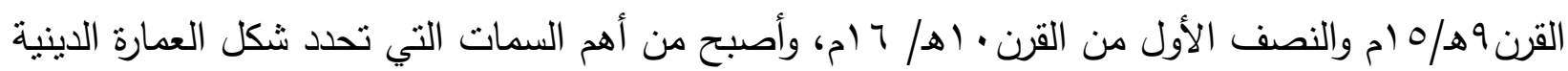

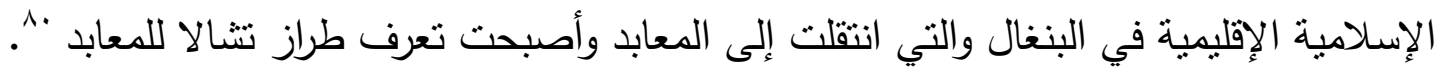

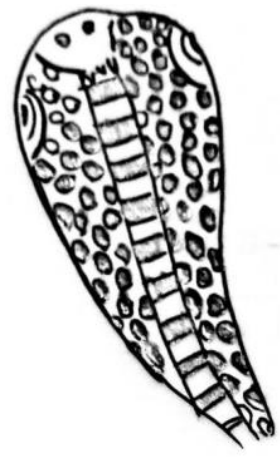

(شكل9) (الثعبان من من تصويرة 10 (جعمل الباحثة 10

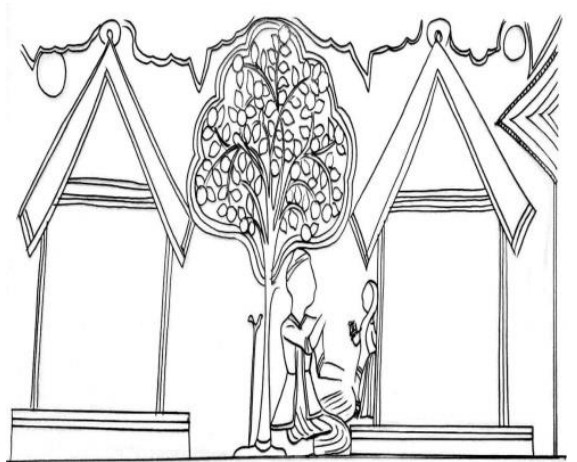

9 (نكل1)(الأسقف الجمالونية من تصويرة (C)

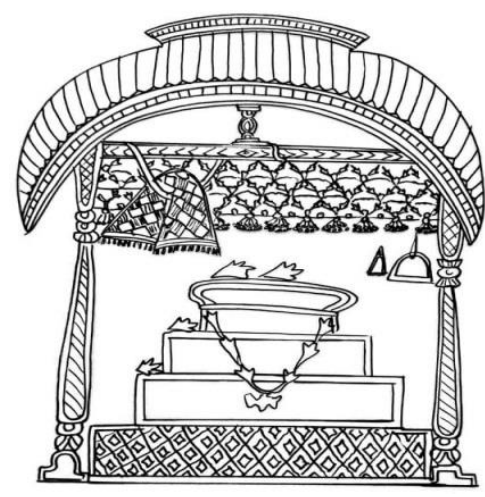

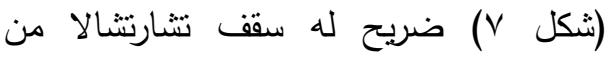
تصويرة بr (Cعمل الباحثة

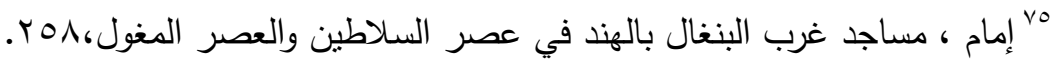

${ }^{76}$ Michell, G., The Islamic Heritage of Bengal , Paris: United Nations Educational , Unesco,1984, .20.

77 GUHA,S. \& Bandyopadhyay,A.: «Terracotta Temples of Bengal : A Culmination of Pre-existing Architectural Styles», The Chitrolekha Journal on Art and Design, vol.1, №.1 , 2017, 47.

78 GuHA, \& Bandyopadhyay, Terracotta Temples of, 56.

${ }^{79}$ MiCHELL, The Islamic Heritage of Bengal ,148.

${ }^{80}$ HITESRANJAN S.: «Religious architecture in Bengal(15 $15^{\text {th }}-17^{\text {th }}$ Century): A Study of the Major Trends», Proceedings of the Indian History Congress, vol.32, №.1,1970, 417-420. 
ومما سبق نستطيع القول: إن لوحات باتا البنغال أمدتتا بجانب واقعي في تصاويرها عند التعبير عن جانب

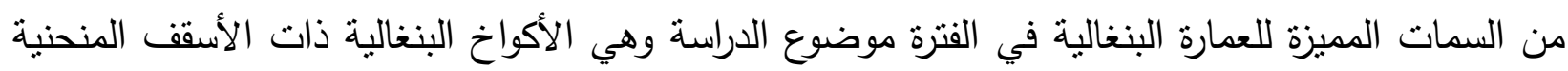

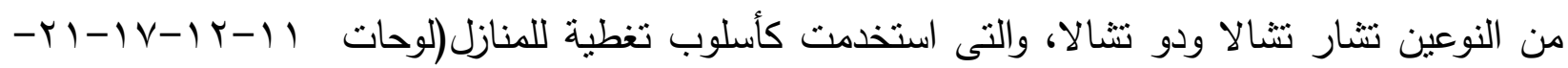
ا اب-r-r

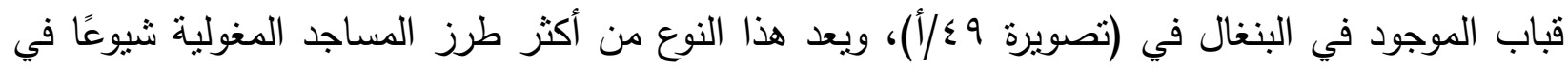

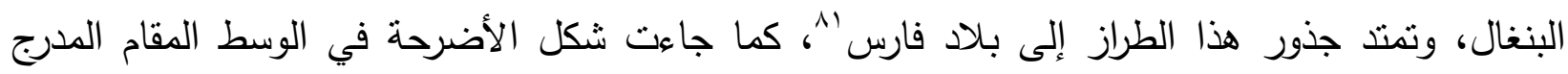

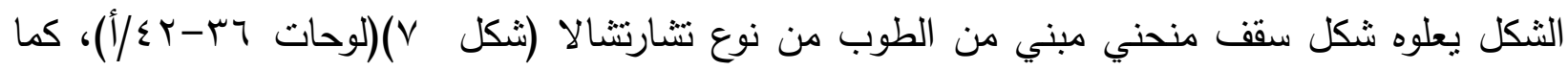

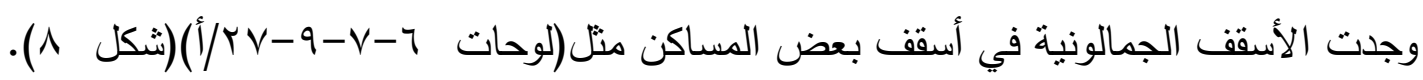
ץ, צ, أشثكال العقود: ترجع العقود الثلاثية المستتدة على أعمدة إلى الموروث المحلي البنغالي حيث كانت

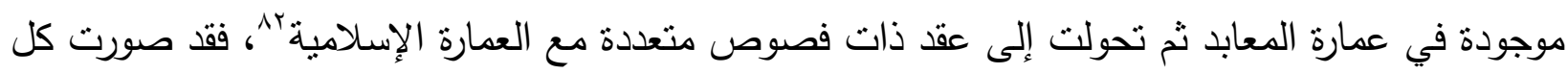

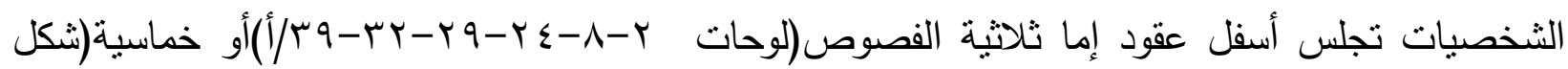

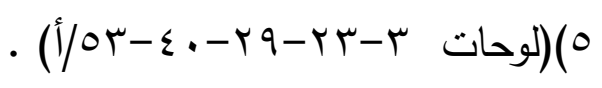

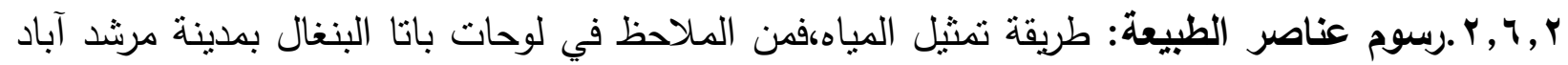

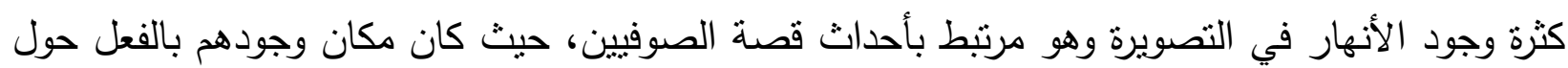

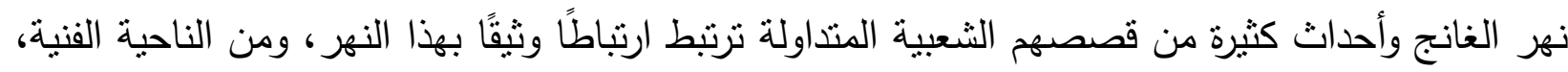

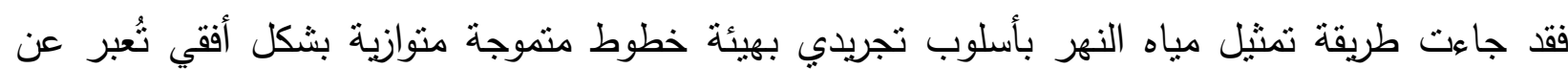

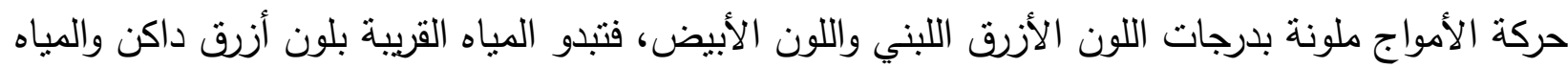

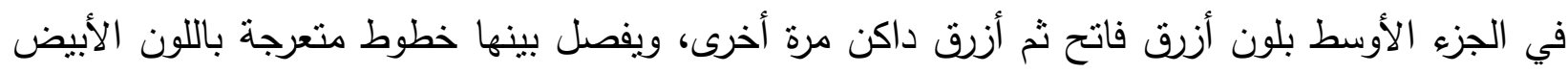

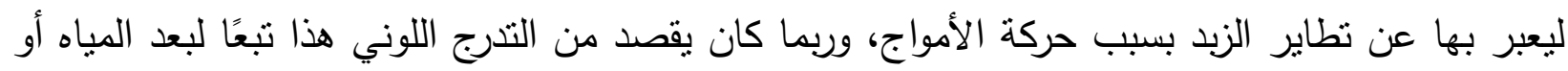

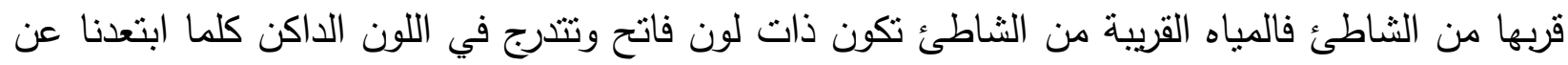

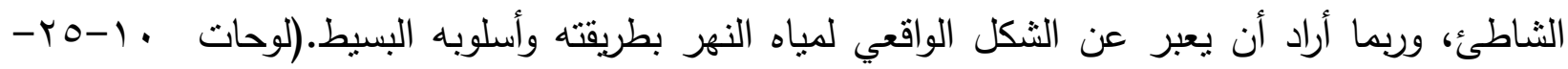

$$
\text { (I/ } / \text { I) }
$$

دائما ما تظهر بها الأسماك و الأوز السابح في المياه كما وجدت الفيلة ووحوش النهر

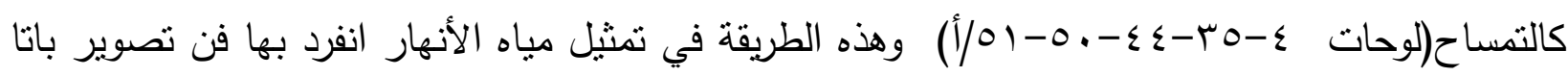

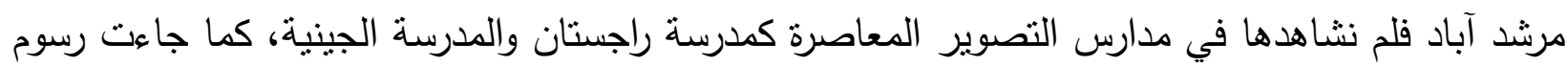

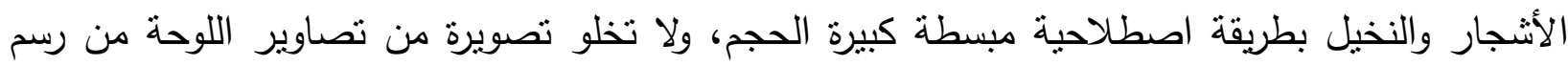

${ }^{81}$ IsLAM, I., \& NOBLE,A.G.: « Mosque Architecture in Bangladesh : The Archetype and Its Changing Morphology», Journal of Cultural Geography, vol.17, № 2 2,1998, 9.

${ }^{82}$ GUHA, \& BANDYOPADHYAY, Terracotta Temples of Bengal ,53. 
الأشجار، وهو أمر واقعي خاصة وأن البيئة التي تدور بها أحداث الأسطورة كانت في غابات البنغال،

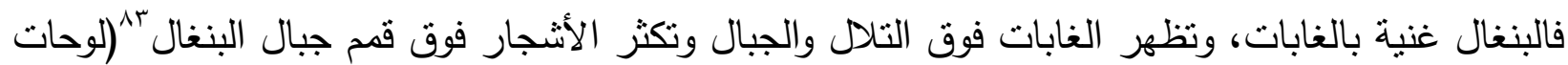
. (أ) $/$ / $\leqslant-17-0$

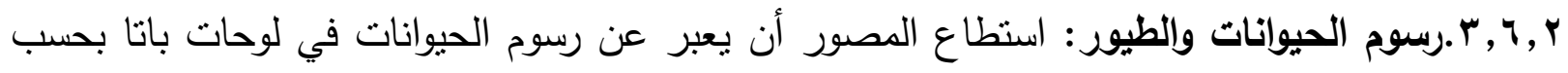

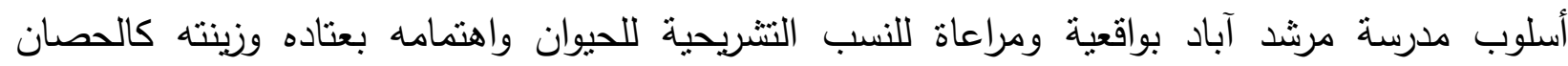

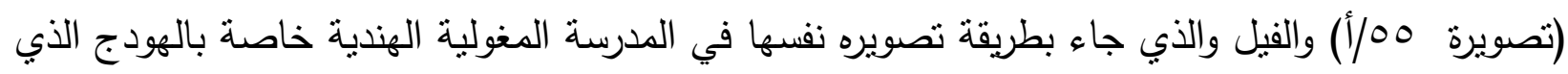

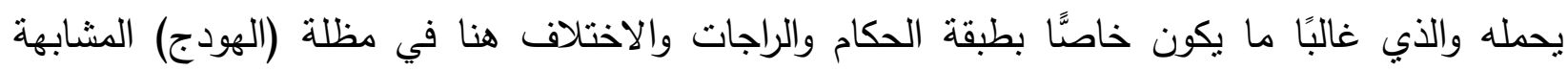

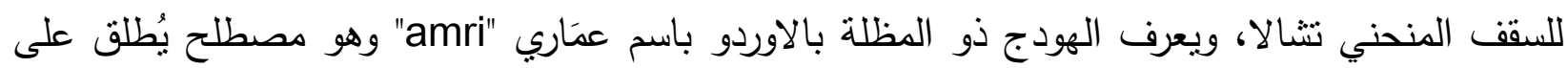

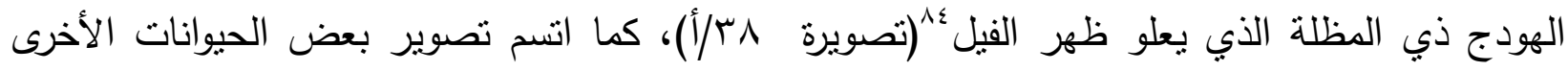

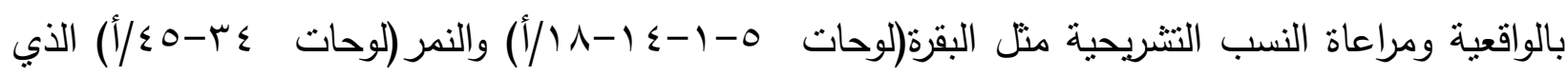

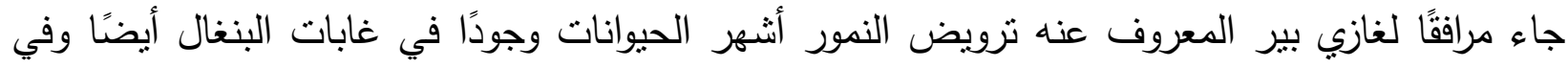

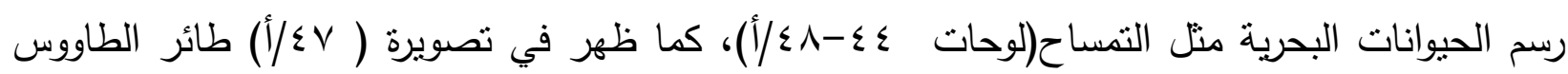

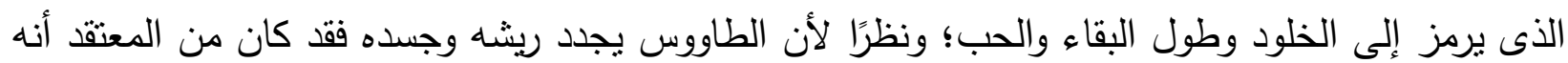
غير قابل للفناء، كما يرمز إلى القديسين حيث إن ذيله مثل الهالة النورانية، وكان قديمًا ريش الطاووس هو الفاء الجائزة التي تُمنح لأصحاب المقام الرفيع ولكبار الموظفين تقديرًا لخدماتهم الجليلة، حيث إنه يدل على التأييد

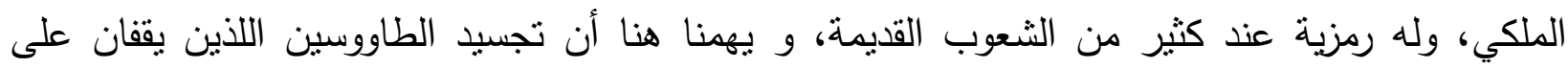

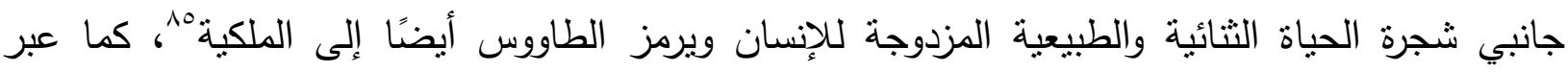

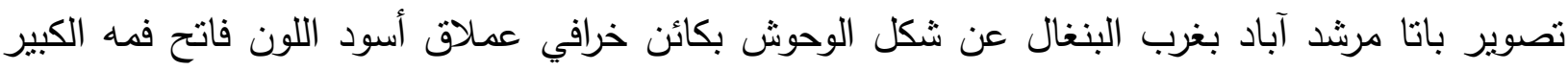

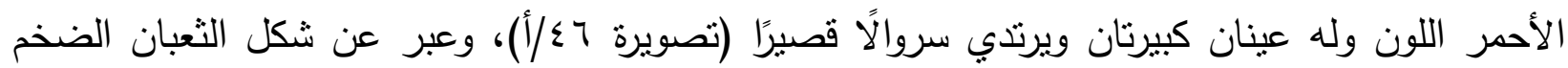

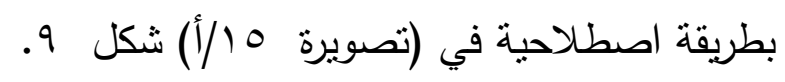

بالإضافة إلى رسم حصان مزين بالوورد وعليه أسلحة من ترس وسيف وقوس وجعبة سهام وهو بذلك

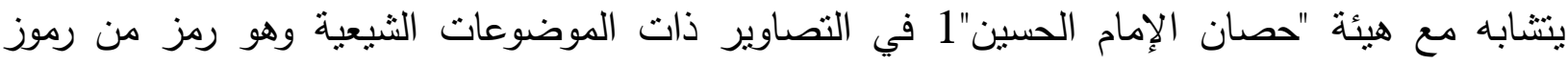
الثيعة أثناء احتفالات الثيعة بذكري كربلاء كرمز للمعركة. وهو بذللك يشير الى أن المصورين الذين قاموا بتصوير هذه اللوحة يعتقون الإسلام على الدذهب الثيعي.

$$
\text { ك دم عبد الحليم، الأوضاع الاقتصادية والاجتماعية، } 109 \text {. }
$$

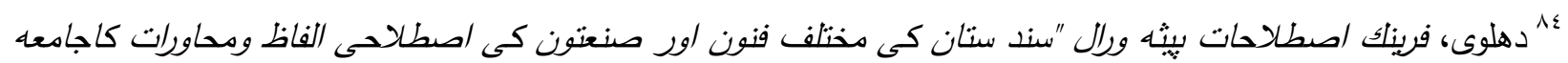

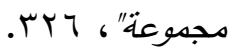
ه^ كوبر ، جي. سى. ، الدوسوعة الدصورة للروز التقليدية، ترجمة مصطفي محمود، القاهرة: المركز القومي للترجمة، 
وجاءت طريقة رسم السماء في كل التصاوير تتشابه مع طريقة رسم السماء في تصاوير المخطوطات

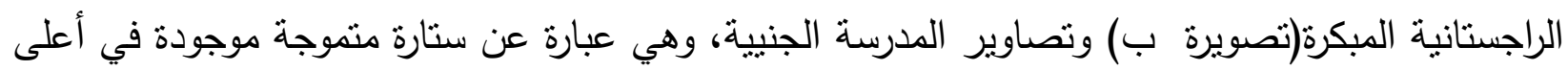

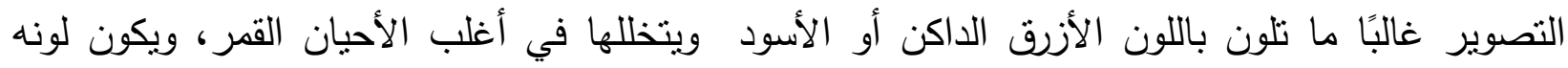

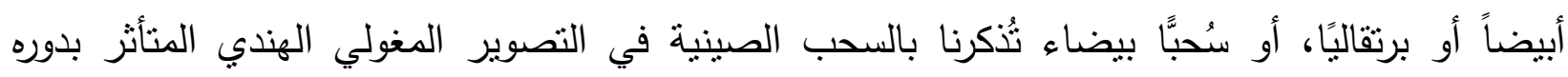

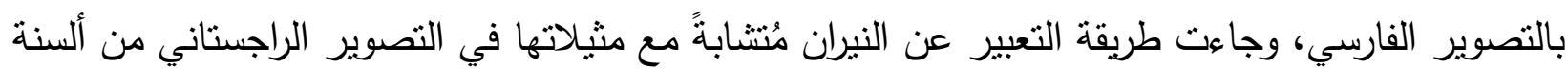

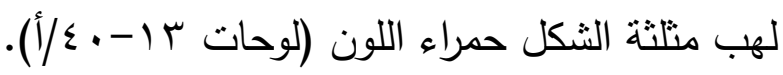

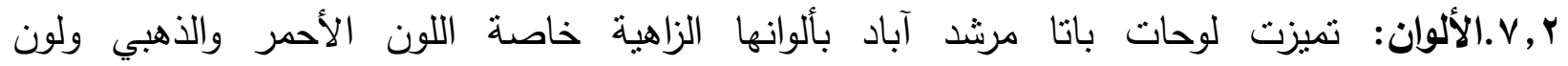

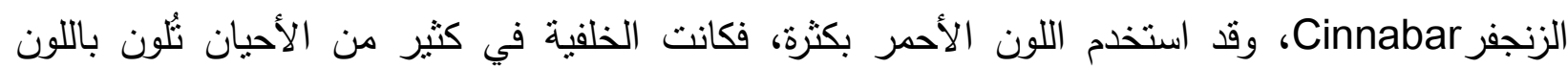
الأحمر وتعرف الخلفية الحمراء في لوحات باتاتثيترا بصفة عامة باسم

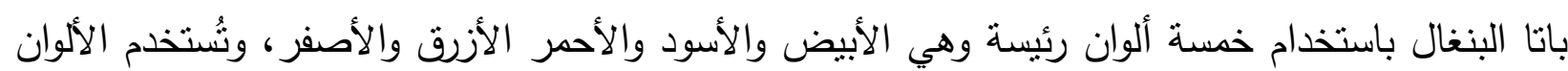

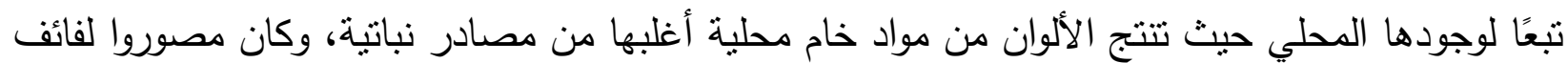

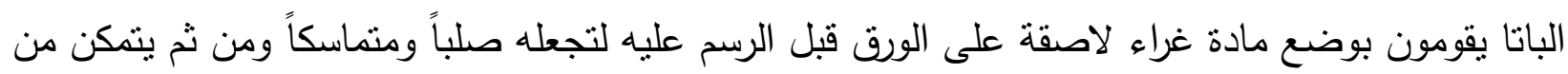

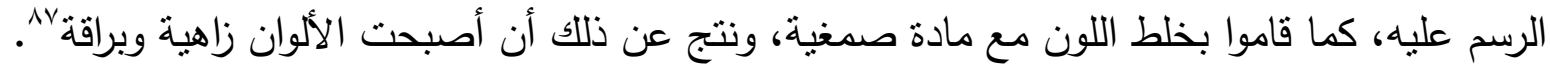

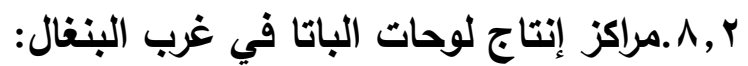

كharatpur - kandi- كان بمدينة مرشد آباد مراكز فنية للتصوير الثنبي "الباتا" مثل قرية jemorkandi-Gokarna -

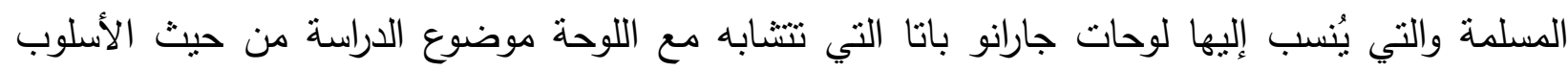

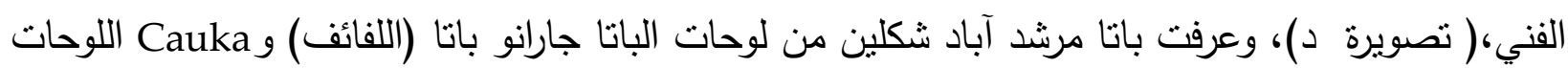

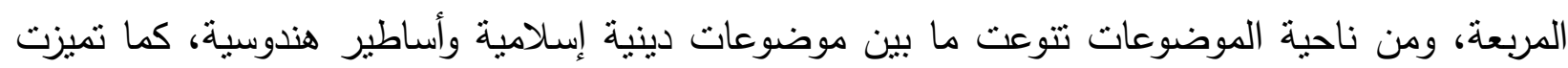

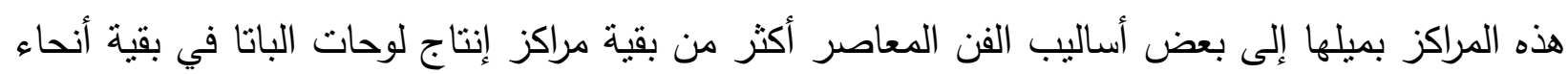

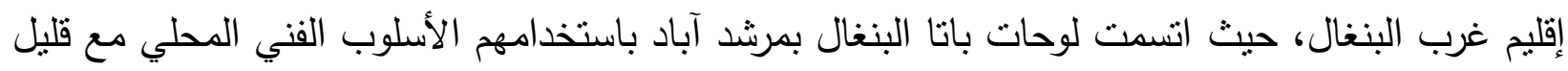

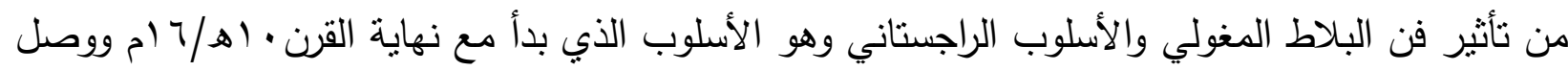

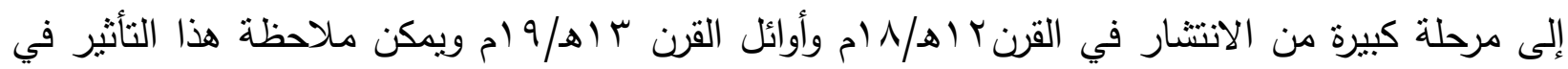
الأزياء وطريقة تصوير طبقة الأثرياء المعاصرين، كما تميزوا بالدقة في رسم العناصر الفنية واستخدام الألوان في إبراز الرسوم الآدمية بتفاصيلها كافة من ملامح الوجوه والملابس والحلي التي يرتدونها، وظهر تميزهم

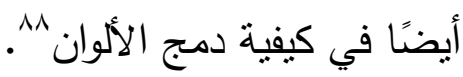

${ }^{86}$ BHATTACHARYA, \& NARAYANASWAMI, Pattachitra, Indian Art in Context,.21.

${ }^{87}$ DAS, Importance of Linearity in Indian art , 109.

${ }^{88}$ DATTA,S., Folk Paintings of Bengal,.105-106. 
الخاتمة والنتائج:

تمنتل هذه الدراسة من الأهمية كونها أول دراسة تناولت فرعًا من التصوير الثعبي بالبنغال المعروف

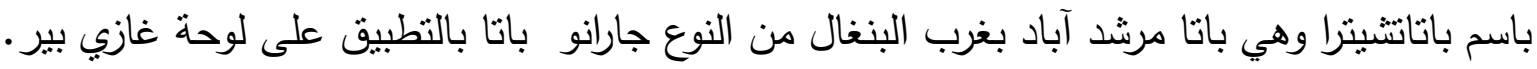
- وضحت اللوحة موضوع الدراسة أهمية رجال الدين الإسلامي من المتصوفة "البير" لدى شعوب مناطق شرق الهند. - - بينت الدراسة أهمية فن التصوير الثعبي في البنغال المعروف بباتا البنغال، كوسيلة اتصال بالجماهير من خلا عرض لفافة مصورة تحتوي على قصة أسطورية أو ملحمية يصاحبها الحكواتي أو الباتو الذي فئي يروي القصة للمشاهدين مع عرض اللوحة.

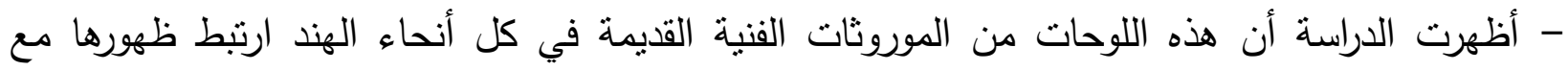

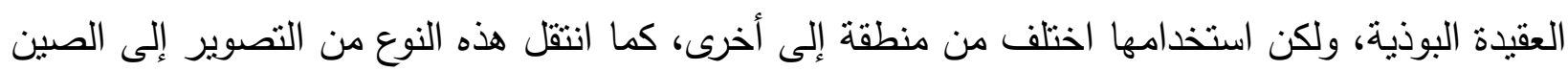

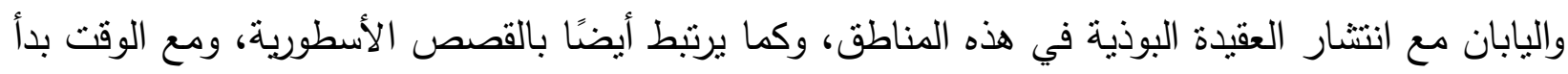

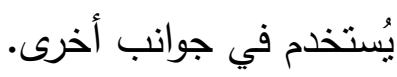

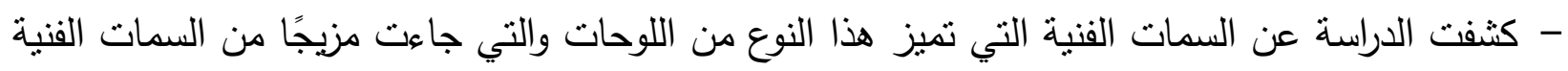

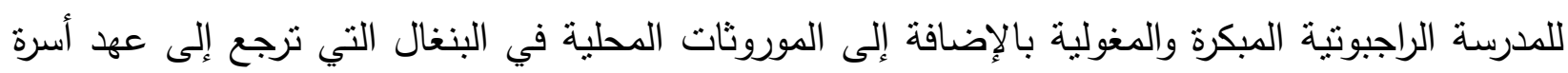

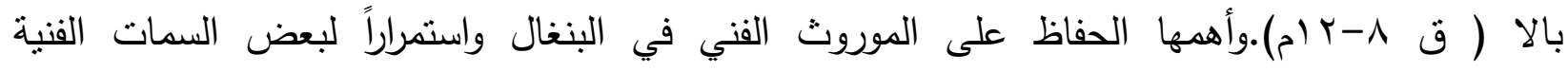
لمخطوطات مدرسة أسرة بالا، مع تأثرها بمدرسة التصوير الراجبواتية المبكرة في كثير من العناصر الفنية.

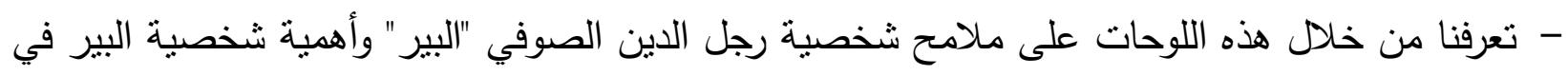

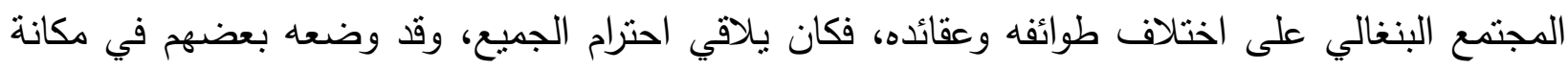
الآلهة الهندوسية لديهم.

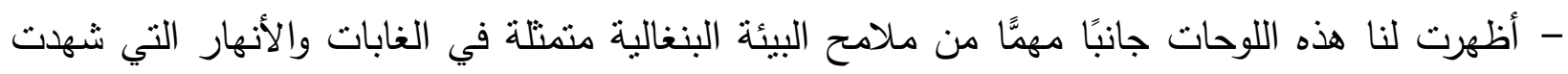

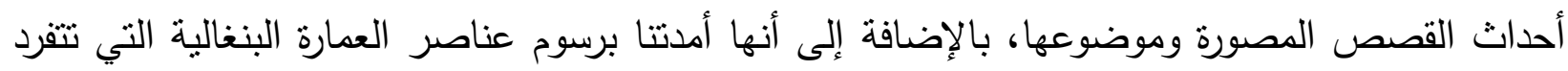

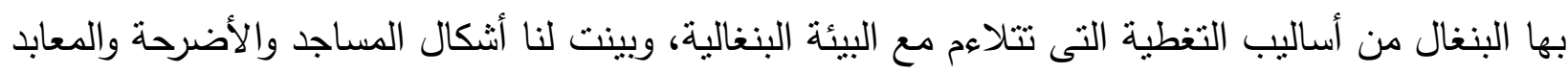
في إقليم البنغال.

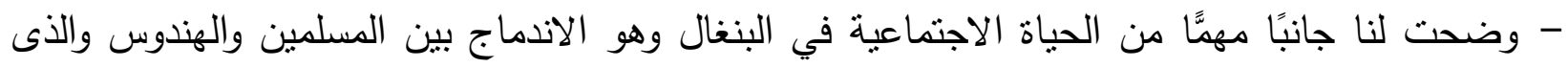
وضحت آثاره في اتفاقهما على الإيمان بمعجزات رجال الدين الإسلاهي من الصوفية وكراماتهم، وزيارات

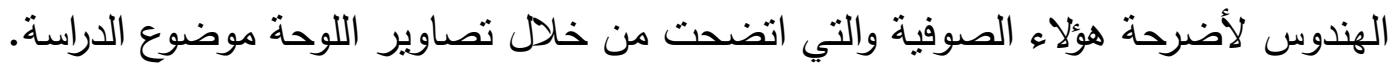
- كثفت لنا هذه اللوحات عن وجود فن تصوير شعبي يتتاسب مع ثقافة الريف المستمع لقصة يشاهدها

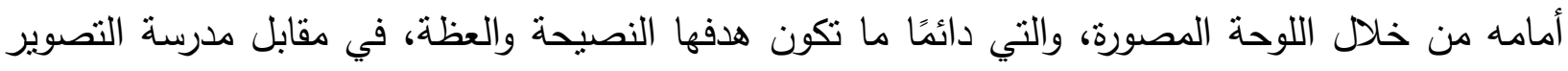
التابعة للبلاط الحاكم والتي كان مقرها العاصمة مرشد آباد وكانت تعد أحد فروع المدرسة المغولية الهندية، 
فكانت مواكبة للنطور الذي حدث لفن التصوير في هذه الفترة على عكس فن التصوير الثنبي المتمثل في

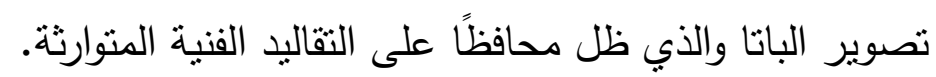

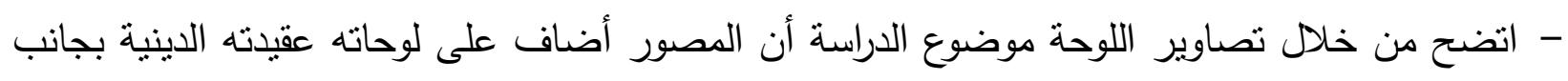
القصة فنجده يضيف تصاوير ليس لها علاقة بموضوع القصة مثل تصويرة تمثل البراق وهو يحمل التعزية لتصنية التي يحملها الثيعة عند احتفالاتهم بذكري كربلاء ونشاهد بداخل التعزية عمامتين تثيران إلى الحسن لتصن والحسين.

- توصي هذه الدراسة بمحاولة دراسة جهود المصورين المسلمين في مدارس التصوير المحلية في أنحاء

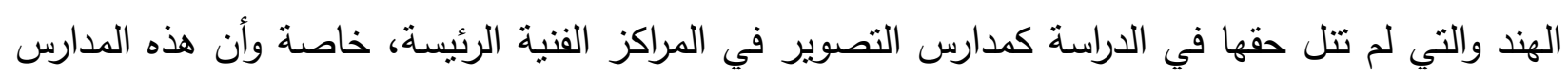

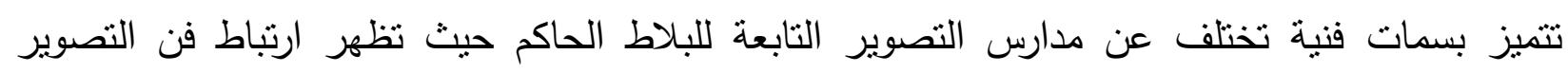
باحتياجات الثخص العادي، وتحمل الكثير من العناصر الفنية التي نظهر ملامح الحياة الاجتماعية والبيئية. 


\section{ثبت المصادر والمراجع}

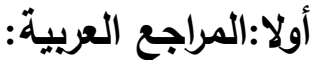

- الثوكي، أحمد السيد،" ملابس وحلى المرأة الهندية من خلال تصاوير المخطوطات المغولية والدكنية"، مجلة رسالة

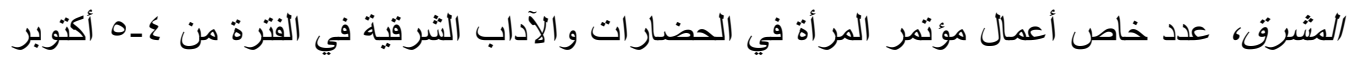

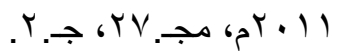

- AL-ŠAWKĪ, AḤMAD AL-SAYID, «Malābis wa ḥuly al-mar'ā al-hindīya min hilāl tașāwīr almaȟtūtāt al-maġūlīya wa'1 -dkunīya», Mağalat risālat al- mašriq 27,№. 2, A special issue of the works of the Women's Conference in Eastern Civilizations and Literatures, from 4-5 October2011.

- بارندر ، جفري ، الدعتقدات الدينية بين الثعوب، ترجمة: إمام عبد الفتاح إمام، مراجعة: عبد الغفار مكاوي، عالم

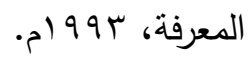

- BĀRINDAR, ĞAFRĪ, al-Mu 'taqadāt al-dīnīya baīn al-šu '̄ūb, Translated by: Imām 'Abd alFattāḥ, Reviewed by: 'Abd al- Gaffār Mikāwī, 'ālam al-m'rifa, 1993.

- دهلوى، ظفر الرحمن صاحب، فرينك اصطلاحات بيثه ورال "سند ستان كى مختلف فنون اور صنعتون كى اصطلاحى

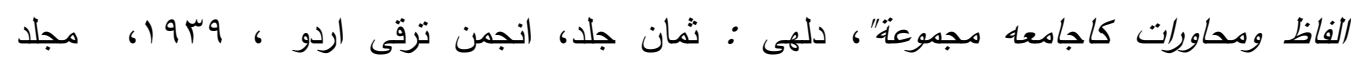

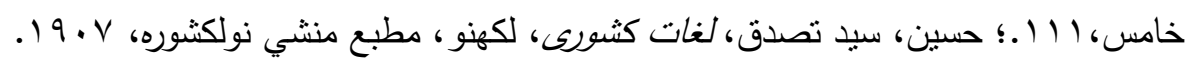

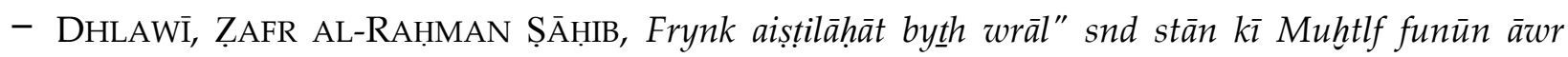
șan 'twn kì 'aștlāḥ̄ al-fāz wa mhāârāt kāğām 'h mağmw'a, dlhī, 8 vol., Army Development Association 1939, vol.5/111 by Ḥusayn, Sayīd tașdq, Vocabulary country, lakhnw: mnšy nwlkšwrh Press,1907

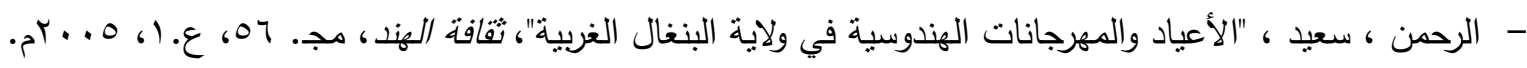

- AL-RAHMAN, SA'īD, “al-A yād wa'l-mahrağānāt al-Hindūsīya fī wilāyat al-Bingāāl algarbīya1", Taqāfat al-Hind,vol.56,2005.

- - الزبون، أحمد محمد عقلة، "آداب الثيخ والمريد الواردة في الرسائل والمؤلفات الصوفية في الفترة الزمنية الممندة من القرن

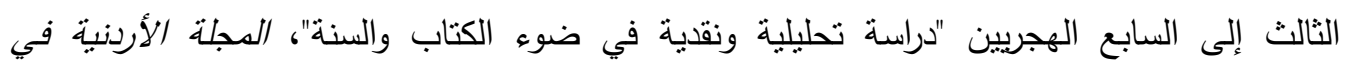

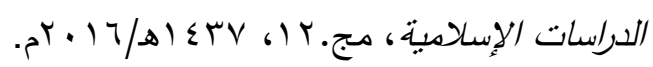

- AL-ZubūN, AḤMAD MuḤAMMAD 'AQLA, «Adāb al-Šaỵh wa'l-marīd al-wārida fī al-rasā'i 1 wa'l -mū' alafāt al-șūfīya fī al-fatra al-zamanīya al-mumtada min $3^{\text {rd }}$ to $7^{\text {th }}$ AD century Dirāsa taḥlīlīya wa naqdīya fī ḍ̣̄' al-kitāb wa'l -sunna», Jordan Journal of Islamic Studies vol.12, 1437 A.H / 2016 A.D.

- عبد الرحيم، عاطف على، "رسوم المذبات في تصاوير المدرسة المغولية الهندية"، مركز الدراسات البردية والنقوش، جامعة

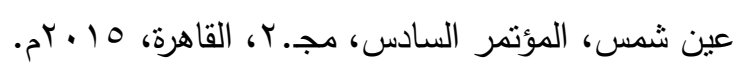

- 'ABD AL-RAṬīM, 'ĀṬif 'ALĪ, « Rusūm al-maḍabāt fī tașāwīr al-madrasa al-Magìlīya alHindīya», Markaz al-dirāst al-bardìya wa'l-nuqūšs, Ain-Shams University, Six ${ }^{\text {th }}$ conference, vol.2, Cairo, 2015.

$$
\text { - عبد الفتاح، سعيد، رسائل صوفية مخطوطة، مج. ا، ط. ا، بيروت: دار الكتب العلمية، ل . rم. }
$$

- 'ABD AL-FATTĀḤ, SA İD, Rasā’il șūfìya mahțūṭa, Vol.1, 1 est ed., Beirut: Dār al-kutub al-'ilmīya, 2007. 


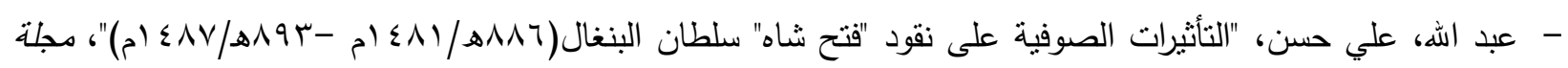

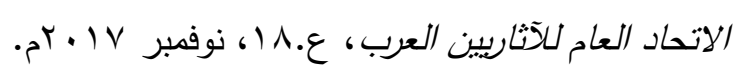

- 'ABDUllaH, 'Alī ḤASAN, «al-Ta'tịrāt al-ṣūfīya 'alā nuqūd" Fatḥ šāh" Sultān al-Binḡāl (886 1481 A.H / 8931487 A.D)», Mağalat al-itiḥād al- 'ām li'l-atāàryìn al-'arab 18, November 2017.

- قبيصي، سارة محمد ، "صورة المجتمع الهندى في شعر نظير أكبر آبادى مع ترجمة مختارات"، سالة ماجستبر، قصم

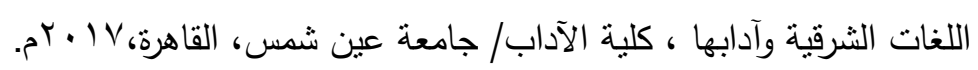

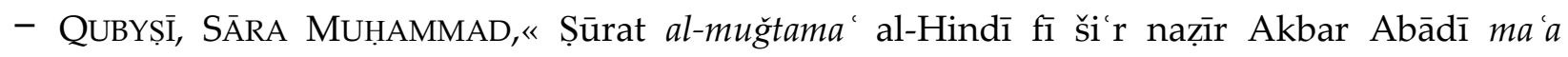
tarğamat muhtāāāt», Master Thesis, Department of Oriental Languages and Literature, Faculty of Arts/Ain Shams University, Cairo , 2017.

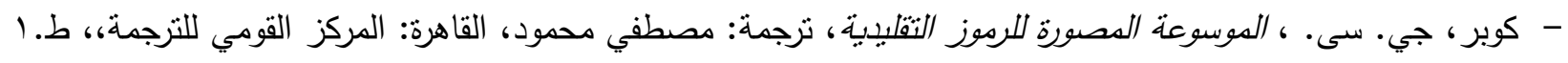
$\cdot{ }^{2}+1 \leqslant 6$

- COOPER, G. C., al-Mawsū̄a al-muṣawara li'-rumūz al-tqlīdìya, Translated by: Muștafā Maḥamūd, Cairo: National Center for Translation, 1 1est ed., 2014.

- الثيخة، ماجدة على ،" تصاوير المعارك الحربية للجيش المغولى الهندى من خلال المخطوطات والتحف التطبيقية"، رسالة

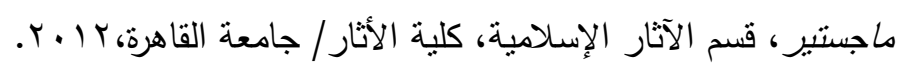

- AL-ŠAYḥA, MĀĞIDA 'ALĪ , «Tsāwīr al-m ārik al-ḥarbīya li’l-ğaȳ̌š al-Maḡūlī al-Hindī min hilāl al-mahtūtāt wa'l-tuhạ al-tațbīqìya», Master Thesis, Department of Islamic Archeology, Faculty of Archeology/ Cairo University, 2012.

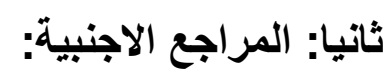

- AbudAyA,M.Ch., and others:«Sayyid Yusuf's 1433 Pilgrimage Scroll (Ziyaratnama) in The Collection of the Museum of Islamic Art Doha», Muqarnas, vol.33,2016.

- .Acharya,P.K., Sacred Complex of Budhi Santani ,New Delhi: Concept Publishing Company, 2003.

- AhMED,S.I.: «Performing and Supplicating Manik Pir: Infrapolitics in the Domain of Popular Islam»,TDR The Drama Review, vol.53, №.2,2009.

- Atsushi, I.: «Profiled Figures: The Modes of Representation of Faces in South Asian Painting», Kyoto Bulletin of Islamic Area Studies , 10(March2017).

- BAJPAI ,L.M.: «Intangible Heritage Transformation - Patachitra of Bengal Exploring Modern New Media», International Journal of History and Cultural Studies, IJHCS1, №. 1,June 2015.

- BANU ,U., Pattcitra of Bengal ; An Emotion of Community, Strangi Bengal Patachitra, New Delhi , 2018.

- BANU, R. SH:. "Acritical Study of The Progressive art movement in Bengal», PhD of Philosophy in Fine Arts, Department of Fine Arts Aligarh,2018.

- Bhattacharya,S. AND Narayanaswami,M., Pattachitra: Indian Art in Context,New Delhi, Indian Studies , 2017.

- Britschgi , J. \& GUY, J., Wonder of the Age : Master Painters of India, 1100-1900 „New York: Metropolitan Museum of Art, 2011. 
- DAS, N.: «Importance of Linearity in indian art with special reference to Eastern Indian folk paintings», Doctor of Philosophy, Department of arts, Assam University,2014.

- Dasgupta,G. Buddhism During the Pala Period», PhD of Philosophy, Department of Fine Arts, Calcutta University,1976.

- DATTA ,S.: « Folk Painting of Bengal»PhD of Pholosophy, Department of ancient indian History and Culture University of Calcutta,1982.

- DehejIA, V.: «On Mode of Visual Narration in Early Buddhist Art», The Art Bulletin, vol.72, №.3, Sep.1990., 377.

- DiNESCHANDRA,S. , Folk Literature of Bengal, Being Lectures Delivered to the Calcutta in 1917 as Ramtanu Lahiri Research Fellow in the History of Bengali Language and Literature, Gyan Publishing House, 2006.

- GHosh,I.: « Murshidabad's Darbari Culture and the Incipient Nawabi of Bengal c.A.D. 17041740»,Urbanisation in India: Past and Present: Professor Nisith Ranjan Ray Birth Centenary Volume, Edited by Chittabrata Palit, Institute of Historical Studies,2009.

- GuHA,S. AND BAndyOPADHYAy,A.: «Terracotta Temples of Bengal : A Culmination of Preexisting Architectural Styles», The Chitrolekha Journal on Art and Design, vol.1, №.1, 2017.

- GUPTA, S.D.: «Village of Painters: A Visit to Naya, Pingla», Chitrolekha International Magazine on Art and Design, vol. 1, №.3,2011.

- GuPTA,S . D.: «Village to Naya, Pingla, Traditional Art», Chitrolekha International Magazine on Art and Design, vol.1, №.3,2011.

- HAuser,B.: «From Oral Tradition to "Folk Art": Reevaluating Bengali Scroll Paintings», Asian Folklore Studies, vol.61, №.1,2002.

- HITESRANJAN SANYAL:«Religious architecture in Bengal(15 ${ }^{\text {th }}-17^{\text {th }}$ Century): A Study of the Major Trends», Proceedings of the Indian History Congress, vol.32, №.1,1970.

- IsLAM ,I \& NOBLE, A.G.: « Mosque Architecture in Bangladesh : The Archetype and Its Changing Morphology», Journal of Cultural Geography,vol.17,№.1,1998.

- JAIN, J.: «The Art of Indian Picture Showmen : Tradition and Transformation", Storyelling and Puppet traditions of India, Dhurjjati Sarma, New Delhi: Indira Gandhi National Centre For the Arts,2010.

- JANA, TH.: «Educational Marginality : A Crisis Among the Patuas at Naya, West Bengal», Chitrolekha International Magzine on Art and Design, vol.6, №.2,2016.

- JefFerson, P.: «The Art of Survival Bengali Pats Patuas and Evdution of Folk Art in India» , Independent Study Project (ISP) Collection1815,2014.

- KOlay, S. AND ROY, SH. Th, Designing alternative Paradigm for Traditional Visual Storytelling, ICORD'15, Indian Institute of Science, Bangalore, 7-8 January,2015.

- LOSTY, J.P.: «An Album from Bengal 1795-1810’ in F. Galloway, Imperial Past: India 16001800», Francesca Galloway sale catalogue, London, 2011. 
- LOSTY, J.P.: «Early Views of Gaur and Pandua by the Indian Artist Sita Ram», Journal of Bengal Art, v.1, 1996.

- Losty, J.P., 'Towards a New Naturalism: Portraiture in Murshidabad and Avadh 1750-80', in After the Great Mughals: Painting in Delhi and the Regional Courts in the 18th and 19th Centuries, Bombay: ed. B. Schmitz, 2002.

- Majumdar, S.N.: «Bengal Pata Chitra: Painting, Narrating and Siging with Twists and Turns», Strangi Bengal Patachitra, New Delhi, 2018.

- MAJUMDER ,R.: «Disappearing Traditions, The Narrative Songs of Bengal Pata Painting» , Kalakalpa-IGNCA Journal of Arts, vol.IV, №. 2, 2020.

- MANDAL, R., «Historical Ornamentation of Chinese Scroll Painting and Bengal Pata Painting», The Chitrolekha Journal on Art and Design, vol.2, №.3,2018.

- Michell, G., The Islamic Heritage of Bengal , Paris: United Nations Educational , Unesco,1984.

-Mitra ,A.: District handbooks Murshidabad ,Calcutta: Sree Saraswaty press,1953.

- NOORUR RAHMAN,SH., «Pir Cult Evidence of Hindu-Muslim Amity in Mughal Bengal», Proceedings of the Indian History Congress, Golden Jubilee Session, vol.50, 1989.

- PALIT ,S. \& DATTA, D.B.: «Transformation from Performativeaer to Demonstrative Art: A Survival Strategy for Patachitra», Asian Journal of Multidisciplinary Studies, vol.4, №.2, 2016.

- RoY,A. CH., history of Bengal: Mughal period, Calcutta: Nabharat publishers, 1968.

- Rudgley,R. The Encyclopedia of Psychoactive Substances, New York: Great Britain - Brown and Company, 1999.

- Schendel, W.V., The Bengal Borderland: Beyond State and Nation in South Asia, Delhi: Anthem South Asian Studies, 2004.

- Sen ,B.: «Betwixt Hindusand Muslims», Asian Ethnology, vol.76, №.2, 2017.

- SouMIK N. M.: «Bengal Pata Chitra: Painting, Narrating and Siging with Twists and Turns», Satrangi Bengal Patachitra, Ojas Art, New Delhi, 2018.

- STEWART, T.K.: «The Tales of Manik Pir-Protector of cows in Bengal, Tales of God's Friends», Islamic Hagiography in Translation, ed. John Renard, Berkeley: University of California Press,2009.

- TRIPTHY, M.:«Folk art at the crossroads of tradition and modernity: A study of Patta Painting in Orissa», Journal of the Anthropological Society of Oxford 29, №.3, 1998.

ثالثاً: المواقع الاكترونية:

- https://www.britishmuseum.org/collection/object/A_1955-1008-0-95(Accessed 12/9/2020)

- https://www.metmuseum.org/art/collection/search/74909(Accessed 21/12/2020) 

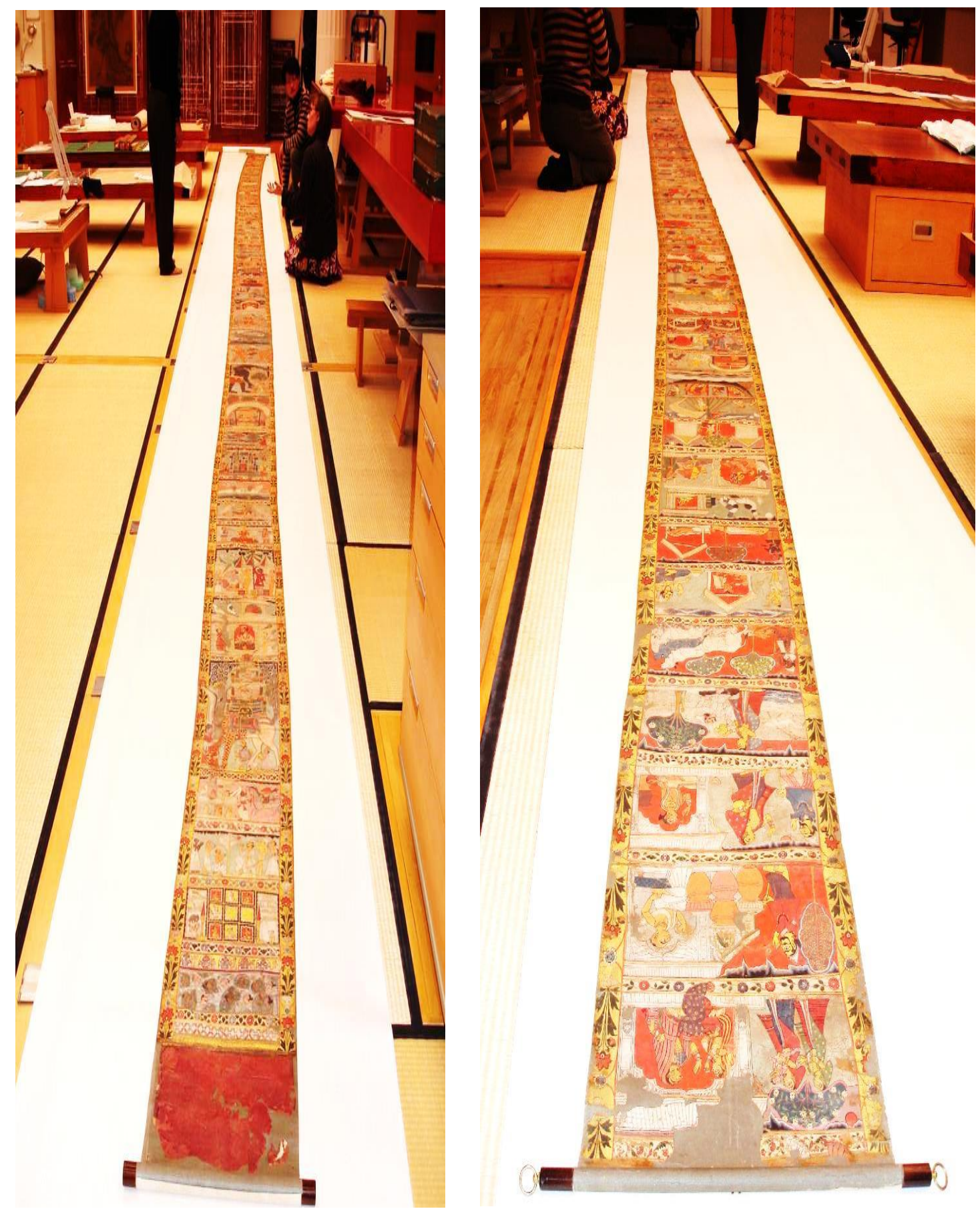

تصويرة أ لفافة مصورة “جورانو بانا” تمنل قصة الصوفي غازي بير - ترجع الى مدينة مرشد اباد بغرب البنغال - محفوظة فى المتحف البريطاني بلندن رقم الحفظ: 1955,1008,0.95 رابط الموقع: https://www.britishmuseum.org/collection/object/A_1955-1008-0-95 


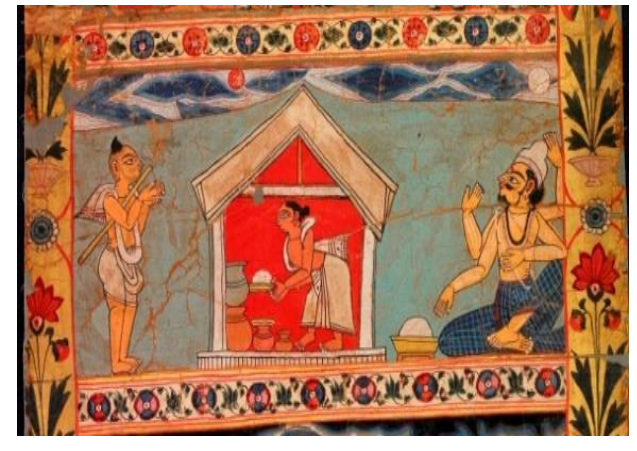

تصويرة 1 أ

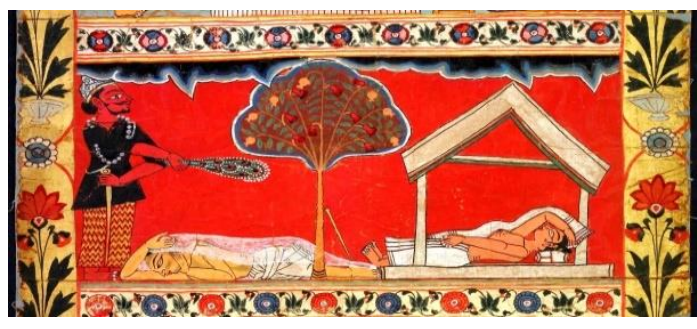

تصويرة V/

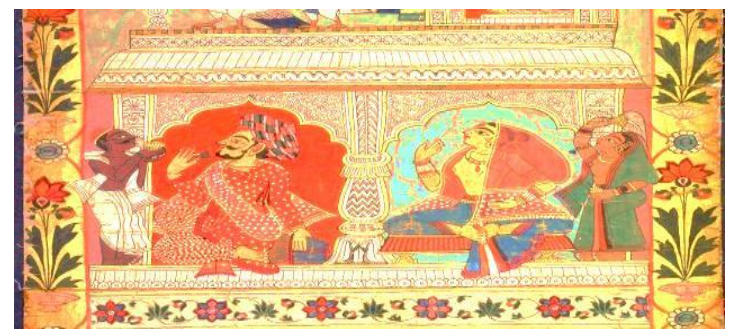

تصويرة Aأ

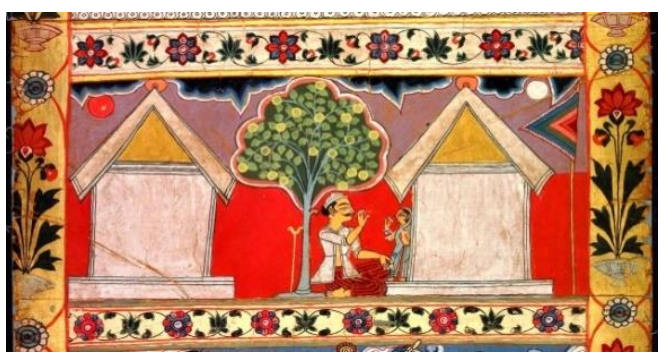

تصويرة 9 أ

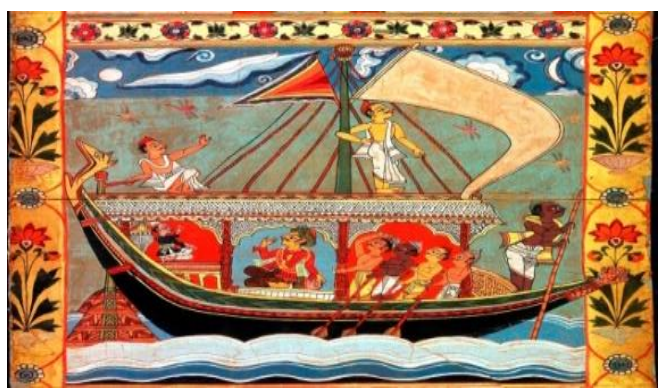

تصويرة · ل

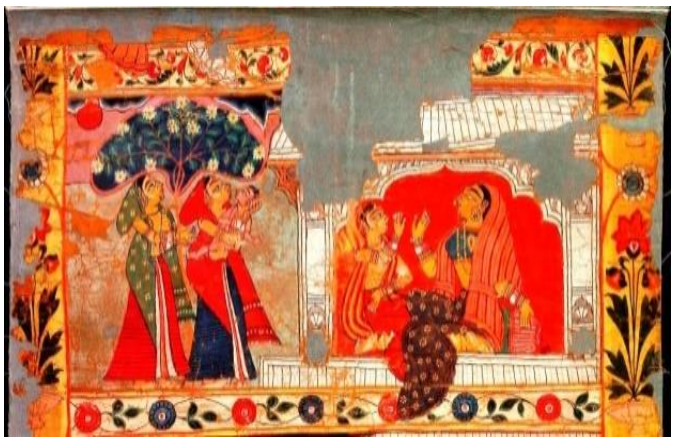

تصويرة 1/أ

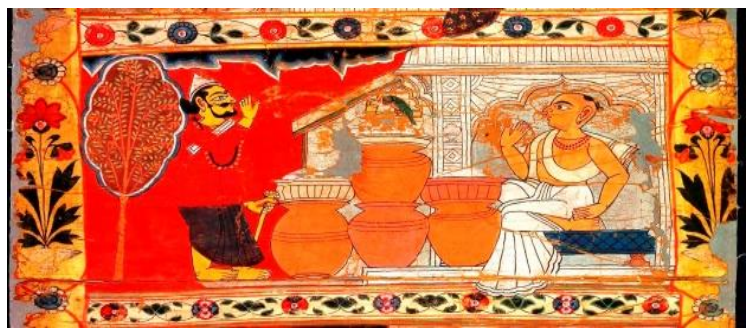

تصويرة بأ

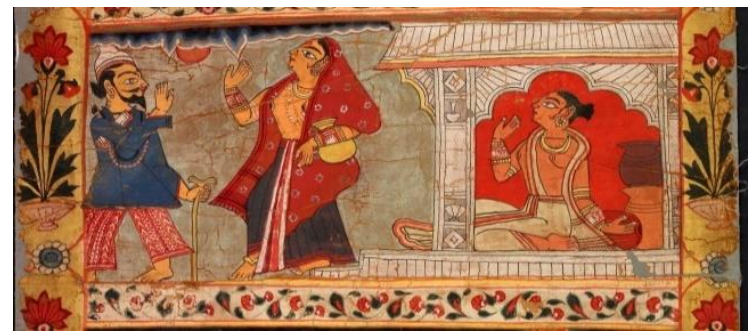

تصويرة م/أ

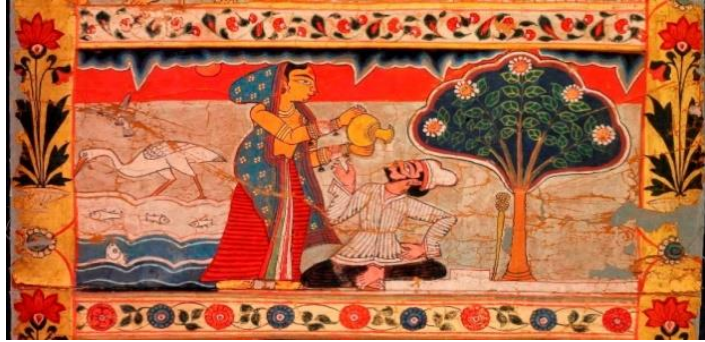

تصويرة عأ

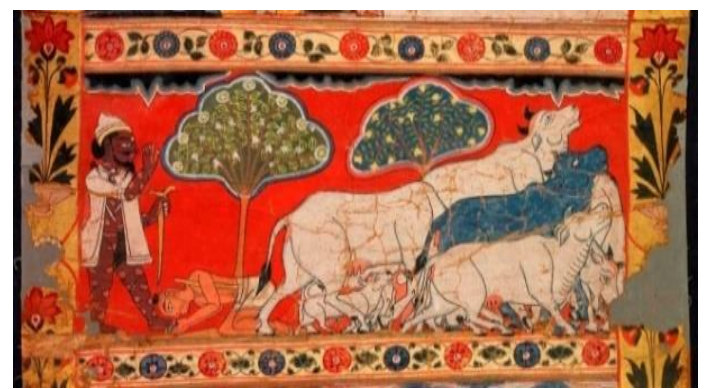

تصويرة أ 


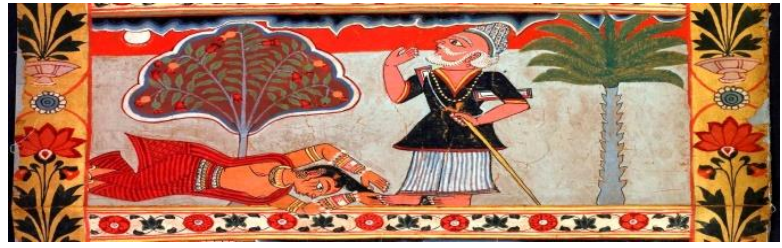

تصويرة 1/19

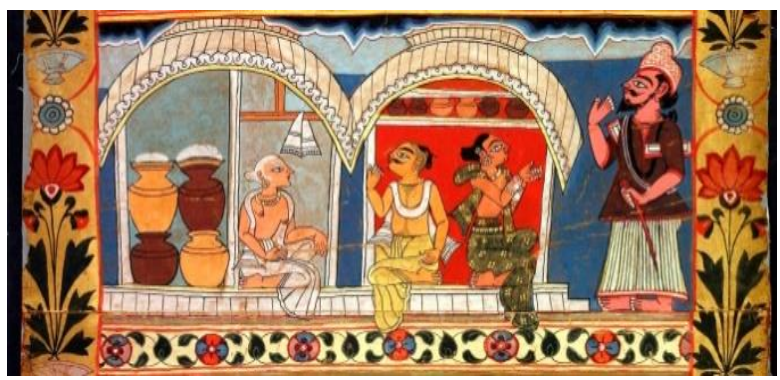

تصويرة VV

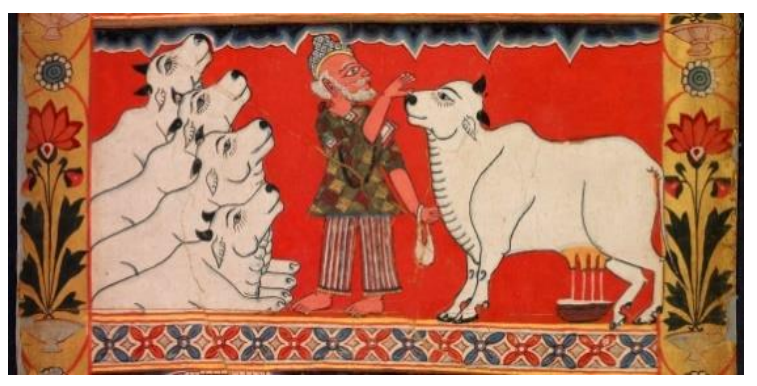

تصويرة 1/1أ

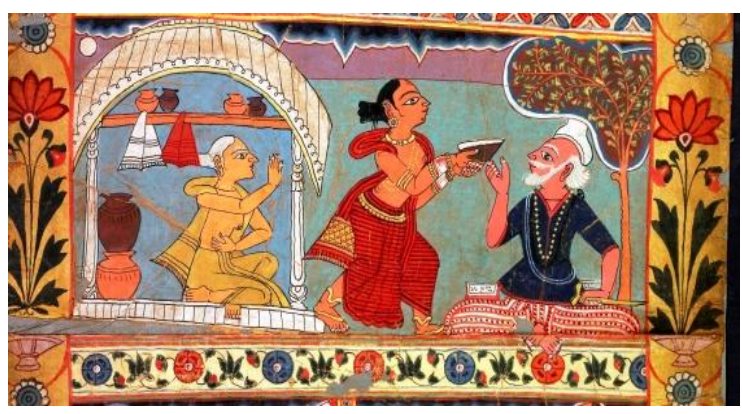

تصويرة 9

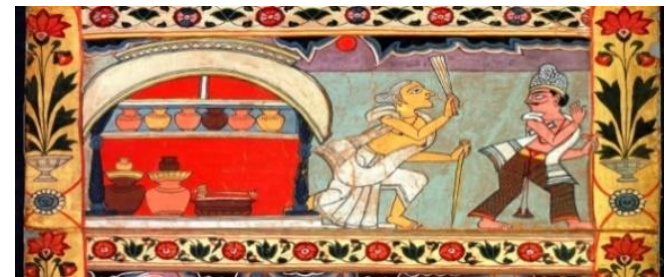

تصويرة 11/1

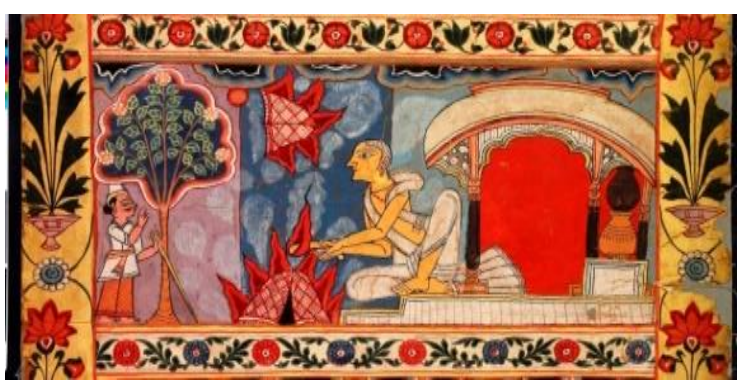

تصويرة r/أ

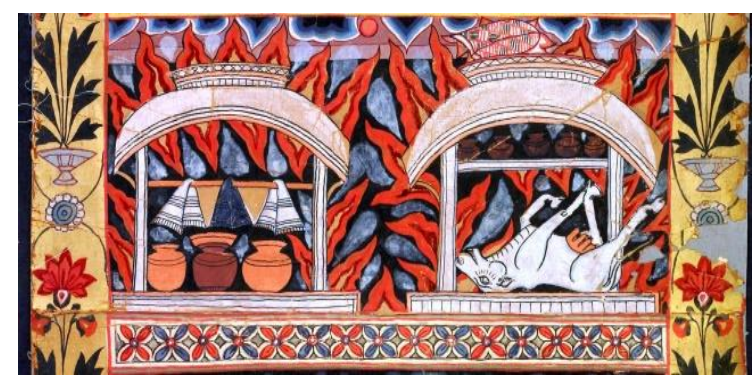

تصويرة rأ

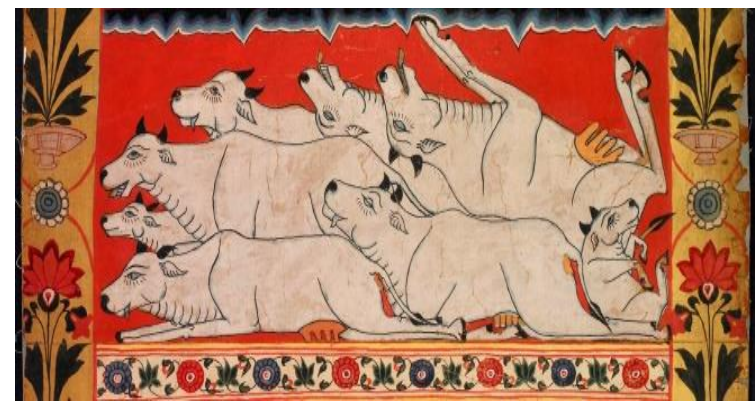

تصويرة عا/I 


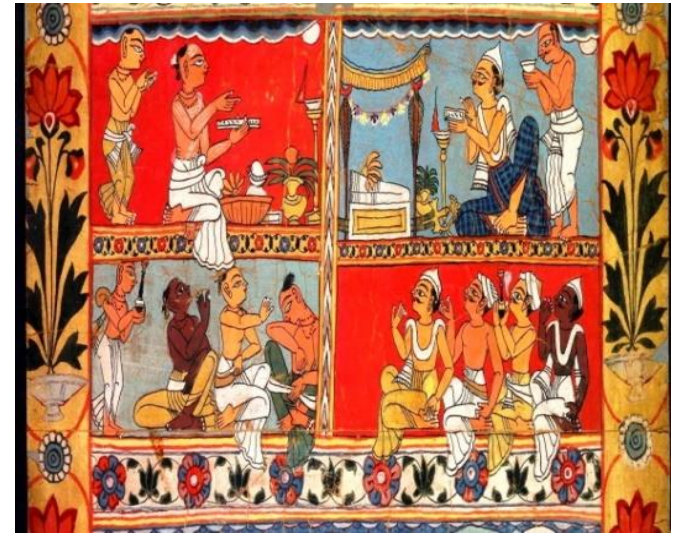

تصويرة ·r/أ

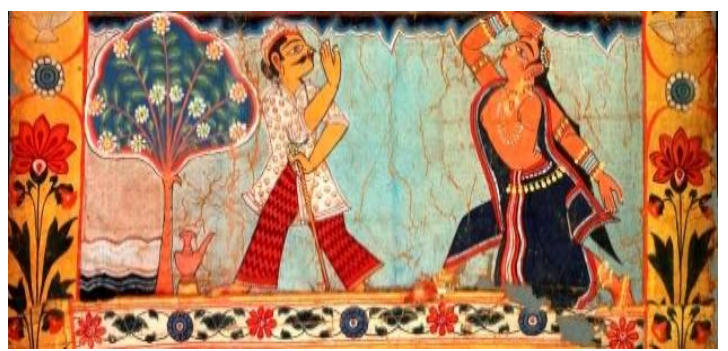

تصويرة بr/أ

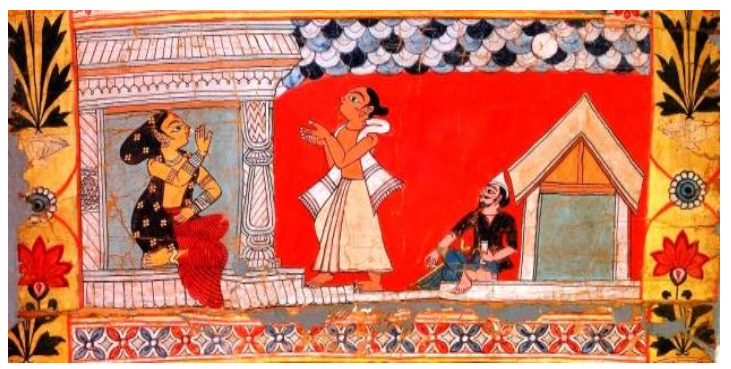

$$
\text { تصويرة }
$$

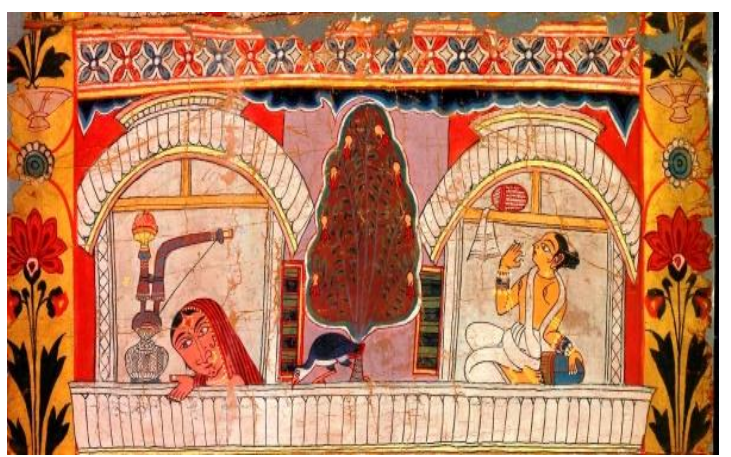

$$
\text { تصويرة 1/K^ }
$$

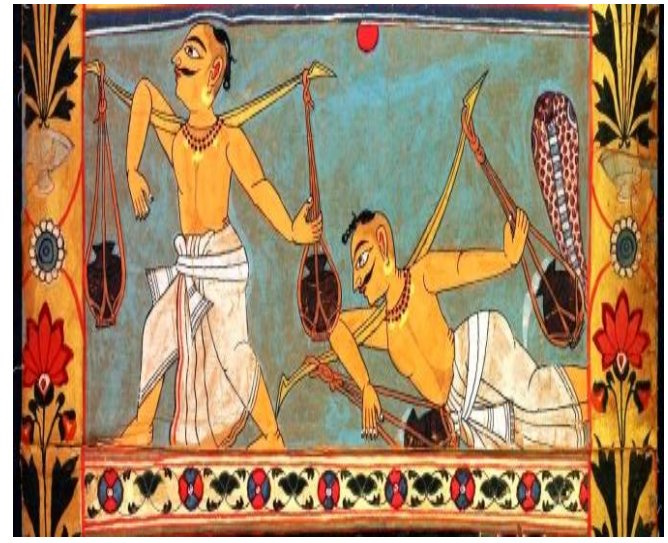

تصويرة 1/10

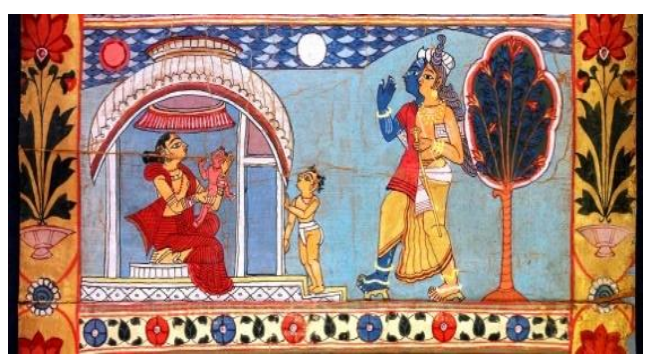

تصويرة 1/

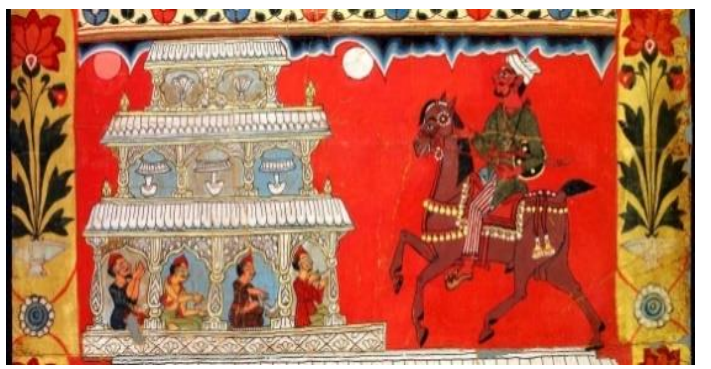

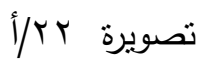

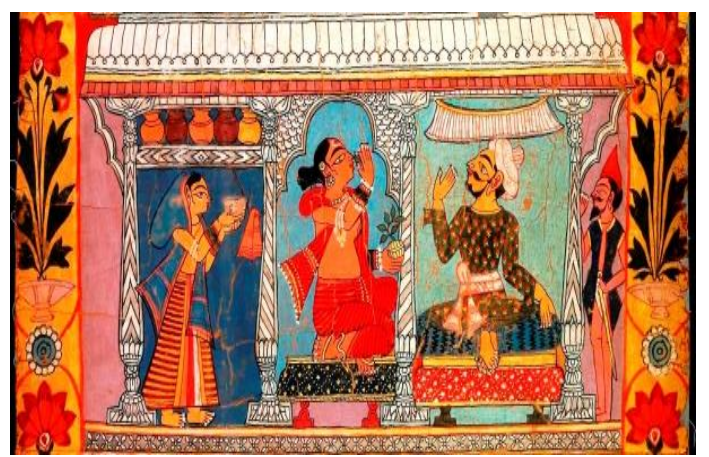

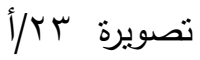




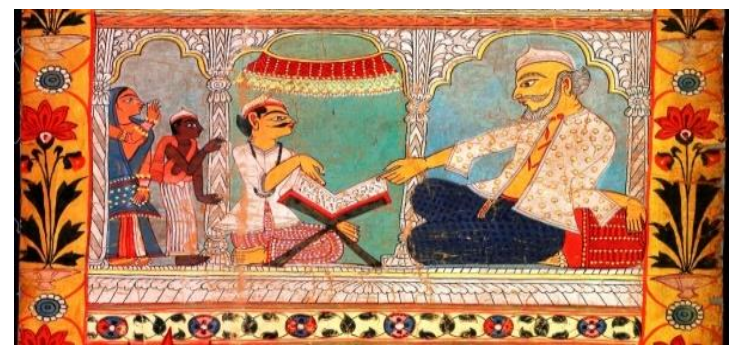
تصويرة و 9 أ

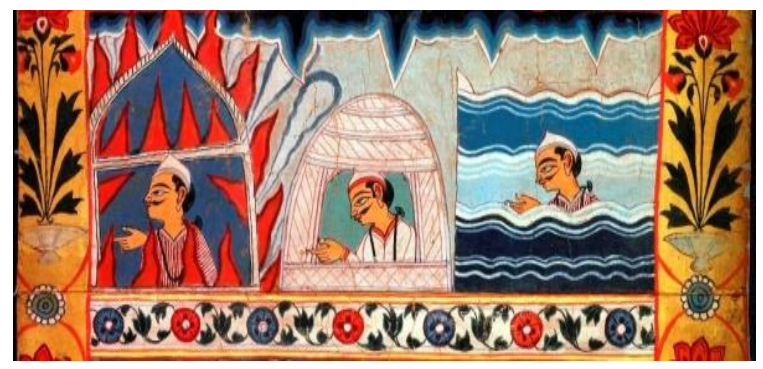

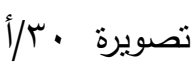

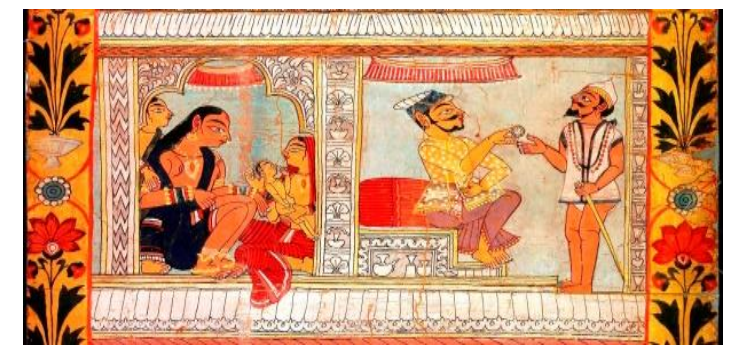

تصويرة ع

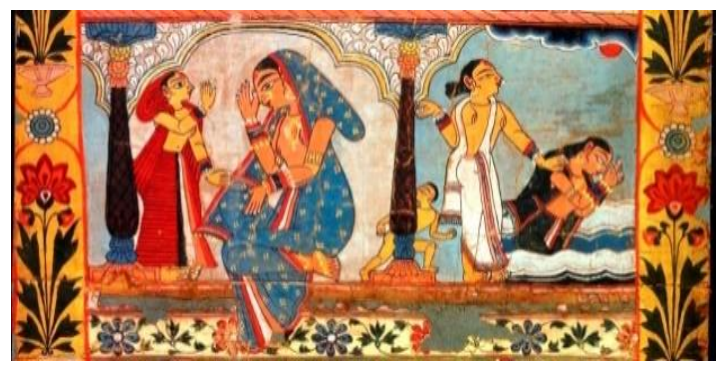

تصويرة

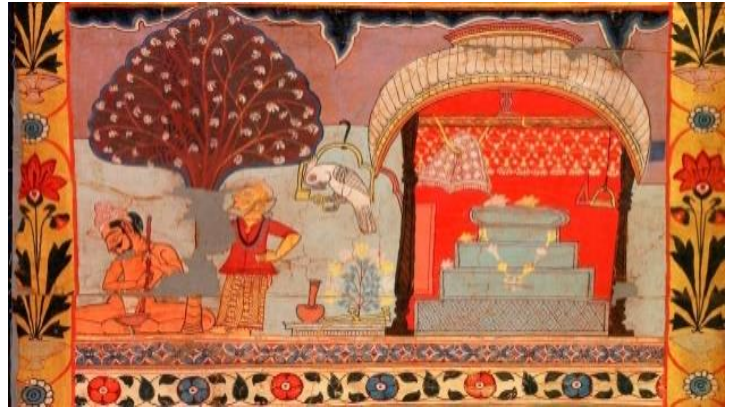

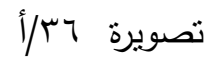

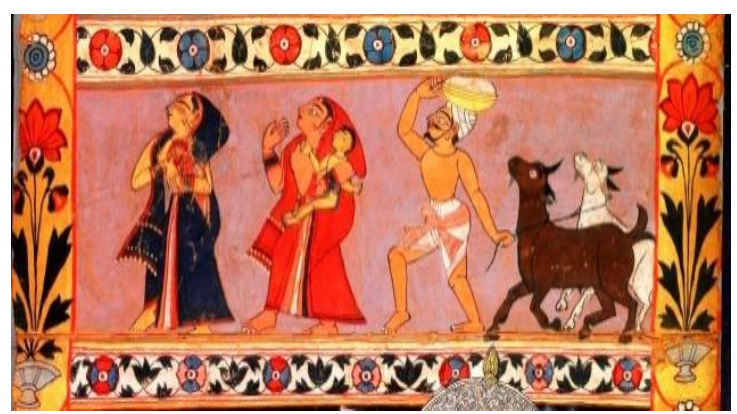

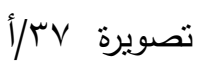

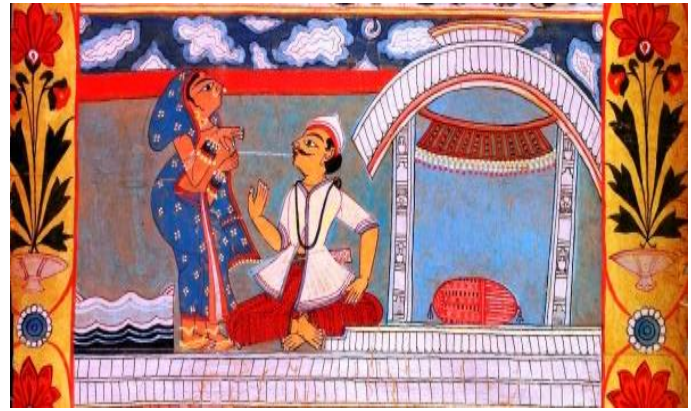

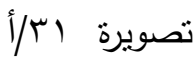

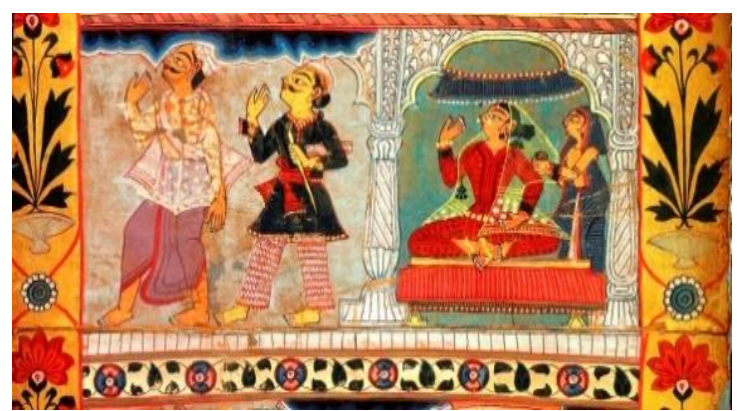

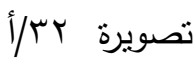




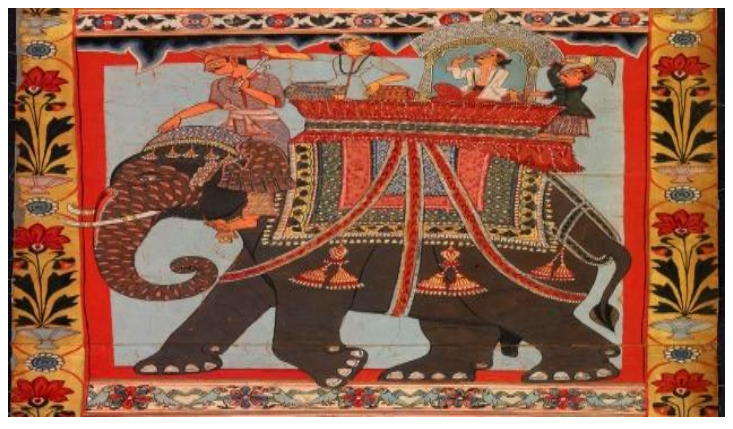

تصويرة مب/أ

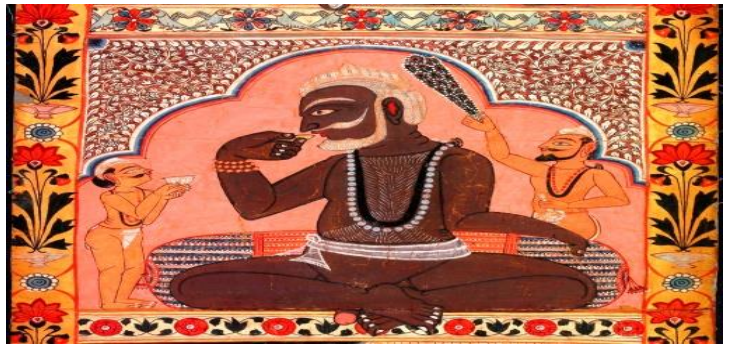

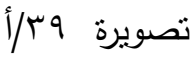

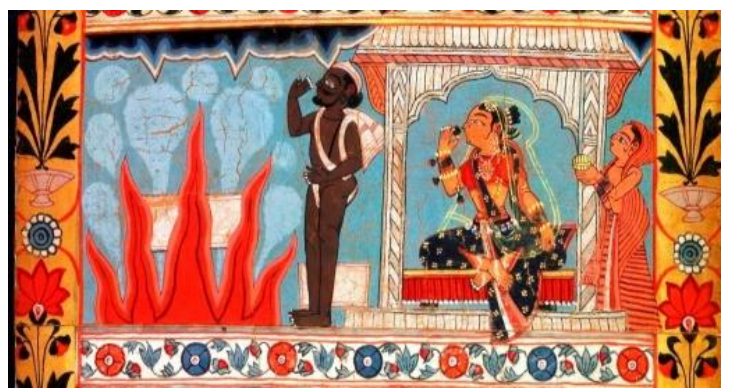

أنصويرة

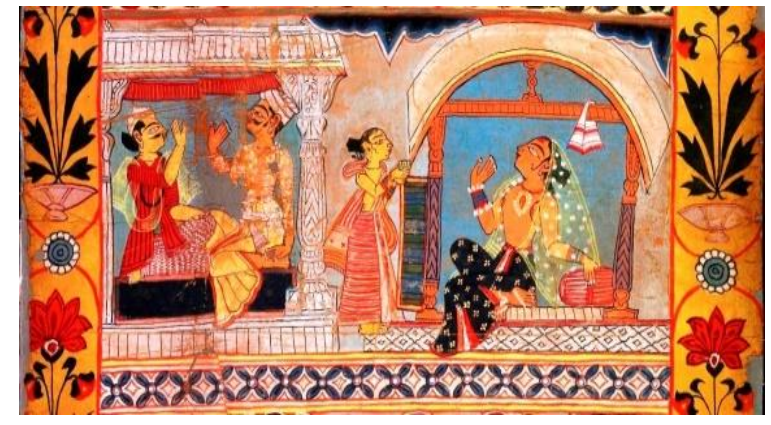

تصويرة سم/أ

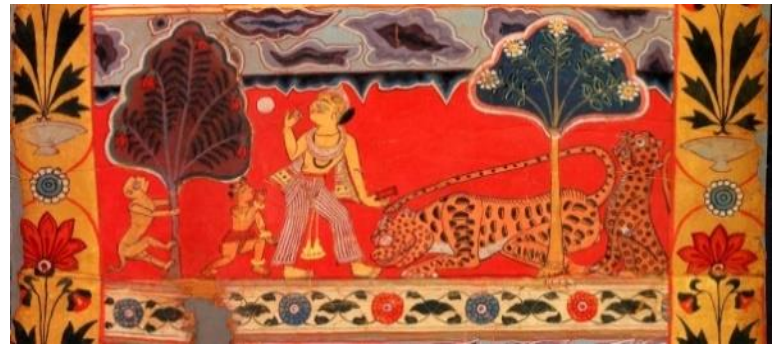

تصويرة ع أ

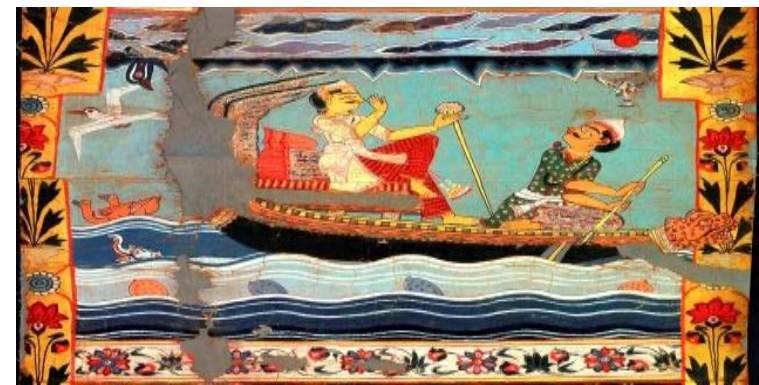

تصويرة هr/أ

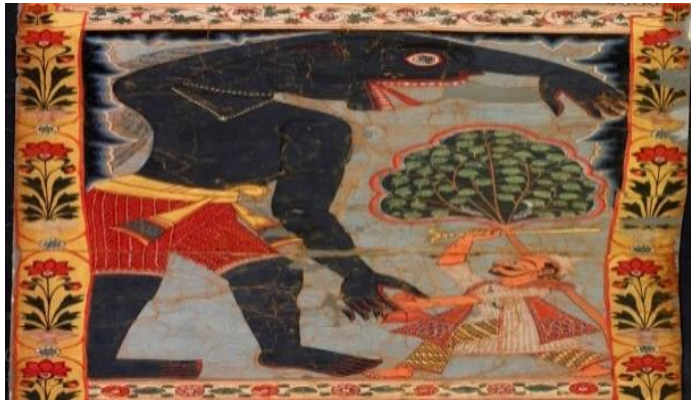

تصويرة

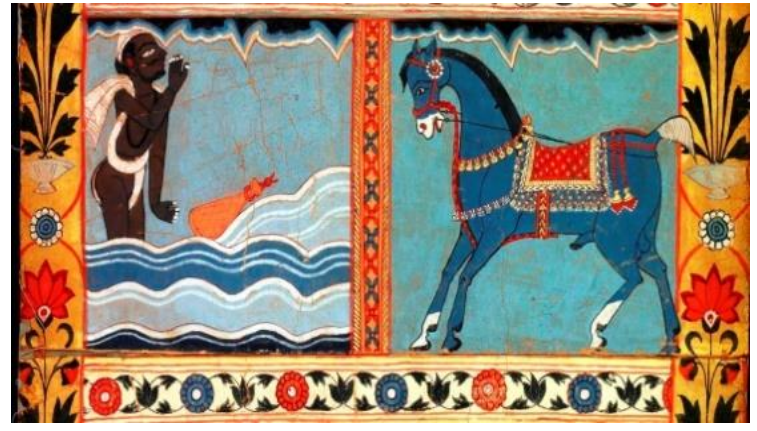

تصويرة 1ـ/أ 


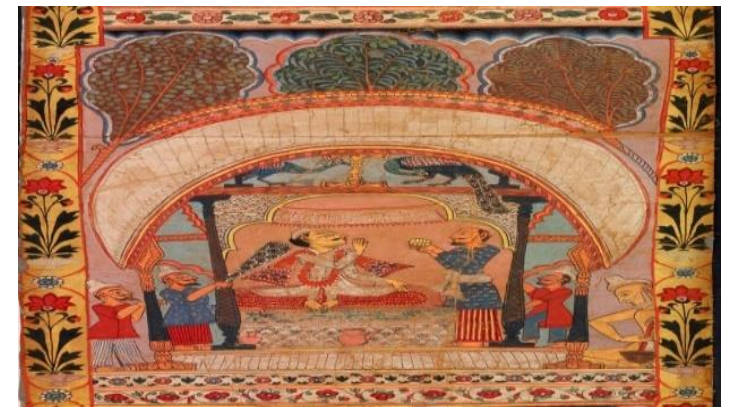

ISV تصويرة

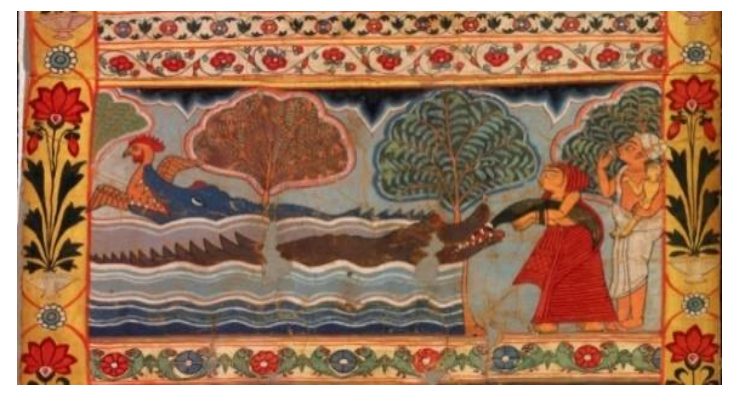

تصويرة

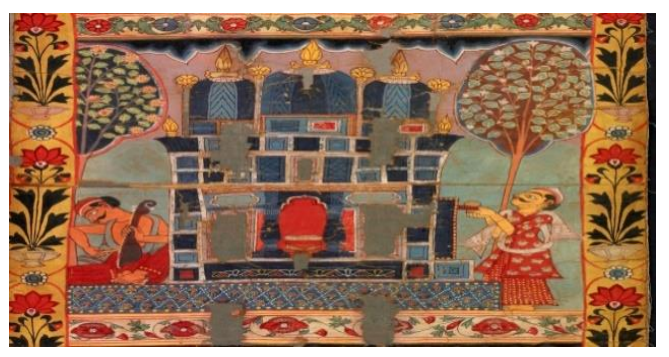

تصويرة 9 \&

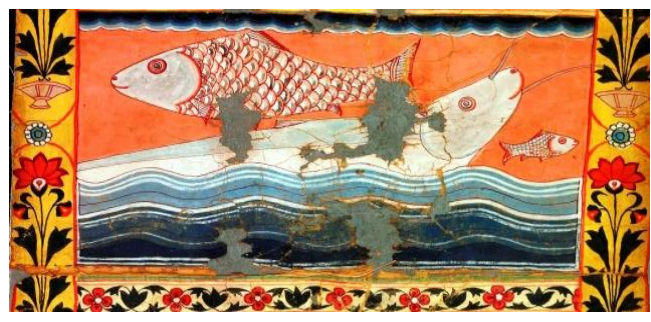

تصويرة .0.

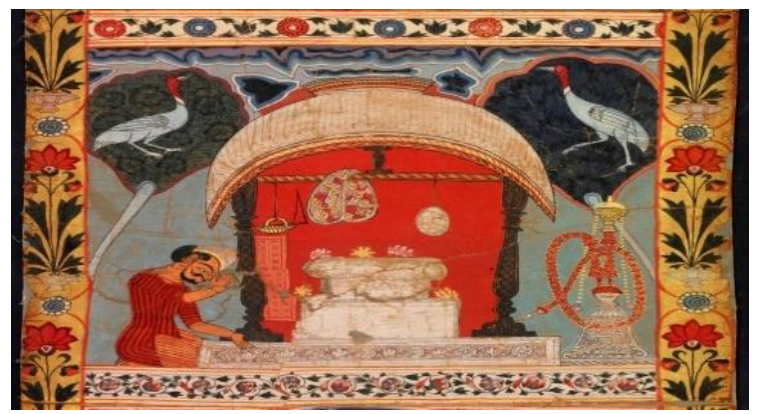

تصويرة

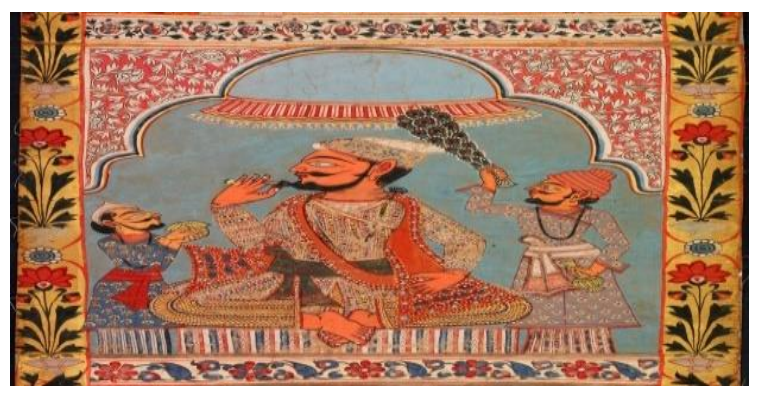

تصويرة rأ

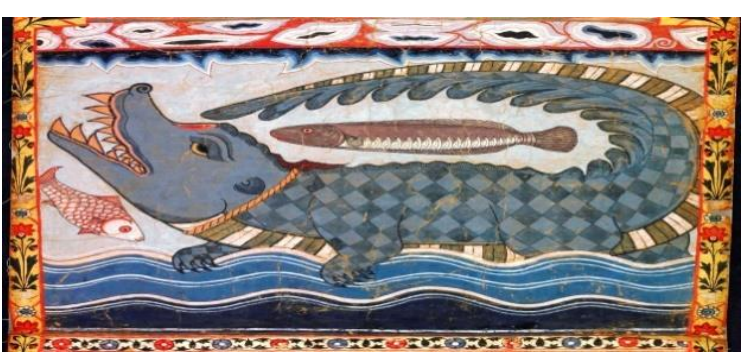

تصويرة ع ع|أ

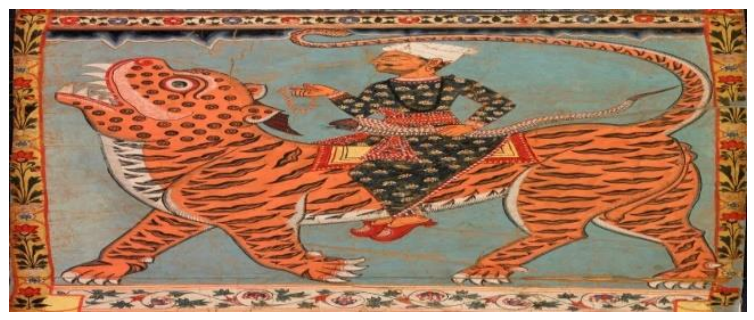

تصويرة 


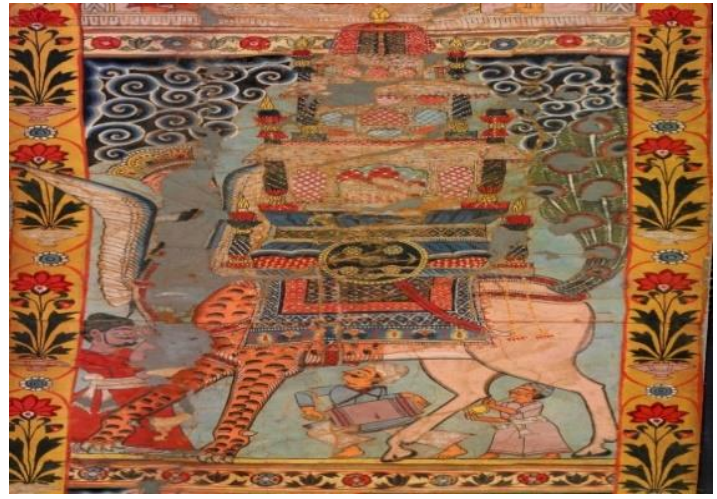

تصويرة ع 1/0

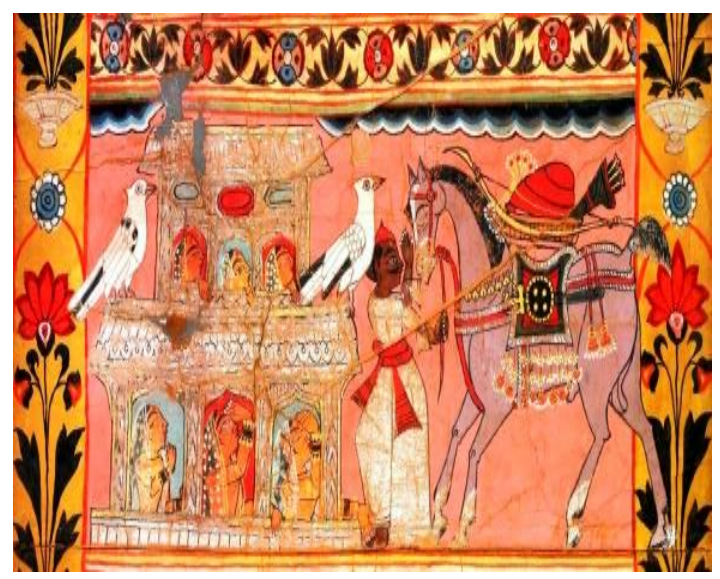

تصويرة 1/00

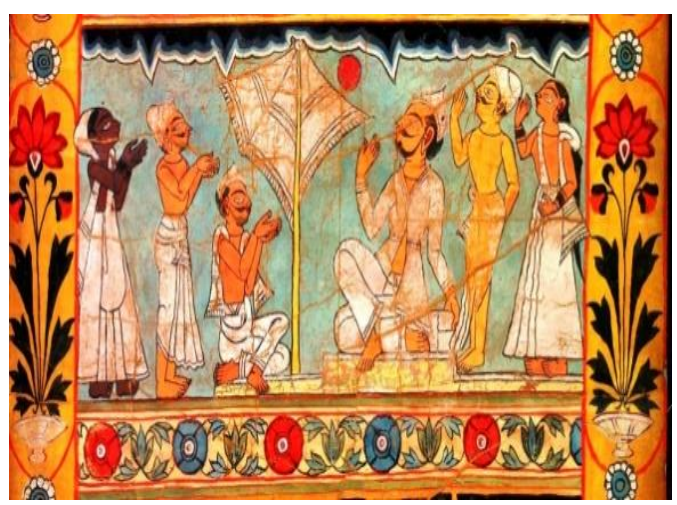

تصويرة 1/04

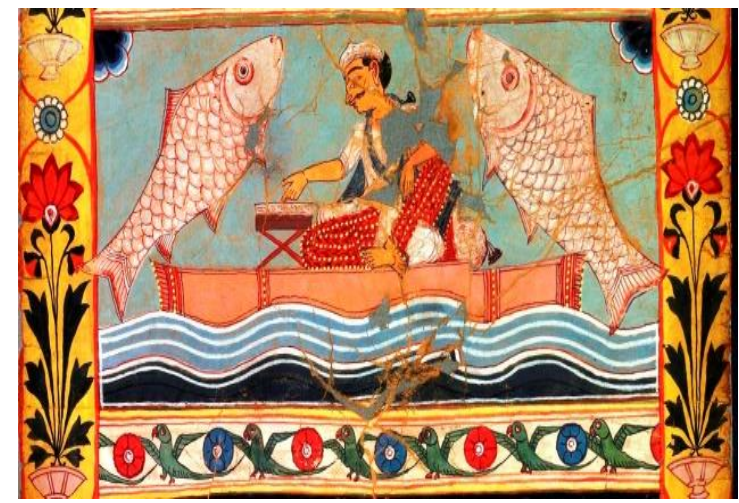

تصويرة 1/01 - 201

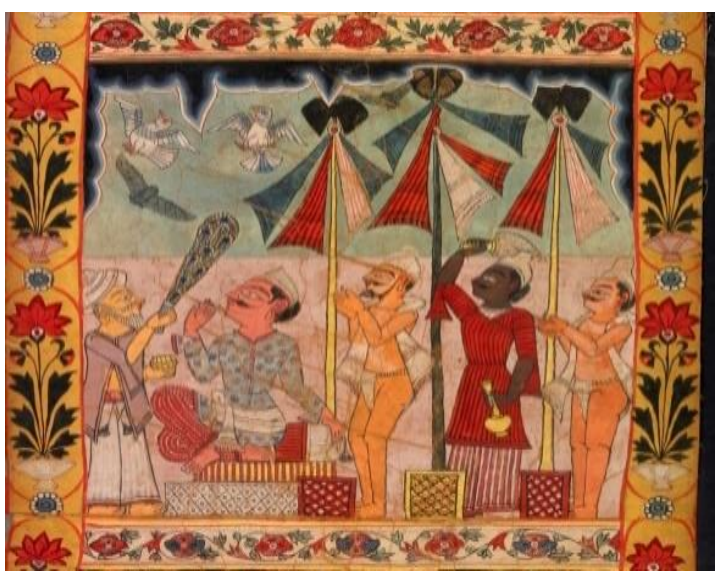

تصويرة أ ن أ

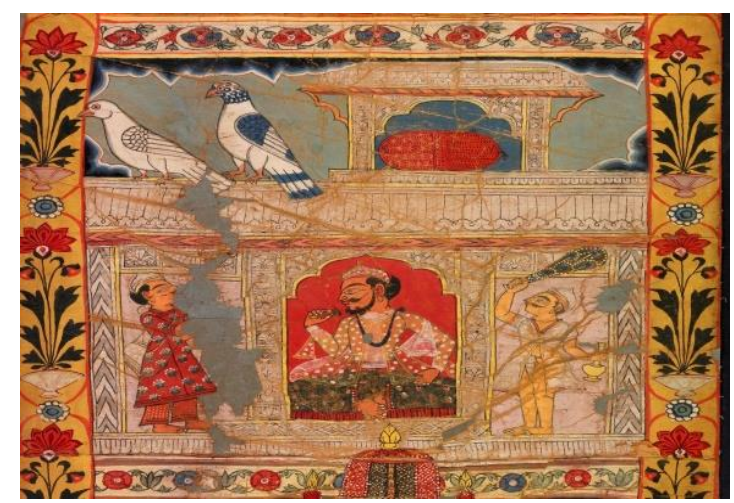

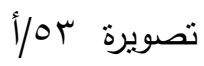




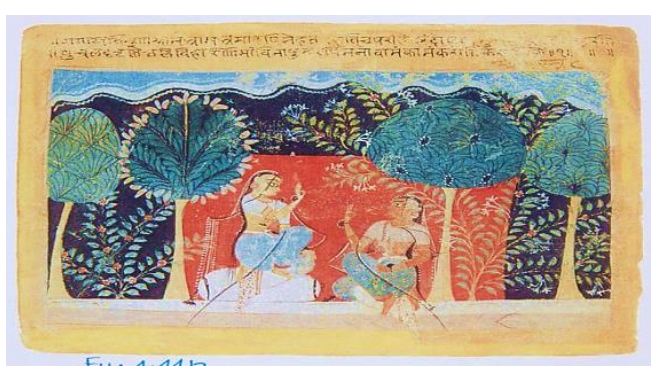

تصويرة ب تمنل رادها تخبر صديقتها ساخي عن

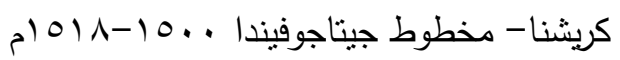

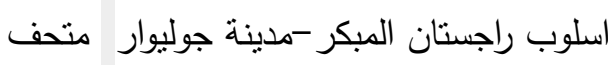

$$
\text { الفنون الجميلة - بوسطن. }
$$

Orchha ,Datia , Konrad Seitz ,Panna:

«Malwa»-Miniaturen von den

Rajputischen Höfen Bundelkhands 1580 -

1850 , vol. I, Fig. 1.10B, 84.

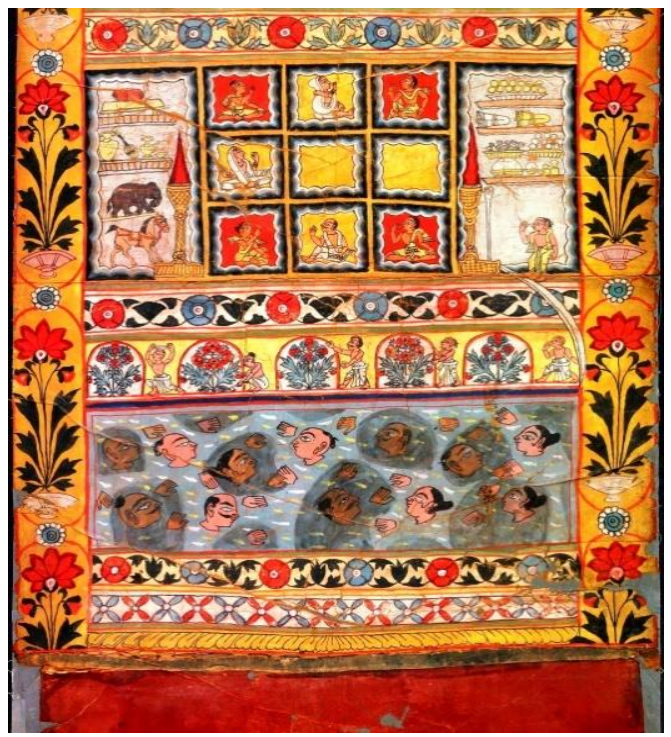

تصويرة I/OV

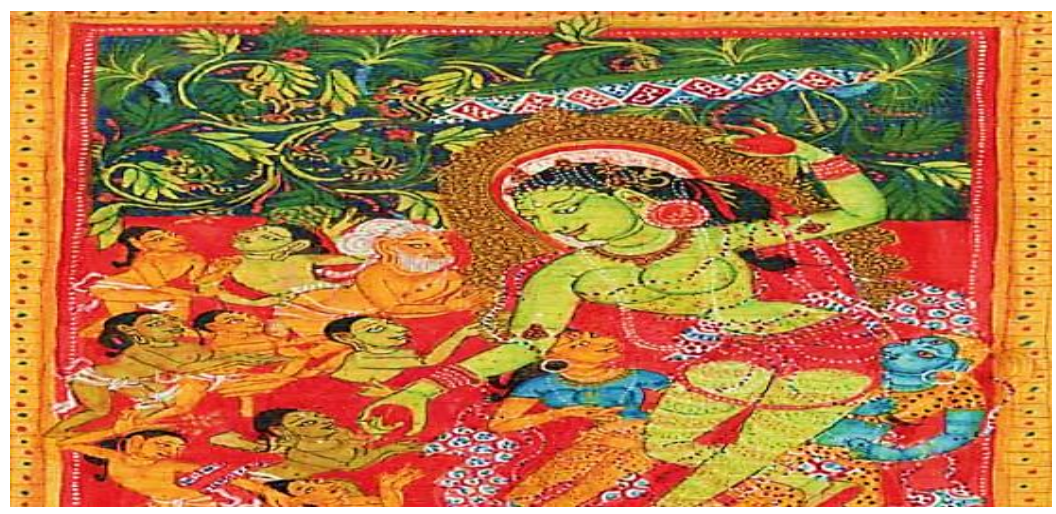

تصويرة ج تصويرة من مخطوط Ashtasahasrika Prajnaparamita من مدرسة بالا اوائل القرن Y ام - غرب

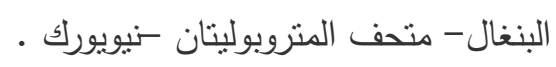

\section{https://www.metmuseum.org/art/collection/search/74909(Accessed 21/12/2020)}
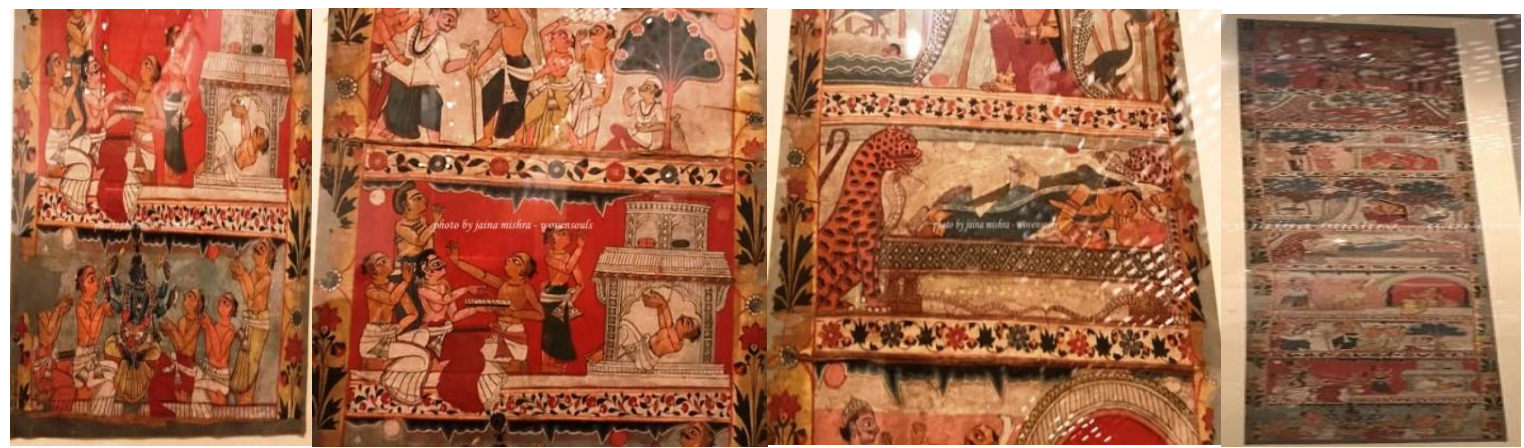

تصويرة د لوحة أو لفافة غازي بير - مرسومة على الورق - القرن با هـ/N ام تتسب إلى قرية جانكار - مدينة مرشد

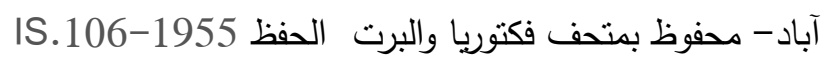

http://collections.vam.ac.uk/item/O17892/scroll-painting-unknown(Accessed 12-9-2020) 